\title{
OPTIMAL FLOW CONTROL OF A FORCED CIRCULATION SOLAR WATER HEATING SYSTEM WITH ENERGY STORAGE UNITS AND CONNECTING PIPES.
}

by

\section{Sula Ntsaluba}

Submitted in partial fulfillment of the requirements for the degree

Master of Engineering (Electrical Engineering)

in the

Department of Electrical, Electronic and Computer Engineering Faculty of Engineering, Built Environment and Information Technology UNIVERSITY OF PRETORIA

May 2015 


\title{
SUMMARY
}

\section{OPTIMAL FLOW CONTROL OF A FORCED CIRCULATION SOLAR WATER HEATING SYSTEM WITH ENERGY STORAGE UNITS AND CONNECTING PIPES.}

by

\section{Sula Ntsaluba}

\author{
Supervisor(s): $\quad$ Prof. X. Xia \\ Department: $\quad$ Electrical, Electronic and Computer Engineering \\ University: University of Pretoria \\ Degree: $\quad$ Master of Engineering (Electrical Engineering) \\ Keywords: $\quad$ Flat plate solar collector, flow rate optimization, maximum energy \\ extraction, system thermal losses, thermal comfort.
}

Solar water heating systems (SWHS) have fast become a suitable alternative to conventional water heating systems due to growing energy demands. A SWHS generally consists of a solar collector (which is used to convert solar radiation to heat), a water storage tank, and a flow control device such as a pump in the case of forced circulation SWHS. Extensive research and analysis on the operation and performance of these systems has been conducted, and results show that optimal flow control is an important factor that can be used to improve the performance and efficiency of SWHS.

This study focuses on pump flow rate optimization for forced circulation SWHS with pipes. The system analyzed consists of an array of flat plate solar collectors, two storage tanks (one for the circulation fluid and one for the water), a heat exchanger, two pumps, and connecting pipes which are considered as one of the components of the SWHS so as to account for their thermal effects. The proposed model is developed using mainly the first and second laws of thermodynamics. The model is used to maximize the difference between the energy extracted from the solar collector and the combined sum of the energy extracted by the heat exchanger and corresponding energies used by the pumps in the primary and secondary loops. The objective function maximizes the overall system energy gain whilst minimizing the sum of 
the energy extracted by the heat exchanger and energy used by the corresponding pumps in the secondary loop to conserve the stored energy and meet the user requirement of water tank temperatures.

The model is solved using the fmincon solver in MATLAB's optimization toolbox. When compared to other flow control techniques, in particular the most suitable energy efficient control strategy, the results of this study show a significant increase in the system's overall energy gain. The results also illustrate the effects of system pipe thermal losses for the different control strategies, hence highlighting the importance of developing a model that takes such losses into account so as to improve the overall accuracy of the model. 


\title{
OPSOMMING
}

\section{OPTIMALE VLOEIBEHEER VAN 'N GEFORSEERDE SIRKULASIE-SONVERHITTINGSTELSEL MET ENERGIESTOOR-EENHEDE EN VERBINDINGSPYPE.}

\author{
deur
}

\section{Sula Ntsaluba}

\author{
Studieleier(s): $\quad$ Prof. X. Xia \\ Departement: $\quad$ Elektriese, Elektroniese en Rekenaar-Ingenieurswese \\ Universiteit: $\quad$ Universiteit van Pretoria \\ Graad: $\quad$ Magister in Ingenieurswese (Elektriese Ingenieurswese) \\ Sleutelwoorde: Plat plaat sonkollektor, vloeitempo optimalisering, maksimum en- \\ ergie onttrekking, stelsel warmteverlies, termiese gemak.
}

Sonenergie-waterverwarmingstelsels (SWV) het vinnig 'n geskikte alternatief vir konvensionele waterverwarmingstelsels geword, weens die groeiende vraag na energie. 'n SWV bestaan gewoonlik uit 'n sonkollektor wat gebruik word om sonstraling om te skakel na hitte, 'n opgaartenk vir water, en 'n vloeibeheertoestel soos 'n pomp, in die geval van geforseerde sirkulasie SWV. Uitgebreide navorsing en ontleding op die werking en prestasie van hierdie stelsels is uitgevoer en die resultate toon dat die optimale vloeibeheer 'n belangrike faktor is wat gebruik kan word om die prestasie en doeltreffendheid van SWV verbeter.

Hierdie studie fokus op die optimering van die vloeitempo van 'n pomp vir geforseerde sirkulasie sonenergie-waterverwarmingstelsels met pype. Die stelsel bestaan uit 'n verskeidenheid van plat plaat sonkollektors, twee opgaartenks vir die sirkulasievloeistof en water, 'n hitteruiler, twee pompe, en verbindingspype. Die pype word beskou as geskeide komponente in die stelsel sodat hul termiese effekte in ag geneem kan word. Die voorgestelde model is ontwikkel met behulp van hoofsaaklik die eerste en tweede wette van termodinamika. Die model word gebruik om die verskil te vind tussen die energie uit die sonkollektor en die gekombineerde som van die energie wat deur die hitteruiler onttrek word, en die ooreenstemmende energie wat gebruik word deur die pompe in die primêre en sekondêre lusse te 
maksimeer. Die doelfunksie maksimeer die algehele stelsel-energiewins en minimeer die som van die bedrag wat deur die hitteruiler onttrek word en die ooreenstemmende energie van die pomp in die sekondêre lus. Sodoende word daar aan die gebruiker se vereistes vir die watertenktemperature voldoen.

Die model is opgelos deur gebruik van die fmincon oplosser in MATLAB. Wanneer dit vergelyk word met ander vloeibeheer tegnieke, veral die mees geskikte energie-doeltreffende beheerstrategie, toon die resultate van hierdie studie 'n beduidende toename in die algehele energiewins. 


\section{LIST OF ABBREVIATIONS}

$\begin{array}{ll}\text { FPSC } & \text { Flat plate solar collector } \\ \text { PID } & \text { Proportional derivative integral } \\ \text { RES } & \text { Renewable energy sources } \\ \text { RK4 } & \text { Runge Kutta fourth order } \\ \text { SC } & \text { Solar collector } \\ \text { STDP } & \text { Storage tank design parameters } \\ \text { SWHS } & \text { Solar water heating system } \\ \text { VSD } & \text { Variable speed drive }\end{array}$




\section{TABLE OF CONTENTS}

CHAPTER 1 Introduction 1

1.1 Problem statement . . . . . . . . . . . . . . . . . . . . . . . 1

1.2 Research objective and questions . . . . . . . . . . . . . . . 2

1.3 Hypothesis and approach . . . . . . . . . . . . . . . . . 3

1.4 Research contribution . . . . . . . . . . . . . . . . . . . 3

CHAPTER 2 Literature Study 5

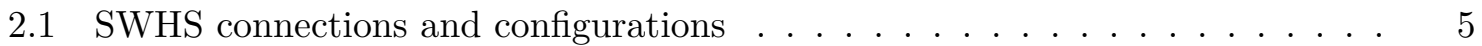

2.2 Solar collector and tank storage parameters . . . . . . . . . . . . . 7

2.2.1 Solar collector parameters . . . . . . . . . . . . . . 8

2.2 .2 Storage tank parameters . . . . . . . . . . . . . . . 9

2.3 Flow rate optimization . . . . . . . . . . . . . . . . . . 11

2.4 Connecting pipe parameters . . . . . . . . . . . . . . . . 13

2.5 Research gap . . . . . . . . . . . . . . . . . . . . 15

$\begin{array}{llr}\text { CHAPTER } 3 & \text { Theoretical Modelling } & 16\end{array}$

3.1 Problem formulation . . . . . . . . . . . . . . . . . . . . . 16

3.2 SWHS mathematical model . . . . . . . . . . . . . . . . . . 17

3.2 .1 Connecting pipe loss factors . . . . . . . . . . . . . . 17

3.2 .2 Solar collector . . . . . . . . . . . . . . . . . . 19

3.2 .3 Circulation fluid storage tank . . . . . . . . . . . . . . . 21

3.2 .4 Water storage tank . . . . . . . . . . . . . . . 23

3.2 .5 Heat exchanger . . . . . . . . . . . . . . . . . . . . 24

3.2 .6 Flow control . . . . . . . . . . . . . . . . 25

3.3 Model optimization . . . . . . . . . . . . . . . . . . . . . . . 28

3.4 Model computational procedure . . . . . . . . . . . . . . . . . . . . 30 
3.5 Validation of model . . . . . . . . . . . . . . . . . . . 32

$\begin{array}{lll}\text { CHAPTER } 4 & \text { Case Study } & 36\end{array}$

4.1 Data presentation . . . . . . . . . . . . . . . . . . 36

CHAPTER 5 Results and Analysis $\quad 43$

5.1 Chapter overview . . . . . . . . . . . . . . . . . . . 43

5.1 .1 Primary and secondary loop mass flow rates . . . . . . . . . . . . 43

5.1 .2 Primary and secondary loop pump power . . . . . . . . . . . . 45

5.1 .3 Rate of energy extraction, gain and thermal losses . . . . . . . . 46

5.1 .4 Solar collector and system efficiency . . . . . . . . . . . . . 55

$\begin{array}{lll}\text { CHAPTER } 6 & \text { Discussion } & 57\end{array}$

6.1 Chapter overview . . . . . . . . . . . . . . . . . . . 57

6.2 Optimal mass flow rates $\ldots \ldots \ldots \ldots \ldots$. . . . . . . . . . . . 57

6.3 Benefits and drawbacks of the different control strategies . . . . . . . . . . . 60

6.4 System gain and pump operating efficiency . . . . . . . . . . . . . . 60

6.5 Tank thermal losses . . . . . . . . . . . . . . . . . . . . . . 61

6.6 Solar collector and system efficiency f . . . . . . . . . . . . . . . 63

6.7 Connecting pipe thermal losses . . . . . . . . . . . . . . . . . . 63

$\begin{array}{lll}\text { CHAPTER } 7 & \text { Conclusion } & 65\end{array}$

7.1 Future recomendations . . . . . . . . . . . . . . . . . . 66

APPENDIX A Solar Collector Parameters $\quad 72$

APPENDIX B Heat Exchanger Parameters $\quad 76$

$\begin{array}{ll}\text { APPENDIX C Pump Parameters } & 78\end{array}$ 


\section{CHAPTER 1}

\section{INTRODUCTION}

\subsection{PROBLEM STATEMENT}

Recently, intensive efforts have been made in attempt to either integrate or replace conventional energy sources with renewable energy sources (RES) in order meet power demands [1]. This is due to the fact that RES are non-polluting and non-depletable whilst having low operation and maintenance costs, thus making them potential sources of alternative energy $[1,2,3]$. Currently, there are more than 30 million square meters of solar collectors installed around the world, making solar energy a popular and widely utilized form of renewable energy. Solar water heating systems (SWHS) are among the most common and favorable renewable energy systems as the use of these systems can result in significant energy savings. However, there are limiting factors to be considered when utilizing SWHS. These include:

a) Unpredictable behavior (energy produced from RES may not always meet the demand)

b) Economic viability

c) Thermal performance

It is therefore essential to investigate methods to overcome these limitations so as to increase the viability of SWHS. A common solution to the limitation mentioned in a) and b) is the use of an effective thermal energy storage system (one that is able to store thermal energy at the highest possible temperature whilst exhibiting minimal thermal losses). The main thermal 
energy storage techniques include: thermally stratified storage ${ }^{1}$ and reverable chemical heat storage $^{2}$. A second alternative that will impact a), b), and c) involves integrating SWHS with a flow control device (pump) in order to increase the rate of energy transfer thereby maximizing energy transfer from the solar collector to the energy storage units (tanks) [4, 6]. Optimal flow control is therefore an important factor that can be used to increase the performance of SWHS.

The work presented in this dissertation focusses on maximizing the overall gain for a forced circulation SWHS so as to improve its performance. This is achieved by finding the optimal values for the circulation fluid and water mass flow rates.

\subsection{RESEARCH OBJECTIVE AND QUESTIONS}

The objective of this research is to investigate the possibility of finding optimal flow rates that can increase the overall gain of a SWHS. The effects of flow rate control on the system thermal losses will also be investigated. A mathematical model of the SWHS will be developed. The model will accurately represent a SWHS and take into account connecting pipe losses. The model will be used to maximize the overall energy gain of the a SWHS through maximizing energy transfer to the energy storage tank of the SWHS. This is achieved by optimizing the SWHS's circulation fluid and water flow rates. The goals of this research are to obtain the mentioned flow rates that will optimize the system so as to determine what effects these flow rates will have on the system's performance.

This study aims to address the following research questions:

- What are the optimum mass flow rates required to maximize energy transfer to the load of an active solar water heating system?

- Can the thermal performance and operating efficiency of a forced circulation solar water

\footnotetext{
${ }^{1}$ Thermal stratified storage is a technique that is widely used in energy conservation and load management applications. Stratification describes the temperature difference that can exist between different levels inside a tank. A multinode approach (the tank is typically divided into $\mathrm{N}$ nodes) is used to characterize the energy in the tank $[4,5]$.

${ }^{2}$ Reversible chemical heat storage is a technique that is based on the conversion of solar radiation into high-temperature heat. This technique utilizes a system of reactants that either transfer energy to the storage tank or extract energy from the tank. The system is connected in an open loop or closed-loop configuration[4].
} 
heating system be improved through optimization of its circulation fluid and water flow rates?

- What impact do the pump mass flow rates have on the tank and connecting pipe thermal losses?

\subsection{HYPOTHESIS AND APPROACH}

It is hypothesized that the thermal performance and operating efficiency of a forced circulation SWHS can be improved through optimization of its fluid and water mass flow rates. This will impact the system's thermal losses and payback period.

The approach to be followed in order to achieve the required outcome for the proposed research is listed below:

1. Literature study - A literature study on the theory of Solar Water Heating systems (SWHS) will be conducted, where all relevant literature relating to the different configurations and models of active (SWHS) will be reviewed.

2. Development of a mathematical model - A mathematical model that can be used to characterize forced circulation SWHS and optimize its flow rates to maximize energy transfer to the load will be developed.

3. Simulation and results - A Matlab based algorithm will be selected and used used to solve the optimization problem.

4. Case study and analysis - A case study will be presented and solved in order to illustrate the application of the developed model and to analyze the results in order to answer the proposed research questions.

\subsection{RESEARCH CONTRIBUTION}

In the current literature, certain models that have been developed to optimize energy transfer for a SWHS were identified. These models consist of pumps that are connected in the fluid and water circulation loops and are controlled by either bang bang control (the pumps 
are switched on at a constant flow rate during times where energy can be transferred from the collector of SWHS to its load, and off when this is not possible), through the use of a proportional controller (the flow rate resulting from the pump speed is proportional to the temperature difference between the collector and tank of the SWHS), or a proportional integral derivative (PID) controller. Some models propose a constant optimal flow rate through out the optimization interval whilst others propose an alternate switching strategy such that the flow rate switches continuously between its minimum and maximum values during periods where solar radiation is available.

The proposed research will attempt to firstly improve the accuracy of current models through considering pipe thermal losses which are neglected previous models. In the proposed model, the losses are characterised as a function of the heat loss coefficients of the pipes (which are calculated for every sample instant as oppose to keeping them constant), as well as dimensions of the connecting pipe (inner diameter, length, and surface area). Secondly, while most existing models have optimized flow rates for the daytime period where there is an opportunity to extract energy, the proposed study will consider a SWHS with two storage tanks (a circulation fluid tank and a water tank). The presence of these two energy storage tanks will make it possible to optimize the flow rates of the two pumps over a 24 hour period as opposed to only during the period when energy available from the Sun. Finally, unlike other models that either aim to maximize the energy extracted from the solar collector or to maximize the difference between the energy collected and the energy used by the pumps, the proposed model is developed with two unique objectives; in the primary loop of the SWHS, the flow rates are optimized for maximum energy transfer to the energy storage tank, whilst in the secondary loop, the flow rates are optimized for minimum energy extraction from the first energy storage tank in order to conserve energy. Along with this, the SWHS must meet the user requirement of water tank temperatures at different hours of the day so as to increase thermal comfort. Our objective is therefore to maximize the overall energy gain of the SWHS in order to have a positive impact on the system's thermal performance. 


\section{CHAPTER 2}

\section{LITERATURE STUDY}

With an ever growing energy demand, SWHS have fast become a popular and suitable alternative for water heating. This has led to an extensive amount of research that has been conducted, with the aim of improving the overall performance of SWHS. In this chapter, a summary of existing research that is focused on modelling and optimization of SWHS is presented. In doing so, the research gap and area of focus regarding the proposed research is highlighted.

\subsection{SWHS CONNECTIONS AND CONFIGURATIONS}

When modelling a SWHS, it is important to establish the type of connection that exists between each of the units of the system. Units of a SWHS can be connected in either an open loop or closed-loop configuration. This is shown in fig.2.1 and fig.2.2, where $T_{1}$ is the water storage tank and $T_{c w}$ is the temperature of fresh incoming water to the storage tank. 


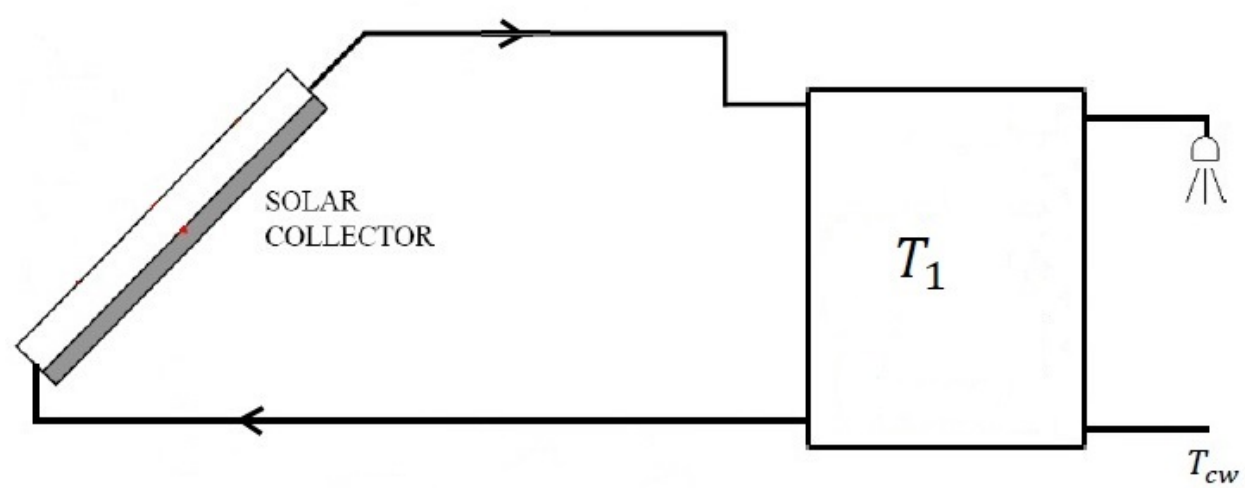

Figure 2.1: SWHS connected in an open loop configuration.

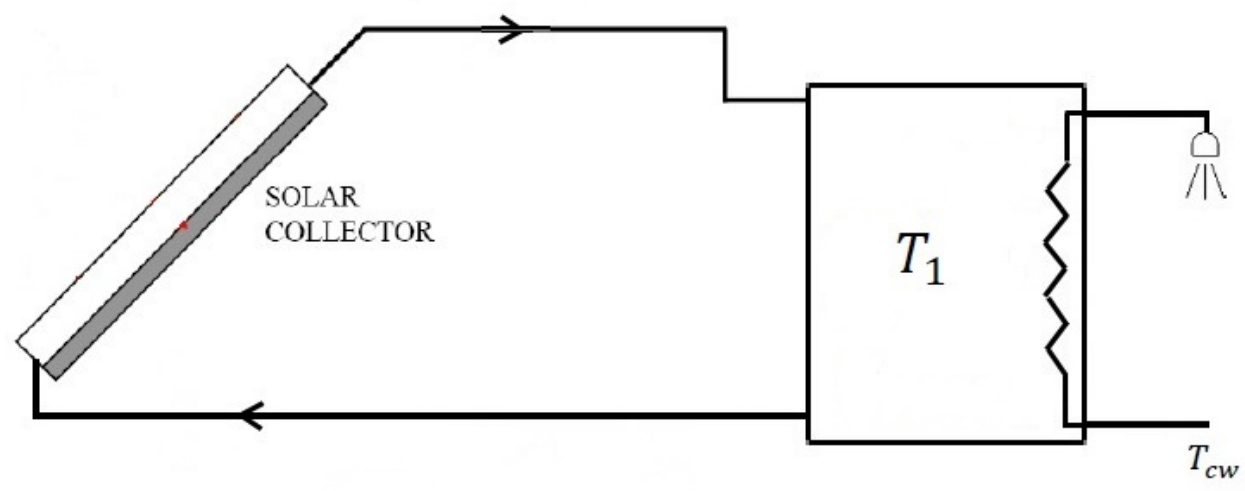

Figure 2.2: SWHS connected in a closed-loop configuration.

There are generally two methods of transferring heat from a solar collector to the storage tank. The first method uses a passive SWHS (also known as a natural circulation or thermosyphon). This system consists of a solar collector and a storage tank that is located above the solar collector in order to allow water to flow through natural convection whenever a difference in density is established in the storage tank due to an addition of energy from the solar collector. Fig.2.1 and fig.2.2 illustrate a passive SWHS as there is no pump connected to system to control the fluid flow rate [5]. The second method uses a forced circulation SWHS (also known as an active SWHS). This system requires the use of a pump that is turned on during the day for fluid circulation and off during the night to prevent reverse circulation. The 
fluid in the tank may either be water or an antifreeze mixture (for climates where freezing temperatures occur). An active SWHS may be connected in an open loop or closed-loop configuration. Fig. 3.10 shows an active SWHS connected in an open loop configuration where $P_{1}$ represents the fluid circulation pump [5].

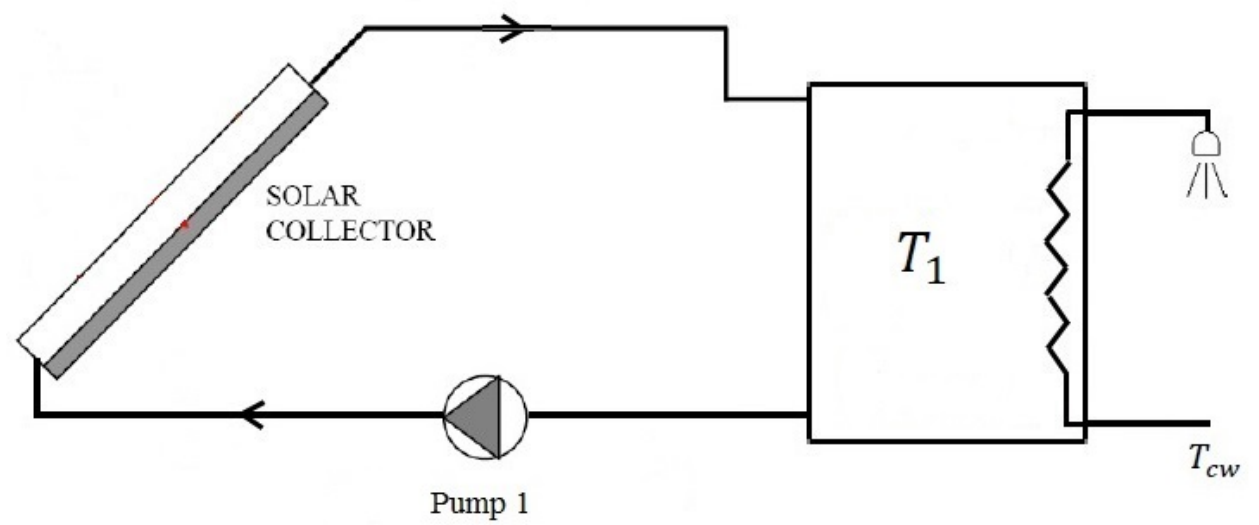

Figure 2.3: Active SWHS connected in a closed-loop configuration with a pump.

Optimization of SWHS connected in either an open loop or closed-loop configuration are reported in $[4,7,8,9,10,11,12,13]$, with results suggesting that SWHS connected in an open loop configuration result in a higher rate of energy transfer from the input loop to the load when compared to SWHS connected in a closed loop configuration.

\subsection{SOLAR COLLECTOR AND TANK STORAGE PARAMETERS}

When modelling a SWHS, it is important to characterise its different units as a function of the flat plate solar collector (FPSC) design parameters, storage tank design parameters (STDP) as well as other external parameters such as the global irradiation. While certain parameters such as global irradiation can not be modified as they are not in our control, there are are other parameter such as FPSC and STDP that can be modified in order to enhance the performance of a SWHS. 


\subsubsection{Solar collector parameters}

When considering the solar collector, a first common design parameter involves selecting the appropriate material for the absorber plate and cover for the collector. The two general options are plastic and glass, with each option having its advantages and disadvantages. Studies conducted in $[14,15,16]$ show that a glass cover has the ability to absorb a large amount of radiation when compared to that of plastic. However, glass covers are fragile and have a high installation costs. Plastic covers are both low in weight and cheaper, however, this material experiences significant thermal losses as well as long term degradation due to exposure to the environment.

A second common set of design parameters is the collector heat loss coefficient and the heat removal factor. These parameters are affected by a number of factors such as the selected number of transparent collector covers, the bond conductance and the dimensions of the collector (width, length of pipes, inner and outer diameter of pipes).

A study conducted in [17] investigates the effects that varying the number of transparent collector covers would have on the collector heat loss coefficient and the overall performance of the solar collector (SC). The results showed that increasing the number of covers reduces the overall heat loss coefficient, and in doing so, increases the performance of the FPSC.

In [18], a new experimental method for the measurement of the bond conductance between the absorber plate and the tube of a solar collector was developed. The bond conductance is estimated based on the comparison between the energy generated and the energy absorbed. The results of this study show that an increase in the bond conductance increased the collector heat removal factor and performance of the solar collector.

A third common set of design parameters is the collector tilt angle and orientation. These parameters change the radiation that reaches the surface of the collector, and in doing so highly influence the performance of the collector. Most studies regarding these design parameters are focused on finding the optimal orientation and tilt angle for a fixed collector. In studies conducted in $[19,20,21]$, the optimal tilt angles and orientation of FPSC used for different heating applications are investigated. The results of [19] suggest that the optimum tilt angle is dependent on the operation strategy as well as the season, while in [20], it is suggested 
that for certain countries it will be beneficial to mount the collector at a monthly average tilt angle and adjust the slope accordingly every month. In [21], a performance analyisis of the collector is conducted when the collector tilt angle is corrected annually, seasonally and monthly. The results show that an increase in the the collector tilt angle correction frequency leads to a $5.98 \%, 13.55 \%$ and $15.42 \%$ improvement in the energy collected.

\subsubsection{Storage tank parameters}

Aside from the SC, one may also improve the performance of a SWHS by selecting appropriate design parameters for the storage tank. These parameters include the dimensions (which would determine the volume) as well as the thermal properties of the tank. In [22], a methodology is presented for determining the optimal sizing of the main components (solar collector and storage tank) of a SWHS in order to minimize energy consumption and cost, whilst maximizing the solar fraction. The results of this study show that there is an optimal value for the tank dimensions, though this value may be dependent on the SWHS and the water heating requirement, if given. The impact of the storage tank dimensions on the performance of a SWHS is briefly analysed in [7] where the height of the tank is treated as a control variable. It was found that an increase in the tank height increases the volume of the tank and in doing so, the thermal energy lost through the walls of the tank is increased. It was also found that in the case of a constant mass flow rate, there exists an optimal tank volume to tank height ratio that will optimize that the overall performance of the SWHS.

When working with storage tanks, it is important to establish whether or not the tank operates with significant degrees of thermal stratification. Thermal stratification occurs when a tank is at different temperature levels along the height of the tank as shown in fig. 2.4. This can become extremely dangerous, especially in tanks that do not operate under the fully mixed regime (passive SWHS) and have a common water inlet and outlet. When a storage tank operates under the fully mixed regime, there is a constant circulation of water in the tank which ensures that: the water temperature is at the same level, and most importantly that there is a mixing of fresh water with the water already in the tank. When considering a tank that operates under large degrees of thermal stratification, water in the tank is circulated through natural convection resulting in thermal stratification. Due to this lack of water 
circulation, when fresh water enters the tank, a thermocline ${ }^{1}$ is created which can persist for many days trapping old water at the top of the tank and over time the old water may lose its residual disinfectants making the water prone to growing disinfectant products such as bad odours and bacteria $[5,24]$. This would generally occur in large water tanks where the water in the tank is much larger than the daily water usage.

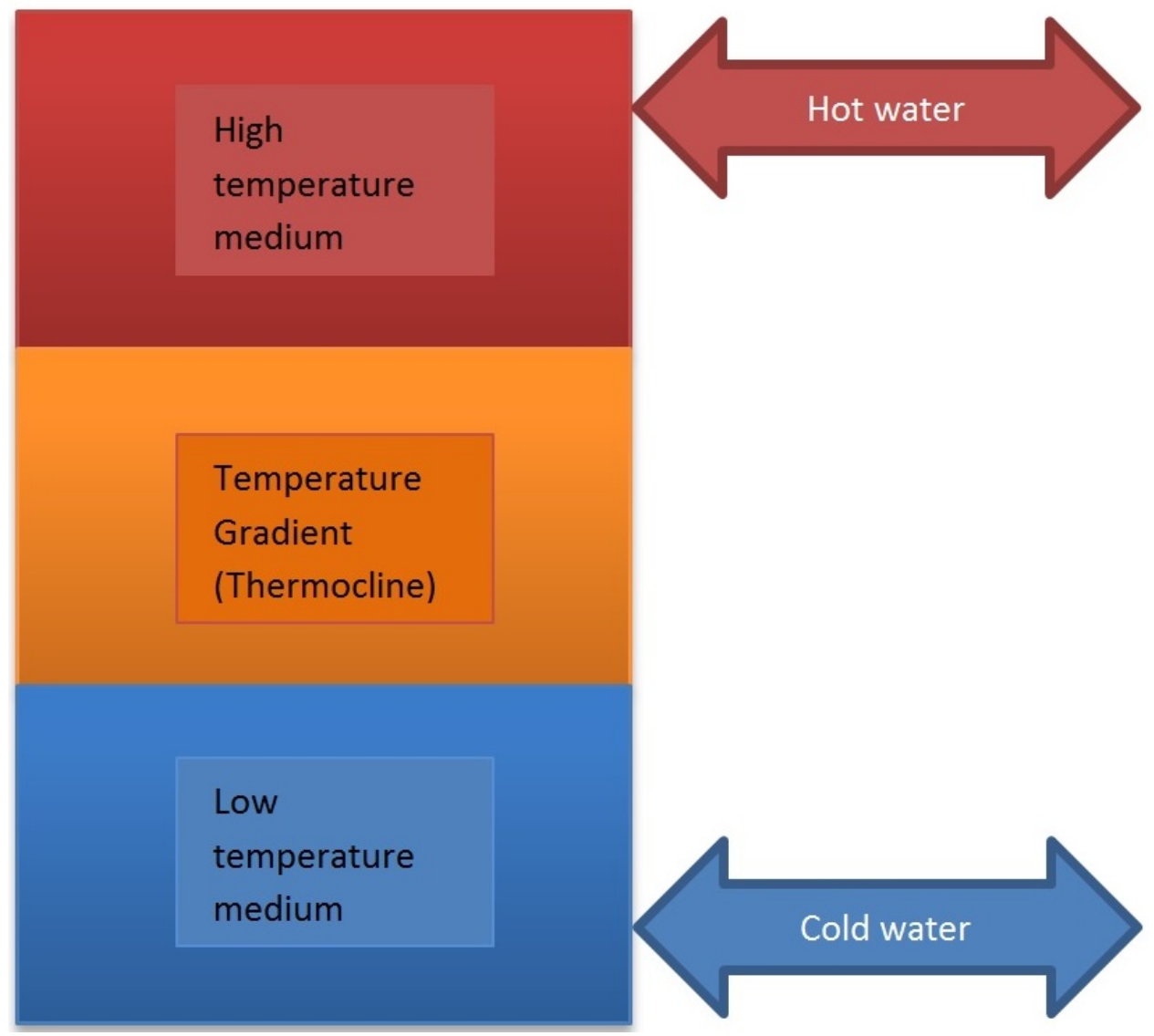

Figure 2.4: Storage tank with thermal stratification.

Many stratified tank models have been developed in order to accurately model the variation of temperature along the height of the tank. These models generally fall into two categories. One involves a multinode approach, where a tank is modelled such that it is sectioned into $\mathrm{N}$ nodes with energy balances written for each section of the tank. The result of this would be $\mathrm{N}$ differential equations that can be solved to find the temperatures of each of the nodes as a function of time. The other involves a plug flow approach, where segments of liquids at different temperatures are assumed to move through the tank, and the models keep track of the size, temperature and position of the segments [5].

\footnotetext{
${ }^{1} \mathrm{~A}$ thermocline refers to a sharp thermal boundary that will prevent the tank water from mixing [23].
} 


\subsection{FLOW RATE OPTIMIZATION}

Optimal flow control is an important factor that can be used to increase the performance of a SWHS. This strategy involves integrating a SWHS with a flow control device such as a pump in order to increase the rate of energy transfer from the SC, thereby maximizing energy transfer to the storage tank. $[4,6]$. This can be achieved through the application of optimal flow rate strategies.

Optimization will however result in different optimal strategies based on the objectives and constraints of the defined problem. For instance, different optimal flow control strategies may be obtained when considering cost minimization as oppose to energy maximization. Existing approaches to energy maximization through mass flow rate control are reported in $[4,7,9,8,10,11,12,13,25]$. In particular, [7] investigates optimal flow control of a closed-loop SWHS with one and two serpentines used for heat exchange in the storage tank.

In this study, the tank is assumed to operate in the fully mixed regime in order to avoid thermal stratification. The objective of this study is to determine the optimal flow rates in the primary loops of the SWHS. The results show that optimal switching between the minimum and maximum flow rate (mainly known as bang-bang control) yield a greater energy gain, system efficiency and reduced system thermal losses when compared to traditional flow strategies such as constant flow rate, proportional and proportional integral derivative (PID) control. In the analysis of these results, it was shown that though the strategy proposed reduces the rate energy transfer to the tank during the off period of the pump, there is a reduction in the collector thermal losses during these intervals such that the overall gain exceeds that of a system which would have had the pump on continuously during the day. It was also noted that a SWHS model without a serpentine in the storage tank of the system produces a greater energy gain when compared to a system with a serpentine, as its presence reduces the rate of energy transfer from the primary loop to the tank and from the tank to the secondary loop, at a rate that is proportional to the efficiency of the serpentine. Finally, it was noted that the optimal control strategy differs seasonally, as the pump is kept on for a greater period during the day for overcast days when compared to partially cloudy or clear sky days.

In [9], optimal operation strategies for SWHS connected in an open loop configuration are 
considered. Some authors state that in many instances, energy based measurements of the performance of SWHS may be misleading, and that an exergy based analysis may be a more realistic evaluation of the thermal performance of the system. This is because an exergy based analysis can lead to the identification of inefficient parts of the SWHS as well as optimum operating conditions [9]. The objective of this study was to determine optimal operation strategies in order to maximize exergy gain with the water mass flow rate as the control parameter. The results of this study suggest that a constant optimal mass flow rate (which can be obtained using the overall average of the optimal mass flow rates that are determined for each sample instance of the optimization interval) may be a good strategy during warmer seasons of the year as this can yield results that are very close to the optimum results. It was also found that there exists a correlation between the mass flow rate, fluid inlet temperature and solar irradiation. A significant increase in the mass flow rate occurs with either an increase in the fluid inlet temperature or with an increase in solar irradiation.

In [10], a low temperature solar water collector connected to a thermally stratified tank is considered, with the objective of obtaining optimal mass flow rates required to maximize the net gained energy. The resulting mass flow rate values are close to the minimum and maximum limits which support the strategy of optimal switching between the minimum and maximum available flow rate. It is therefore concluded that for passive SWHS with a stratified storage tank, maximum flow rate is to be applied whenever there is a positive gain from the collector and the thermal capacitance of the system is smaller than a given value. In the event that the objective is to improve the criteria of performance of the system, it is suggested the energy balance equation applied in the tank be expressed through the use of ordinary differential equations so as to improve the overall accuracy of the system.

In [8], a co-generation system is devised for producing heating as well as cooling. The system consists of of a solar collector, gas burner, thermal reservoir, hot water heat exchanger and absorbtion refrigerator connected in a two loop configuration with two pumps. The objective of this study is to maximize the system's performance (reduce exergy destruction) whilst also minimizing the system pull up and pull down times (time taken to reach a set point temperature). A transient solar system mathematical model is developed in order to obtain the system response as well as to calculate the efficiency of the entire system. The results show that there exists a fundamental optimal set of three heat capacity rates that when optimized, characterise the system such that maximum exergy is obtained. Two optimal constant pump 
flow rates values are obtained for the two pumps whilst meeting the secondary objective of minimizing the system's response time (pull up and pull down times).

In [11] an optimal control method for a solar collector loop in a closed-loop configuration is studied. The system is described by a bilinear lumped parameter model for the collector fluid temperature and a bilinear lumped parameter model for the storage fluid temperature. The objective is to obtain optimum values for the collector fluid velocity, in order to maximize the net energy that is collected over a fixed time period. The results agree with [9] and [10] in that optimal switching will occur between the minimum and maximum flow limits. The results also show that in instances where only two switches occur during the period of operation, the optimal control is highly dependent on the temperature difference across the collector.

In $[12,13]$ the application of block orientated type mathematical modeling is applied to the SWHS with pumps. In this paper two different types of bang bang control are used. In the first type (referred to as ordinary control), the on-off status of the pump is temperature dependent, whilst in the second type (referred to as energy based control) the control action is dependent on the comparison between the availability of extractable energy and the pump power used to extract this energy. The results show that the energy based control method results in greater energy gain and a higher water tank temperature.

Finally, a study highlighting the exergy dependence on the aperture area is conducted in [25]. An energetic optimization of flat plate solar collectors is developed in order to determine the optimal performance and design parameters of the system. The objective is to determine the optimum flow rate and collector aperture area combination that will result in a maximized exergy efficiency. The results illustrate the dependence of exergy on the aperture area and flow rate with maximized exergy outputs correlating to maximum flow rate and aperture area values.

\subsection{CONNECTING PIPE PARAMETERS}

Connecting pipes form an integral part of the SWHS as they connect the solar collector to energy storage tank, and in doing so make it possible for energy transfer to occur between the solar collector and the storage tank. Any connecting pipe with a surface that is hotter 
than the surrounding will experience heat losses as well as energy losses [5]. Suitable pipe thermal insulation is a general solution that is used to reduce these losses in order to improve the overall thermal performance of SWHS with connecting pipes $[5,26]$. In most SWHS models that exist, pipe thermal losses are neglected as they are assumed to be insignificant. This is generally a reasonable assumption to make in the case of SWHS with short well insulated pipes. However, this assumption becomes invalid for cases where the solar collector and storage tanks are not located in the same area as shown in fig. 2.5, thereby requiring longer connecting pipes which will experience significant thermal losses. There are existing

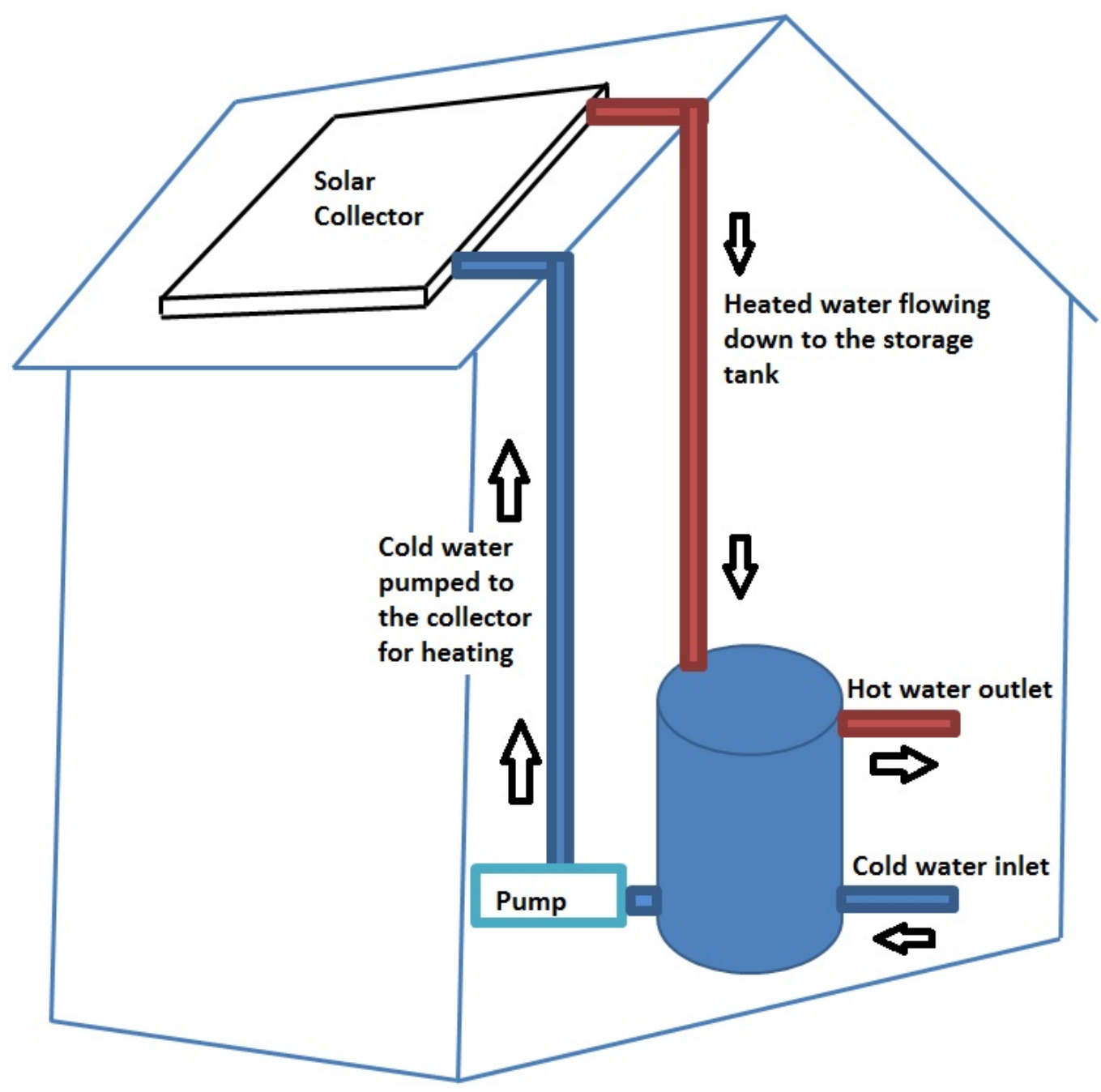

Figure 2.5: Active SWHS with long connecting pipes.

studies that have shown that characterising system losses as a part of the SWHS model can 
provide a more realistic and accurate representation of the performance of a SWHS. In [27] for instance, extended differential equations are used to model a SWHS consisting of a solar collector, heat exchanger, energy storage tank and connecting pipes. The developed model considers pipe thermal losses and simply illustrates the temperature distribution over the components of the SWHS. When compared to measured results from a physical system, the results of this model show lower absolute error values than those of the other models that do not take system thermal losses into account. The results of [27] highlight the importance of considering system thermal losses in order to increase the accuracy of any model. In attempt to further the work that has been developed by the previous authors, this study focusses on the design and optimization of a model that will characterise a SWHS consisting of an array of solar collectors, two energy storage tanks and connecting pipes. The connecting pipe thermal losses will therefore be characterised as a part of the SWHS model.

\subsection{RESEARCH GAP}

It has been shown that there is a large amount of existing studies focused on accurately modeling SWHS with different objectives. Most studies on SWHS with primary and secondary loops focus on finding optimal flow rates to maximize the primary loop gain whilst either minimize the time to reach a set temperature, cost or payback period of the overall system. Studies that aim to simultaneously maximize energy gain in the primary loop and minimize energy loss to the secondary loop to conserve energy have not been identified. In the case of active SWHS, no models have been identified with a combination of two energy storage tanks and a specific output temperature load profile to allow for a 24 hour optimization of the mass flow rates. Finally, when considering existing research where the mass flow rates were optimized, current models are not designed to take the thermal losses of the connecting pipes into account. In light of this, the proposed research is focused on pump flow rate optimization for an active SWHS with two storage tanks and connecting pipes. The objective is to maximize the overall energy gain of the SWHS, whilst taking into account the energy extracted from the solar collector, the energy used by the pumps, as well as the energy transfer that occurs between the two tanks. The presence of two storage tanks allows for optimization in tanks 1 and 2 during the day and in tank 2 during the night. Finally the model developed includes connecting pipe thermal losses so as to obtain a more realistic model that can resemble that of a physical SWHS to a greater degree of accuracy than current existing models. 


\section{CHAPTER 3}

\section{THEORETICAL MODELLING}

\subsection{PROBLEM FORMULATION}

The system considered in this paper is shown in fig.3.1. It consists of a flat plate solar collector with surface area $A_{\text {coll }}$, a storage tank $\left(T_{1}\right)$ used to store circulation fluid with mass $M_{c f}$, and specific heat capacity $C_{c f}$, a storage tank $\left(T_{2}\right)$ with water tank used to store water with mass $M_{w}$, and specific heat capacity $C_{w}$, connecting pipes $c p_{i}$ of lengths $L c p_{i}$ and inner diameter $d_{c p i}$ for $i=1, \ldots, 6$, as well as two pumps used in the primary and secondary loops of the system. In the primary loop, the circulation fluid flowing at a mass flow rate of $\dot{m}_{c f}$ leaves tank $T_{1}$ at a temperature of $T_{s 1}$, enters the solar collector at temperature $T_{c f, \text { in }}$ and leaves at temperature $T_{c f, \text { out }}$. The secondary loop is used to extract energy from tank $T_{1}$ through the use of a serpentine $(S)$ with a heat transfer surface area, transfer coefficient and efficiency of $A_{s}, H_{s}$ and $\eta_{s}$. In the secondary loop, water flowing at a mass flow rate of $\dot{m}_{w}$ leaves tank $T_{2}$ at temperature $T_{s 2}$, enters the serpentine $S$ at temperature $T_{w, i n}$ and leaves the serpentine at a temperature of $T_{w, \text { out }}$. In order to ensure that water in tank $T_{2}$ is maintained at a certain level, cold water at a temperature of $T_{c}$ enters tank $T_{2}$ at the same mass flow rate $\dot{m}_{\text {out }}$ that water is extracted from $T_{2}$ for hot water usage. Therefore the secondary part of the system is connected in an open loop configuration. 


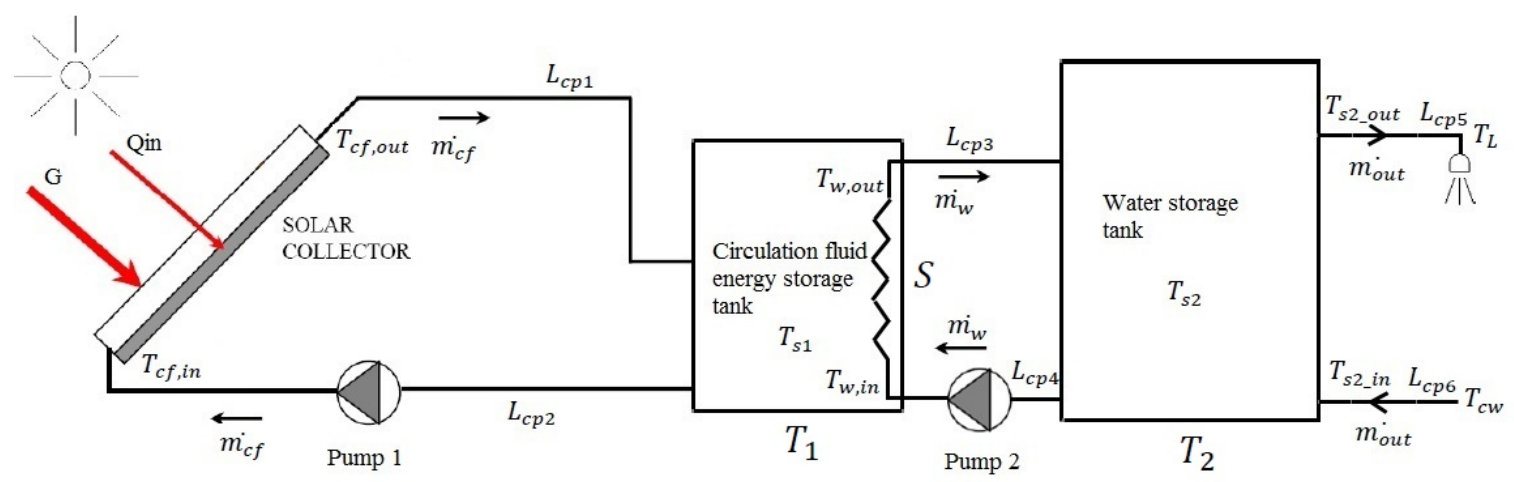

Figure 3.1: Forced circulation SWHS to be optimized.

In tank $T_{1}$, a circulation fluid with low specific heat capacity and low freezing point (when compared to water) is selected to ensure that the liquid does not freeze in areas with cold climates. Another benefit of this liquid is that it has a greater capacity to heat up with a smaller change in energy when compared to specific heating capacity of water, thereby increasing the SWHS's capacity to store energy [28]. It should be noted that SWHS configurations similar to that shown in fig.3.1 have been considered in other studies. More notably, similar systems where considered in $[8,12,13,27]$. What physically differentiates our system from the studies noted above is the circulation fluid and the type of exchanger used the systems primary loop. When considering the mathematical modelling and optimization of this system, none of the studies indicated above model the connecting pipe thermal losses. Finally, the objectives formulated for the system's primary and secondary loop result in a unique problem.

\subsection{SWHS MATHEMATICAL MODEL}

\subsubsection{Connecting pipe loss factors}

Any pipe with a surface that is hotter than the surroundings will experience heat as well as energy losses. These losses are affected by a number of factors, with the dominant ones being: the type of material that the pipe is made of as well as the size and surface temperature of the pipe. Pipe insulation is a popular method used to improve the thermal performance of a pipe. It is therefore necessary to model insulation on a pipe in order evaluate a pipes thermal performance [26]. The pipe thermal loss and decrease in temperature are characterised using equations from $[5,26,29,30]$. Fig.3.2 shows the cross section and length of an insulated pipe. 


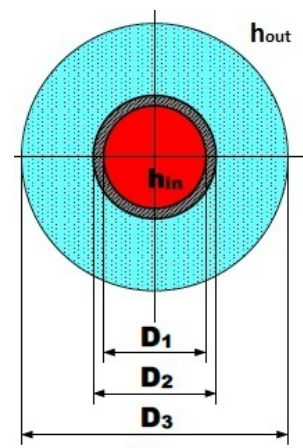

(a)

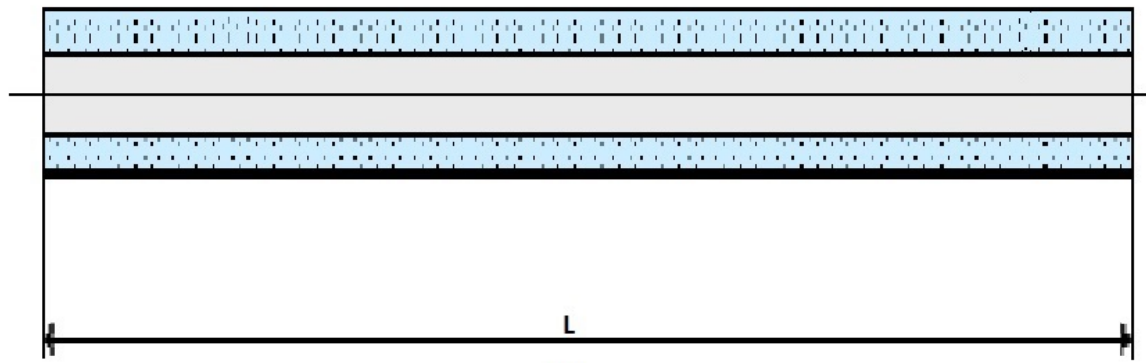

(b)

Figure 3.2: Connecting pipes of SWHS. (a) Cross section and (b) Length of the insulated pipe.

The thermal loss of the pipe may be obtained using the following relation:

$$
Q_{\text {pipe }}=L \cdot \pi \cdot D_{3} \cdot U_{p} \cdot\left(T_{\text {in }}-T_{a}\right) \text {, }
$$

where: $L$ is the length of the pipe, $D_{3}$ the outer diameter, $U_{p}$ is the pipes overall heat loss coefficient, $T_{i n}$ is the pipes inner temperature and $T_{a}$ is the ambient temperature $[26,30]$. The decrease in temperature due to the heat losses is approximated by

$$
\Delta T_{i n}=\frac{U_{p} \cdot L \cdot \pi \cdot D_{3} \cdot\left(T_{i n}-T_{a}\right)}{\dot{m}_{p} \cdot C_{p}},
$$

where $\dot{m}_{p}$ and $C_{p}$ are the mass flow rate and the specific heat capacity of the fluid flowing in the pipe [5]. The pipes overall heat loss coefficient is determined using the following relation:

$$
U_{p}=\left(\frac{1}{\frac{D_{3}}{D_{1} \cdot h_{\text {in }}}+\frac{D_{3} \cdot \ln \left(\frac{D_{2}}{D_{1}}\right)}{2 \cdot k_{\text {pipe }}}+\frac{D_{3} \cdot \ln \left(\frac{D_{3}}{D_{2}}\right)}{2 \cdot k_{\text {insulation }}}+\frac{1}{h_{\text {out }}}}\right),
$$

where $D_{1}, D_{2}$ and $D_{3}$ are the pipe insulation diameters as shown in fig.3.2, $k_{\text {pipe }}$ and $k_{\text {insulation }}$ are the thermal conductivity of the pipe and insulation material, $h_{i n}$, and $h_{\text {out }}$ are the heat transfer coefficients of the inner and outer surface of the pipe [26]. 


\subsubsection{Solar collector}

\subsubsection{Practical solar collector model}

It is often beneficial to also consider the modeling of a practical solar collector. In practice, the efficiency of a solar collector is defined by the following relation:

$$
\eta=\eta_{0}-a_{1} \cdot \frac{T_{m}-T_{a}}{G}-a_{2} \cdot \frac{\left(T_{m}-T_{a}\right)^{2}}{G},
$$

where: $\eta_{0}$ is the zero loss efficiency, $a_{1}$ and $a_{2}$ are the first and second order loss coefficients, $T_{m}$ is the collector mean temperature, and $T_{a}$ is the collector ambient temperature. The rate of energy transfer from the collector is determined using:

$$
P=A \cdot\left(\eta_{0} \cdot G-a_{1} \cdot\left(T_{m}-T_{a}\right)-a_{2} \cdot\left(T_{m}-T_{a}\right)^{2}\right),
$$

where $A$ represents the aperture are of the solar collector and $G$ represents the solar irradiation. In the case of a practical SC model, The fluid mass flow rate and collector mean temperature are assumed to be constant. Depending on the type of practical solar collector, one is able to obtain the required values for $\eta_{0}, a_{1}$ and $a_{2}$ in order to determine its efficiency and performance. In this study, theoretical SC model is selected over the practical SC model as the control variables expressed in the theoretical model are treated as constants in the practical model. The practical model is therefore used to validate the output of the theoretical model. In order to achieve this, the parameters (mass flow rate, first and second heat loss coefficients) of the theoretical model are selected such that the operating conditions of both the theoretical and practical models are matched.

\subsubsection{Theoretical solar collector model}

The basic method of measuring the performance of a solar collector is through exposing it to solar radiation and measuring the inlet and outlet temperatures as well as the flow rate of the fluid [5]. The useful heat gain obtained by the circulation fluid is then:

$$
Q_{\text {in }}=\dot{m}_{c f} \cdot C_{c f}\left(T_{c f, o u t}-T_{c f, i n}\right) .
$$

In order to determine the useful gain of the flat plate collector, it needs to be characterised such that there is an indication of how it absorbs energy, as well as how it losses energy 
to the surroundings. The thermal performance of a collector under steady state operating conditions (also known as the useful gain) is given by:

$$
Q_{\text {in }}=A_{\text {coll }} \cdot F_{r}\left((t \alpha) G-U_{L}\left(T_{c f, \text { out }}-T_{c f, \text { in }}\right)\right) .
$$

This equation is known as the Bliss-Hottel-Whillier relationship where: $F_{r}$ is the collector heat removal factor, $t$ and $\alpha$ are the transmittance and absorbance factors, $G$ is the global irradiance incident on the aperture plane of the solar collector and $U_{L}$ is the collector overall heat loss coefficient. The relation used to characterise the collector heat removal factor is:

$$
F_{r}=\frac{\dot{m}_{c f} \cdot c_{c f}}{A_{\text {coll }} \cdot U_{L}}\left[1-\exp \left(\frac{A_{\text {coll }} \cdot U_{L} \cdot F_{\text {prime }}}{m_{c f} \cdot c_{c f}}\right)\right],
$$

where $F_{\text {prime }}$ is denoted as the collector efficiency. All other parameters in eq.(3.8) are described in section 3.1. The overall thermal loss coefficient over the collector is given by:

$$
U_{L}=U_{t}+U_{b}+U_{e},
$$

where: $U_{t}$ is the collector top thermal loss coefficient, $U_{b}$ is the collector bottom thermal loss coefficient, and $U_{e}$ is the collector edge thermal loss coefficients. Physically, these parameters account for the thermal losses experienced in the top, bottom and edges of the solar collector. The overall transmittance and absorbance factors of the solar collector are given by:

$$
\begin{gathered}
\tau=\tau_{a} \cdot \tau_{r n}, \\
\alpha=1-\tau_{a},
\end{gathered}
$$

where $\tau_{a}$ and $\tau_{r n}$ denote the the collector transmittances due to absorbtion and reflectance. Equations obtained from $[5,18,31,32,33,34]$ are used to develop a model that characterizes $F_{\text {prime }}, U_{t}, U_{b}, U_{e}, \tau_{a}$ and $\tau_{r n}$ as functions of the solar collector design parameters in order to determine $F_{r}, t, \alpha$, and $U_{L}$. This is shown in Appendix A. The flow process to obtain the useful gain of the solar collector is shown in fig.3.3. 


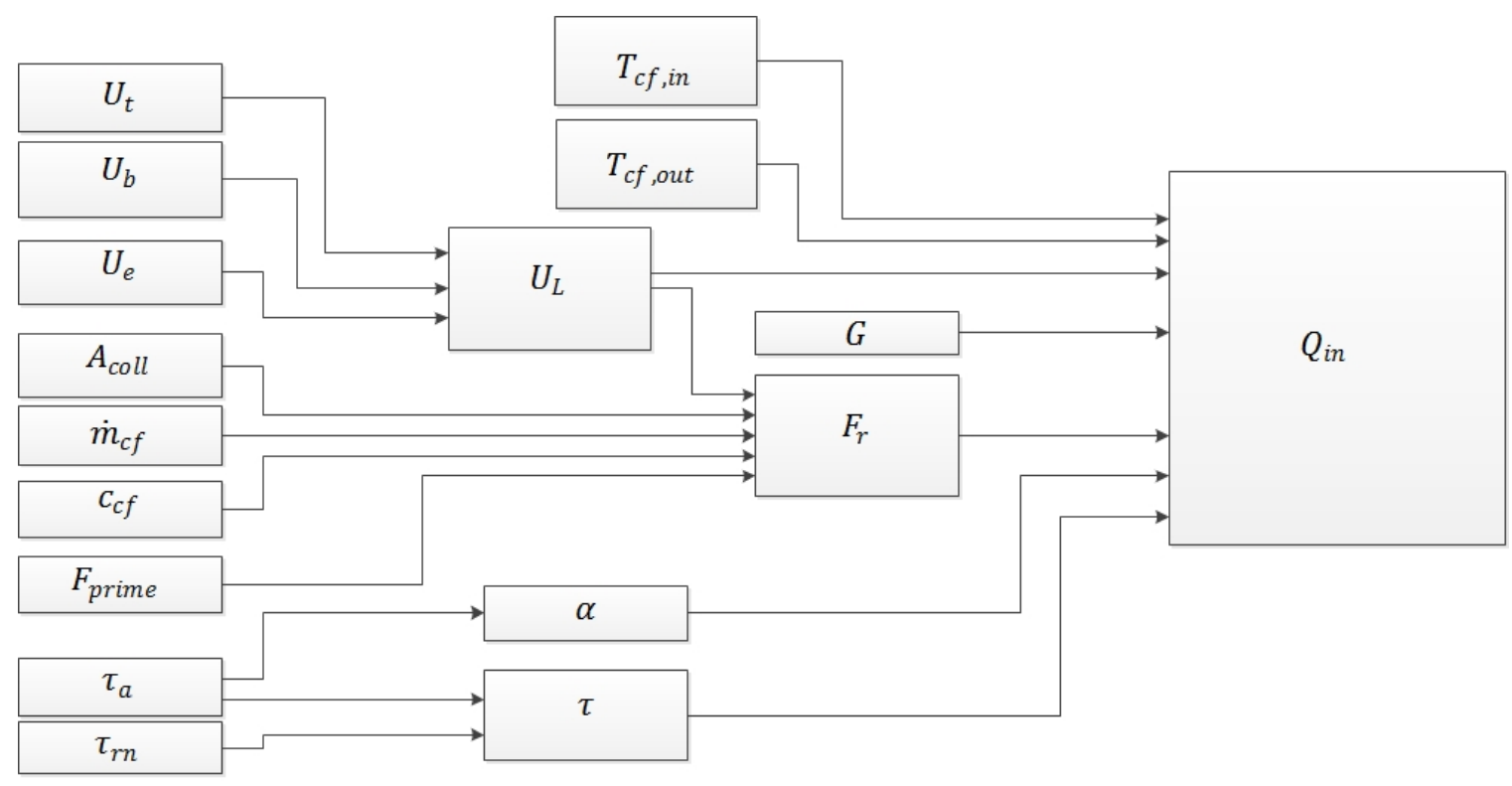

Figure 3.3: Flow process to obtain the useful gain of the solar collector.

Further, it is assumed that the useful gain at the collector is the same as the gain available to the circulation fluid.

\subsubsection{Circulation fluid storage tank}

In order to characterise the thermal performance of the circulation fluid storage tank, the first law of thermodynamics is applied to it. The energy balance in the tank is then given by the following relation:

$$
M_{c f} \cdot C_{c f} \cdot \frac{d T_{s 1}}{d t}=Q_{\text {in }}-Q_{\text {out_1 }}-Q_{\text {loss }}-Q_{\text {pipe } \_1}-Q_{\text {pipe } \_2},
$$

where: $M_{c f}$ is the total mass of the circulation fluid, $Q_{o u t \_1}$ is the heat extracted from tank $T_{1}$ in order to heat up water in tank $T_{2}, Q_{\text {loss }}$ is the heat lost in tank $T_{1}$ due to the tank thermal properties and $Q_{p i p e \_1}, Q_{p i p e \_2}$ are the heat losses due to the connecting pipes in the primary loop $[5,7]$. This is shown in the fig.3.4. 


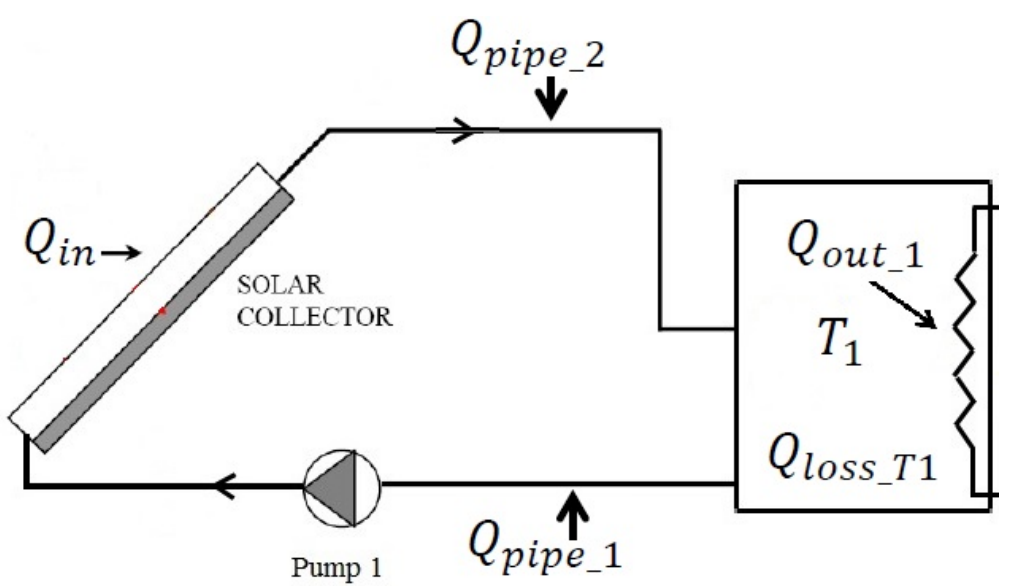

Figure 3.4: Rate of energy extraction in the primary loop.

$Q_{\text {loss }}$ is given by the following relation:

$$
Q_{\text {loss }}=U_{T_{1}} \cdot A_{T_{1}}\left(T_{s}-T_{\text {int }}\right),
$$

where: $U_{T_{1}}$ is the heat transfer coefficient between the circulation fluid stored in $\operatorname{tank} T_{1}$ and the area that tank 1 is located, $A_{T_{1}}$ is the surface area tank $T_{1}$, and $T_{i n t}$ is the temperature of the area where the storage tank is located [5, 7]. Eq. (3.12) must be integrated over time to determine the long term thermal performance of the storage tank. There are many possible numerical integration methods that can be used to achieve this. In this paper we have used the Runge-Kutta fourth order numerical approximation method (RK4). This method is selected due to the small truncation error per step size associated with it when compared to other methods $[35,36]$. The following relation is obtained through discretizing (3.12):

$$
T_{n+1}=T_{n}+\frac{t_{n+1}-t_{n}}{M_{c f} C_{c f}}\left(Q_{i n_{n}}-Q_{o u t_{n}}-Q_{{l o s s_{n}}_{n}}-Q_{p 1_{n}}-Q_{p 2_{n}}\right)
$$

The Runge-Kutta method is then applied where (3.12) is approximated by the following relation:

$$
T_{n+1}=T_{n}+\frac{h}{6}\left(k_{1}+2 k_{2}+2 k_{3}+k_{4}\right)
$$

where

$$
\begin{gathered}
k_{1}=T_{n}+\frac{t_{n+1}-t_{n}}{M_{c f} C_{c f}}\left(Q_{i n_{n}}-Q_{\text {out }_{n}}-Q_{\text {loss }_{n}}-Q_{p 1_{n}}-Q_{p 2_{n}}\right) \\
k_{2}=T_{n}+\frac{\left.\left.t_{(} n+1+\frac{h}{2}\right)-t_{(} n+\frac{h}{2}\right)}{M_{c f} C_{c f}}\left(Q_{i n_{n+\frac{h}{2}}}-Q_{o u t_{n+\frac{h}{2}}}-Q_{\text {loss }_{n+\frac{h}{2}}}-Q_{p 1_{n+\frac{h}{2}}}-Q_{p 2_{n+\frac{h}{2}}}\right) \\
k_{3}=T_{n}+\frac{\left.\left.t_{(} n+1+\frac{h}{2}\right)-t_{(} n+\frac{h}{2}\right)}{M_{c f} C_{c f}}\left(Q_{i n_{n+\frac{h}{2}}}-Q_{\text {out }_{n+\frac{h}{2}}}-Q_{\text {loss }_{n+\frac{h}{2}}}-Q_{p 1_{n+\frac{h}{2}}}-Q_{p 2_{n+\frac{h}{2}}}\right)
\end{gathered}
$$




$$
k_{4}=T_{n}+\frac{\left.\left.t_{(} n+1+h\right)-t_{(} n+h\right)}{M_{c f} C_{c f}}\left(Q_{i n_{n+h}}-Q_{o u t_{n+h}}-Q_{{\text {loss } s_{n+h}}}-Q_{p 1_{n+h}}-Q_{p 2_{n+h}}\right)
$$

In these relations, $k_{1}, k_{4}$ are increments on the slope based on the beginning and end interval and $k_{2}, k_{3}$ are increments based on the slope at the midpoints (using Euler's method) [35, 36]. The step size of each interval is denoted as $h$ and $T_{n+1}$ represents the approximation of the next state of $T_{n}$.

\subsubsection{Water storage tank}

The first law of thermodynamics is applied to water tank $\left(T_{2}\right)$ to form the following relation for the energy balance in the tank:

$$
\left(M_{w} \cdot C_{w}\right) \cdot \frac{d T_{s 2}}{d t}=Q_{i n \_2}-Q_{l o a d}-Q_{l o s s \_T 2}-Q_{c_{w}}-Q_{p i p e \_3}-Q_{p i p e \_4},
$$

where

$$
\begin{gathered}
Q_{c_{w}}=\dot{m}_{\text {out }} \cdot C_{w}\left(T_{s 2}-T_{c_{w}}\right), \\
Q_{\text {load }}=\dot{m}_{\text {out }} \cdot C_{w}\left(T_{s 2}-T_{\text {out }}\right), \\
Q_{\text {loss_T2 }}=U_{T_{s 2}} \cdot A_{T_{2}}\left(T_{s 2}-T_{\text {int }}\right) .
\end{gathered}
$$

In (3.21), (3.22) and (3.23), $M_{w}$ and $C_{w}$ represent the mass and specific heat capacity of water, $Q_{\text {in } 2}$ is the heat added to tank $T_{2}$ by the heat exchanger in tank $T_{1}, Q_{\text {load }}$ is the heat removed from the tank to the load, $Q_{\text {loss_T2 }}$ is the thermal losses of the water storage tank, $U_{T_{s 2}}$ is the heat transfer coefficient between the water stored in tank $T_{2}$ and the area that tank 2 is located, $A_{T_{2}}$ is the surface area tank $T_{2}, Q_{c_{w}}$ is the heat removed from the tank through the addition of cold water at a flow rate of $\dot{m}_{\text {out }}, T_{\text {out }}$ is user required value of the temperature at the output of the SWHS and $Q_{\text {pipe } \_3}, Q_{\text {pipe } \_4}$ are the heat losses due to connecting pipes $c p_{i}$ for $i=3, \ldots, 6$. This is shown in fig.3.5. 


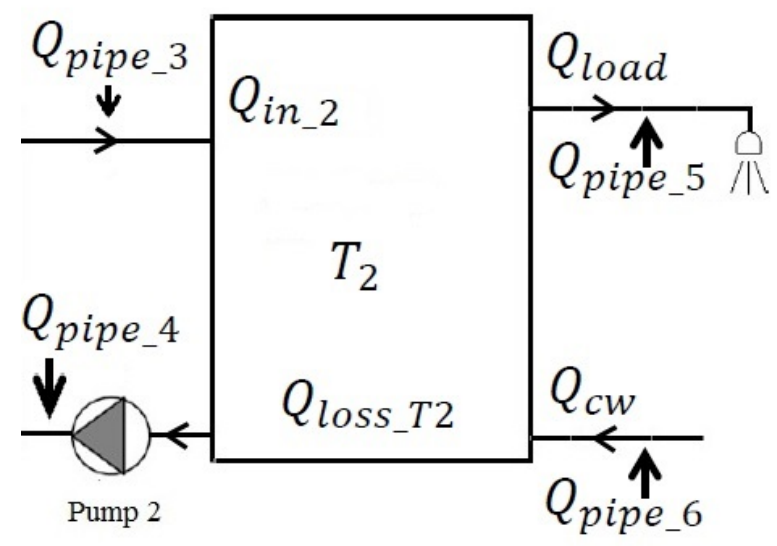

Figure 3.5: Rate of energy extraction the secondary loop.

\subsubsection{Heat exchanger}

The heat or rate of energy transfer to the secondary circuit (denoted as $Q_{\text {out_1 }}$ ) is obtained through using a simple model that characterises the the thermal properties of a serpentine which acts as the heat exchanger. In order to further simplify this model, it is assumed that for a short time interval, the temperature $\left(T_{s 2}\right)$ in the water storage tank $\left(T_{2}\right)$ remains constant. When dealing with a large mass of water $\left(M_{w}\right)$, this assumption is seen to be reasonable as the large mass would result in a small change in $\left(T_{s 2}\right)$ over a small period of time. under the above mentioned assumption, the following relations are used to determine the thermal performance of the serpentine:

$$
\begin{gathered}
\left.T_{w, \text { out }}=T_{s 1}+\left(T_{w, \text { in }}-T_{s 1}\right) \exp \left(\frac{-h \cdot S}{\eta \cdot \dot{m}_{w}} \cdot C_{w}\right)\right), \\
Q_{\text {out_serp }}=\dot{m}_{w} \cdot C_{w}\left(1-\exp \left(\frac{-h \cdot S}{\eta \cdot \dot{m}_{w}} \cdot C_{w}\right)\right) \cdot\left(T_{s 1}-\left(T_{w, \text { in }}\right)\right),
\end{gathered}
$$

where

$$
T_{w, \text { in }}=T_{s 2}-\Delta T_{\text {in_pipe_4 } 4} .
$$

In (3.24) and (3.25), $h, \eta$ and $S$ denote the heat transfer coefficient, the heat transfer surface area, and the heat transfer efficiency of the serpentine. The heat transfer coefficient is determined using the following relation [7]:

$$
h=\frac{h_{\text {lin }}}{\pi \cdot D_{\text {serp }}},
$$


where $h_{\text {lin }}$ and $D_{\text {serp }}$ are denoted as the average linear heat transfer coefficient and the diameter of the serpentine. The heat transfer surface area is given by:

$$
S=\pi \cdot D_{\text {serp }} \cdot L_{\text {serp }}
$$

where $D_{\text {serp }}$ and $L_{\text {serp }}$ are the inner diameter and length of the serpentine. Parameters $\eta$ is dependent on the type of serpentine selected. Equations obtained from $[7,37,38]$ are used to develop a model that characterizes $h$ and $S$ as functions of the serpentine design parameters. This is shown in Appendix B. The flow process to obtain the rate of energy extraction for the serpentine is shown in fig.3.6.

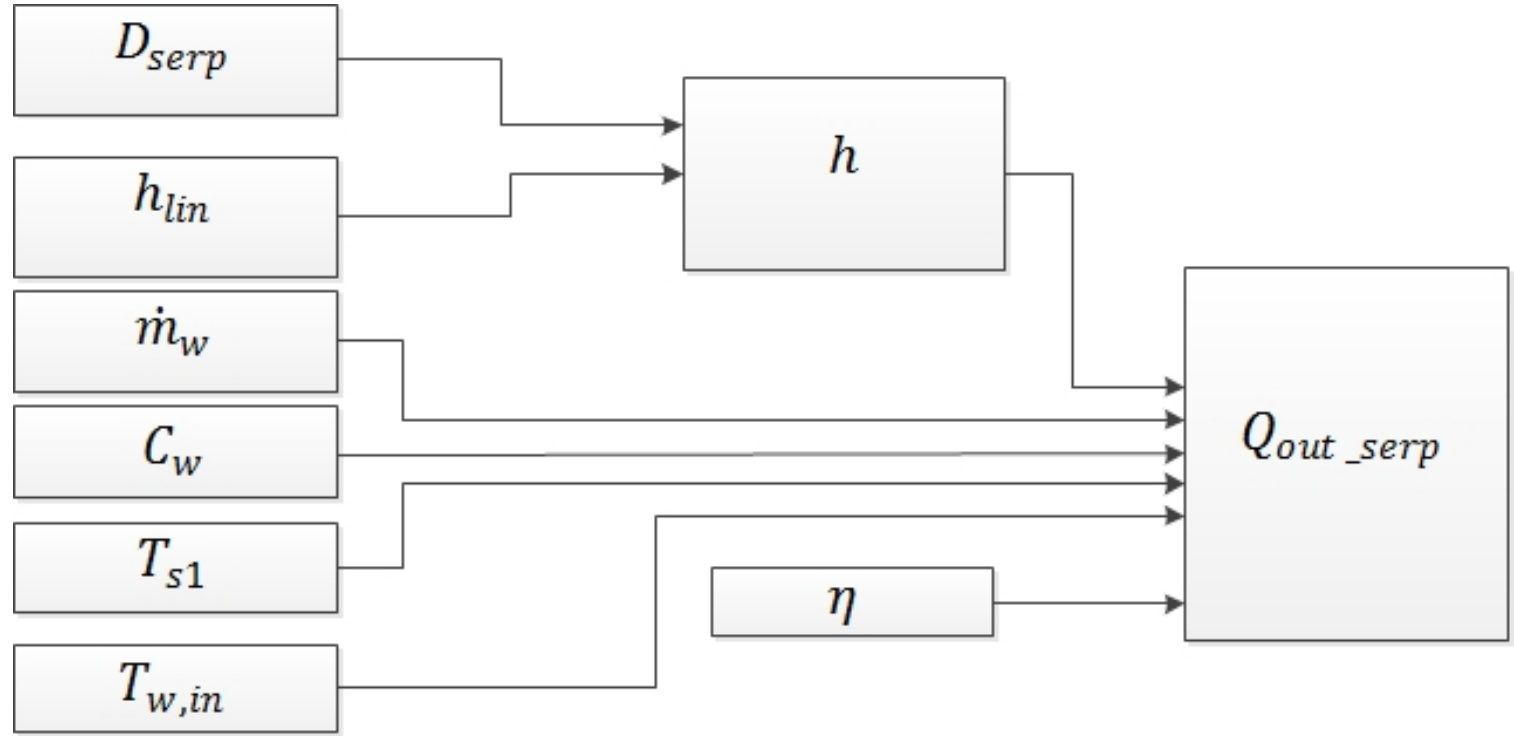

Figure 3.6: Flow process to obtain the rate of energy extraction for the serpentine.

\subsubsection{Flow control}

The thermal performance of a solar collector depends on a number of parameters as illustrated in section 3.2.2.2. The main parameters of interest are the mass flow rates $\left(\dot{m}_{c f}\right.$ and $\left.\dot{m}_{w}\right)$ which are controlled through the use of a water pump for each of the two fluid circulation loops. The computation of the pump mechanical power required to circulate the fluid in the primary and secondary loops of the system is determined using equations from $[7,39]$. The pump mechanical power is given by the following relation:

$$
P_{\text {pump }}=P_{\text {pump }, A}+P_{\text {pump }, \text { duct }},
$$


where: $P_{\text {pump }, A}$ represents the power required to cover the pressure losses in the solar collector, and $P_{\text {pump,duct }}$ represents the power required to cover the pressure losses in the pipes connecting the solar collector to tank 1 in the primary loop, and connecting tank 1 to tank 2 in the secondary loop. $P_{\text {pump }, A}$ is determined using the following equation:

$$
P_{\text {pump }, A}=\frac{A}{A_{\text {coll }}} P_{\text {pump }, \text { coll }},
$$

where: $A$ represents the surface area of of the tubes in the solar collector and $P_{\text {pump,coll }}$ represents the energy required to overcome the pressure losses $\Delta P_{\text {coll }}$ in a single collector. the equations for these parameters are shown below:

$$
\begin{gathered}
P_{\text {pump }, \text { coll }}=\frac{\dot{m}_{\text {coll }}}{\rho_{c f}} \Delta P_{\text {coll }}, \\
\Delta P_{\text {coll }}=\zeta_{\text {coll }} \frac{\rho_{c f} \cdot w_{c o l l}^{2}}{2},
\end{gathered}
$$

where

$$
w_{\text {coll }}=\frac{\dot{m}_{\text {coll }}}{\rho_{c f} \cdot a_{\text {coll }}} .
$$

Parameters $w_{\text {coll }}, \rho_{c f}, \zeta_{\text {coll }}$ and $a_{\text {coll }}$ represent the fluid speed at the inlet of the collector, the working fluid mass density, the pressure loss coefficient and the cross sectional surface area at the collector's inlet. The mass flow rate at the input of the collector is given by:

$$
\dot{m}_{\text {coll }}=\frac{A_{\text {coll }}}{A} \dot{m}_{c f} .
$$

Combining (3.30)-(3.34) results in the following relation:

$$
P_{\text {pump }, A}=K_{p u m p, A} \cdot \dot{m}_{c f}^{3},
$$

where the coefficient $K_{p u m p, A}$ is determined using:

$$
K_{\text {pump }, A}=\frac{\zeta_{\text {coll }}}{2 \rho_{\text {cf }}^{2}}\left[\frac{A_{\text {coll }}}{a_{\text {coll }} \cdot A}\right]^{2} .
$$

The pump power necessary to cover the pressure losses over the collector ducts in the (SWHS) is given by:

$$
P_{\text {pump }, \text { duct }}=\frac{\dot{m}_{c f}}{\rho_{c f}} \Delta P_{d u c t},
$$


where $\dot{m}_{c f}$ and $\rho_{c f}$ represent the fluid speed in the ducts and the working fluid mass density. $\Delta P_{\text {duct }}$ represents the pressure losses over the ducts and is given by:

$$
\Delta P_{d u c t}=\lambda_{d u c t} \frac{l_{d u c t}}{d_{d u c t}} \cdot \frac{\rho_{c f} \cdot w_{d u c t}^{2}}{2},
$$

where $\lambda_{d u c t}, l_{d u c t}$ and $d_{d u c t}$ are the friction factor of the duct, the length of the duct and the inner diameter of the duct. The fluid speed in the duct $\left(w_{d u c t}\right)$ is given by:

$$
w_{d u c t}=\frac{4}{\pi} \frac{\dot{m}_{c f}}{\rho_{c f} \cdot d_{d u c t}^{2}} .
$$

Combining (3.37)-(3.39) yields:

$$
P_{\text {pump }, \text { duct }}=K_{\text {pump }, \text { duct }} \cdot \dot{m}_{c f}^{3},
$$

where the coefficient $K_{\text {pump,duct }}$ is given by:

$$
K_{\text {pump }, \text { duct }}=\frac{8}{\pi^{2}} \frac{\lambda_{\text {duct }} \cdot l_{\text {duct }}}{\rho_{c f}^{2} \cdot d_{d u c t}^{5}},
$$

Finally, combining (3.35),(3.36),(3.40) and (3.41) yields:

$$
P_{\text {pump }}=K_{\text {pump }} \cdot \dot{m}_{c} f^{3}
$$

where

$$
K_{\text {pump }}=K_{\text {pump }, A}+K_{\text {pump,duct }} .
$$

The rate of energy usage of pumps $P_{1}$ and $P_{2}$ can therefore be individually denoted as follows:

$$
\begin{aligned}
& P_{\text {pump }_{1}}=K_{\text {pump }_{1}} \cdot\left(\dot{m}_{c f}\right)^{3}, \\
& P_{\text {pump }_{2}}=K_{\text {pump }_{2}} \cdot\left(\dot{m}_{w}\right)^{3} .
\end{aligned}
$$

It should be noted that for $P_{2}, K_{\text {pump }, A}=0$ as there is no solar collector connected in the secondary loop. Using equations obtained from [7, 40,39], $\zeta_{\text {coll }}$ and $\lambda_{d u c t}$ are characterised as functions of the pump design parameters. This is shown in Appendix C. The flow process to obtain the rate of energy usage of the pumps is shown in fig.3.7 


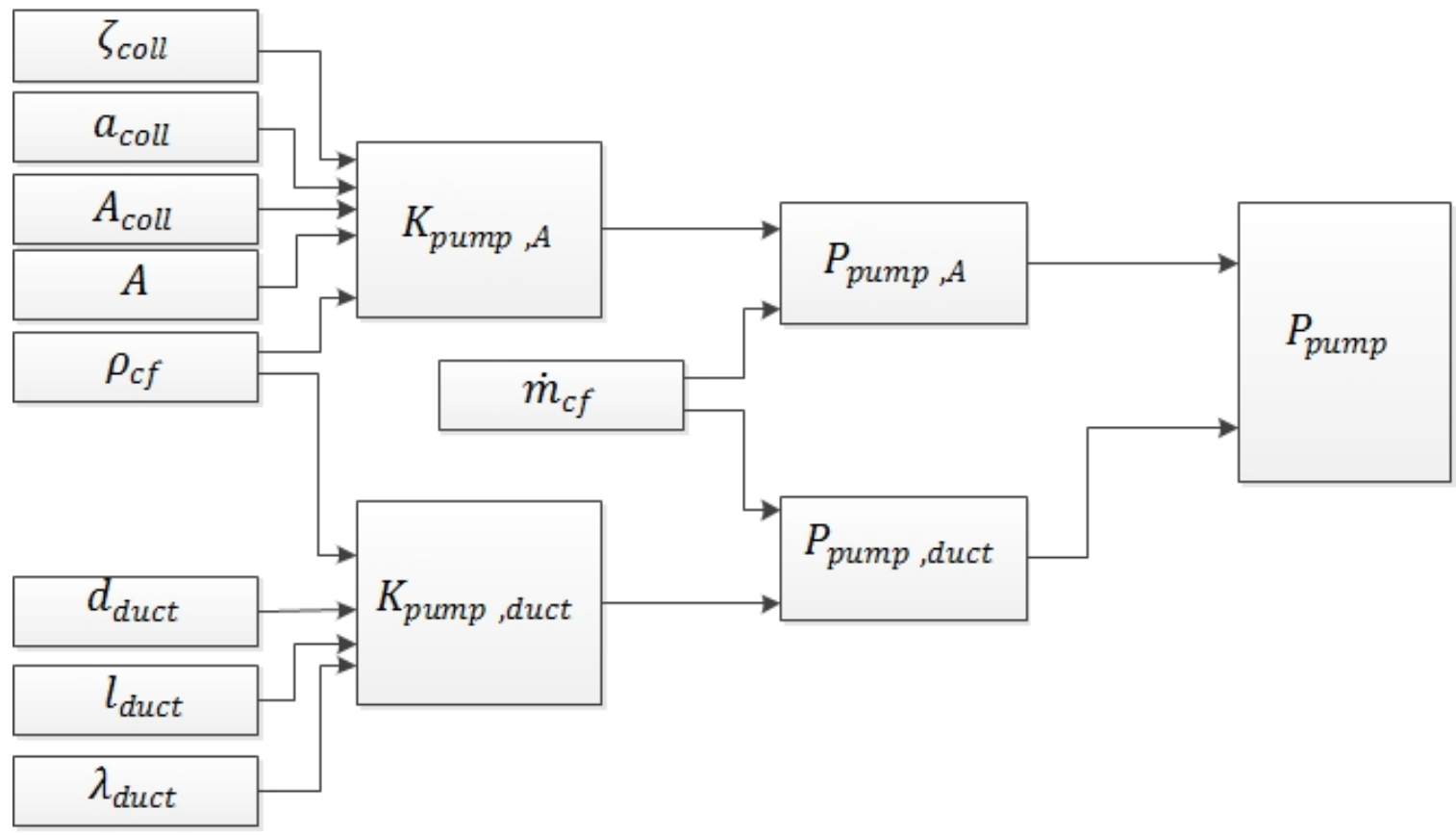

Figure 3.7: Flow process to obtain the rate of energy usage of the pumps.

\subsection{MODEL OPTIMIZATION}

In order to develop a model that will maximize the energy gain in the primary loop whilst minimizing energy usage by the pumps as well as the rate of energy extraction from tank 1 to meet the energy requirements of tank 2 in the secondary loop, the following continuous time objective function is formulated:

$$
J\left(\dot{m}_{c f}, \dot{m}_{w}\right)=\int_{t=0}^{T}\left[Q_{i n}\left(\dot{m}_{c f}\right)-\left(P_{p u m p 1}\left(\dot{m}_{c f}\right)+P_{p u m p} 2\left(\dot{m}_{w}\right)\right)\right] d t .
$$

where $T$ denotes the terminal time or optimization interval which is selected as 24 hours. The objective function is then expressed in the discrete time domain. This is given by:

$$
J\left(\dot{m}_{c f}(i), \dot{m}_{w}(i)\right)=\sum_{i=1}^{N}\left[\left(Q_{i n}\left(\dot{m}_{c f}(i)\right)-\left(P_{p u m p 1}\left(\dot{m}_{c f}(i)\right)+P_{p u m p 2}\left(\dot{m}_{w}(i)\right)\right)\right) \cdot \Delta_{i}\right],
$$

where:

$$
N=\frac{T}{h}
$$

The sample interval which is denoted as $h$ is chosen as 10 minutes. Our objective is to maximize this discrete energy function which consists of the rate of energy transfer over the collector $\left(Q_{i n}\right)$ and the power of the pumps in the primary and secondary loops $\left(P_{\text {pump } 1}\right.$ 
and $\left.P_{\text {pump } 2}\right)$. We therefore aim to maximize the difference between the gain over the SC and the energy used by the pumps and in doing so, to maximize the overall gain of the SWHS. This is achieved through negating and minimizing (3.47) as this is equivalent to maximizing the original function. This is done in order to meet the structural requirements of the Matlab toolbox used to solve the model. The optimization process is then summarised as follows:

$$
\min \left[-J\left(\dot{m}_{c f}(i), \dot{m}_{w}(i)\right)\right]
$$

subject to the following linear inequality constraints:

$$
\begin{gathered}
\dot{m}_{c f}^{\text {min }} \leq \dot{m}_{c f}(i) \leq \dot{m}_{c f}^{\max }, \\
\dot{m}_{w}^{\text {min }} \leq \dot{m}_{w}(i) \leq \dot{m}_{w}^{\max }, \\
T_{s 1}^{\min } \leq T_{s 1}(i) \leq T_{s 1}^{\max }, \\
T_{s 2}^{\min } \leq T_{s 2}(i) \leq T_{s 2}^{\max },
\end{gathered}
$$

for $i=1, \ldots, N$, the following linear equality constraints:

$$
\begin{gathered}
T_{c f, i n}(i)=T_{s 1}(i)-\Delta T_{\text {in,pipe_2 }}(i), \\
T_{s 1}(i)=T_{c f, \text { out }}(i)-\Delta T_{\text {in,pipe_1 }}(i), \\
T_{s 2}(i)=T_{w, \text { out }}(i)-\Delta T_{\text {in,pipe_3 }}(i), \\
T_{w, \text { in }}(i)=T_{s 2}(i)-\Delta T_{\text {in,pipe_4 }}(i), \\
T_{\text {out }}(i)=T_{s 2}(i)-\Delta T_{\text {in,pipe_5 }}(i), \\
T_{s 2 \_i n}(i)=T_{c w}(i)-\Delta T_{\text {in,pipe_6 }}(i),
\end{gathered}
$$

for $i=1, \ldots, N$, and the following non linear inequality constraint:

$$
Q_{\text {out_serp }}(i) \geq Q_{\text {in_2 }}(i)
$$

for $i=1, \ldots, N$, where: $\dot{m}_{c f}^{\min }, \dot{m}_{c f}^{\max }, \dot{m}_{w}^{\min }$ and $\dot{m}_{w}^{\max }$ are the minimum and maximum allowable fluid flow rates for pumps $P 1$ and $P 2$, while $T_{s 1}^{\min }, T_{s 1}^{\max }, T_{s 2}^{\min }$ and $T_{s 2}^{\max }$ are the minimum and maximum allowable fluid tank temperatures based on the tank design parameters. Equations (3.54)-(3.59) regulate the temperature distribution in the SWHS taking into account the temperature losses in the connecting pipes $\left(\Delta T_{i n, p i p e \_} j\right.$ where $j=$ $1, \ldots ., 6$ according to fig.3.1) for each sample instant over the optimization interval, while (3.60) 
ensures that the rate of energy extraction by the serpentine meets the minimum requirement from tank 2 in order to heat water up to the desired user temperature. It should be noted that (3.54)-(3.59) represents system equations that satisfy the system model derived in section 3.2 .

\subsection{MODEL COMPUTATIONAL PROCEDURE}

This section highlights the computational steps of the model. The aim is to obtain optimal flow rates that will maximize the rate of energy extraction from the solar collector in the systems primary loop, whilst minimizing the rate of energy usage of the pumps and the serpentine in the system's secondary loop. With the initial conditions, upper and lower bounds of the control variables $\left(\dot{m}_{c f}\right.$ and $\left.\dot{m}_{w}\right)$ set, the optimization command is executed. The command points to an energy function whose input variables are the control variables $\left(\dot{m}_{c f}\right.$ and $\dot{m}_{w}$ ) ranging from 0.00001 to $0.1 \mathrm{~kg} / \mathrm{s}$ in order to find the optimal solution that will minimize (3.49) over the 24 hour optimization interval. In this function, the secondary loop is analysed first in order to determine the rate of energy required from $T_{1}$ to obtain the required values of $T_{\text {out }}$. In addition to the parameters shown in tables $4.2-4.4$, the developed model uses initial values for $T_{s 1_{i}}, T_{c w_{i}}, T_{p m_{i}}$ and $T_{f m_{i}}$ as entry points. With the user requirement of temperature values at the output of the SWHS $\left(T_{\text {out }}\right)$ known over the 24 hour optimization interval, $T s_{2_{i}}$ is determined using (3.58). The rate of energy transfer to the load $\left(Q_{l o a d}\right)$, the rate of energy loss due to the thermal properties of tank $2\left(Q_{\text {loss_T2 }}\right)$ and the rate of energy loss $\left(Q_{c w_{i}}\right)$ due to cold water entering tank 2 at temperature $T_{s 2_{i}}$ are calculated using (3.21), (3.22) and (3.23). With $T_{s 2_{(i+1)}}$ known, the required rate of energy from the circulation fluid water tank $\left(Q_{i n \_2_{i}}\right)$ is then calculated using (3.20). In the system's primary loop, (3.9)-(3.11) are used to determine $U_{L}$ and the transmittance absorbance product $(t \alpha)$ for the first sample instance. $F_{r_{i}}, Q_{i n_{i}}, Q_{\text {loss }_{i}}, Q_{\text {out_serpi }}, P_{\text {pump } 1_{i}}, P_{{\text {pump } 2_{i}}_{i}}$ and $T_{c f, \text { out }}$ are then calculated. Using these values, the value of $T s_{(i+1)}$ is calculated using (3.12). The value of $T s_{(i+1)}$ is then used to calculate $T_{p m_{(i+1)}}$ and $T_{f m_{(i+1)}}$ using (A.14) and (A.25) which can be found in Appendix A. The model therefore simulates this process with flow rates $\dot{m}_{c f}$ and $\dot{m}_{w}$ ranging from 0.00001 to $0.1 \mathrm{~kg} / \mathrm{s}$ to find the optimal solution that will minimize (3.49) over the 24 hour optimization interval.

A flow chart illustrating the overview of the model computational procedure is shown in fig. 
3.8. A second flow chart illustrating the steps followed in the optimization process is shown in fig.3.9.

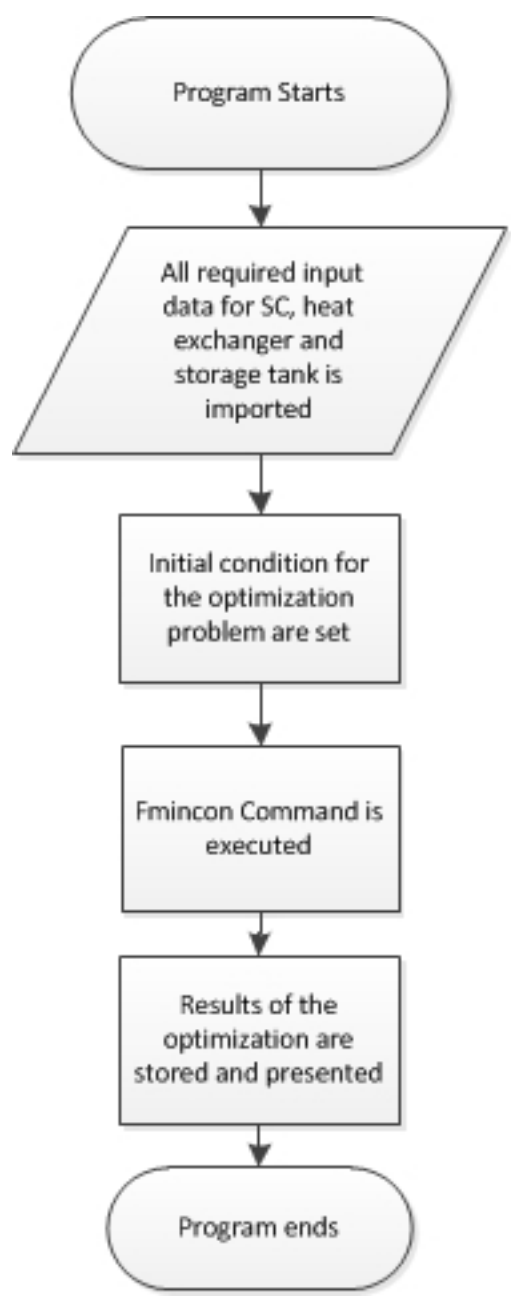

Figure 3.8: Flowchart illustrating an overview of the optimization process. 


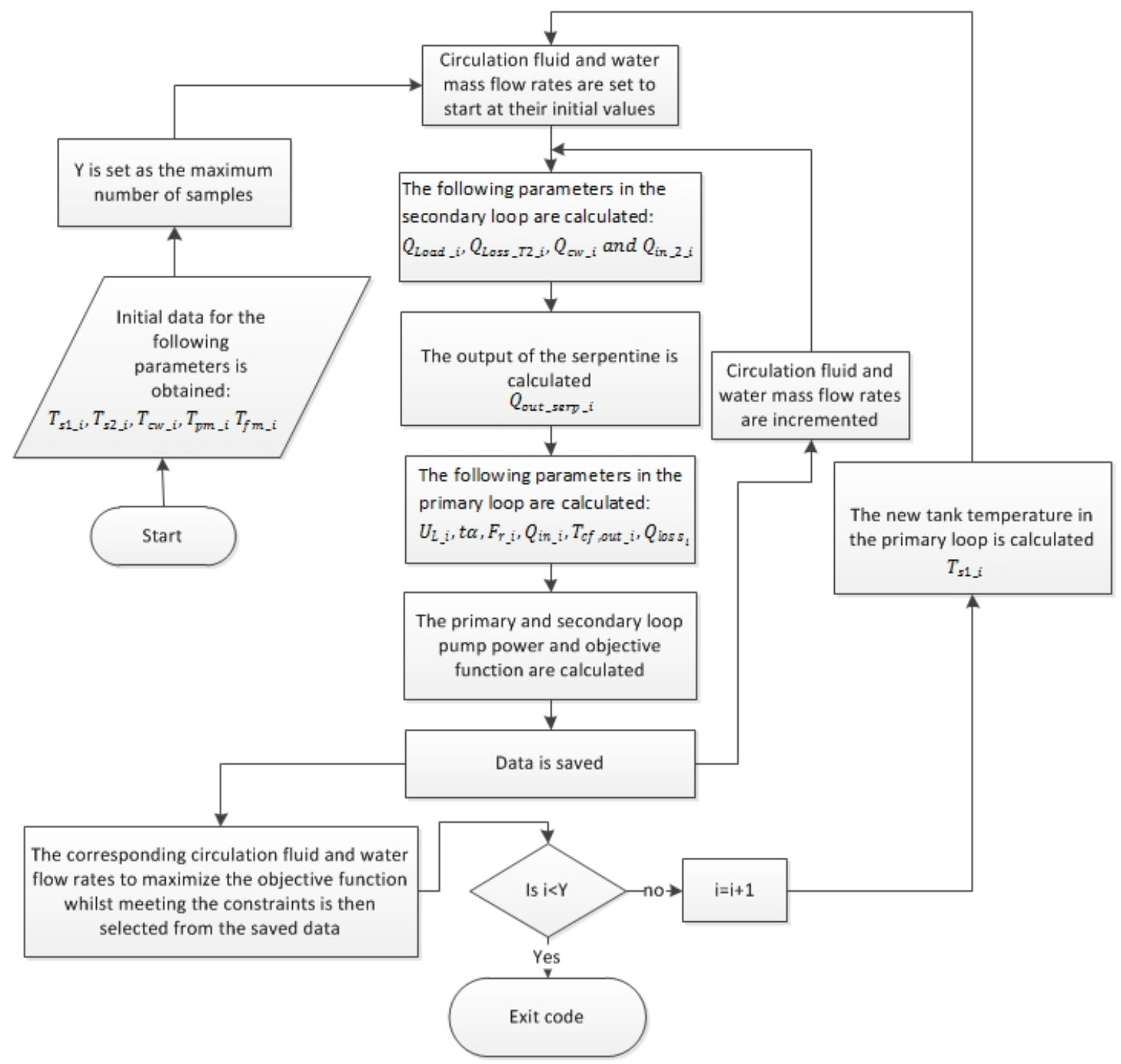

Figure 3.9: Flowchart illustrating the model optimization process.

\subsection{VALIDATION OF MODEL}

In order to validate the output of the proposed model, it was compared to the output of a practical SWHS operating at a constant flow rate and with constant losses. In order to avoid complexity, only the primary loop of the system is considered in the validation process. The secondary loop consists of connecting pipes, a pump and two tanks that are used to store energy. This loop is not evaluated as it is an extension of the primary loop. The system to be considered is shown below: 


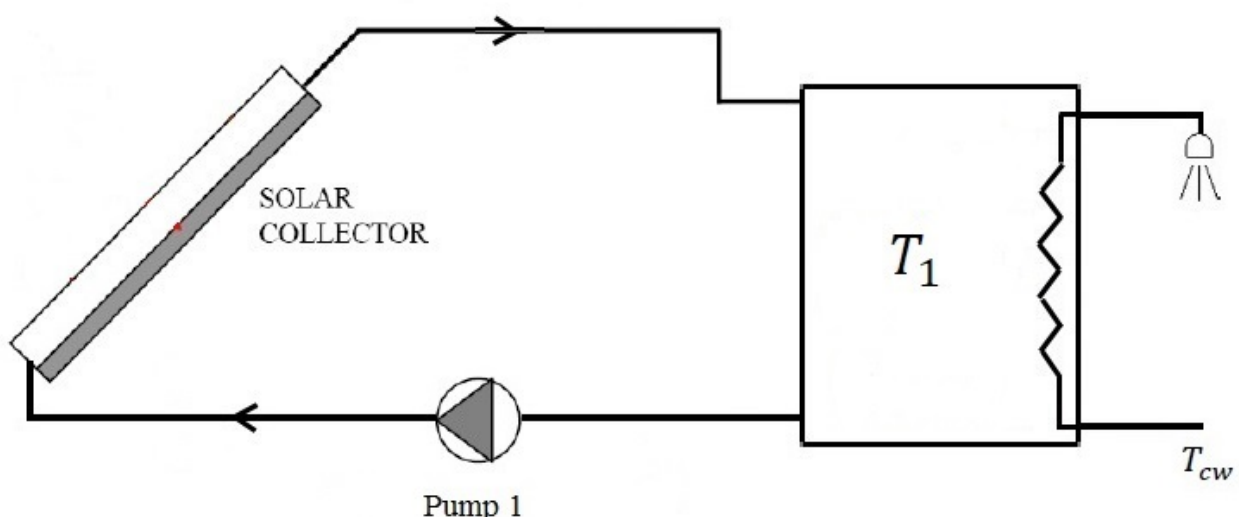

Figure 3.10: SWHS considered in the model validation.

This system represents the primary loop of the SWHS shown in fig.3.1. The efficiency and power of the practical solar collector model are given by (3.4) and (3.5). The collector is connected to a storage tank, whose rate of change of temperature is determined using (3.12). In order to compare the output of the practical solar collector and the theoretical model that we have derived, the input variables and losses must be the same. The parameters of the practical solar collector are shown in table 3.1. The input solar radiation, and ambient temperature used for the two models are shown in fig.4.1 and fig.4.2. Fig. 3.11 shows the gain over the SC for the practical model and the theoretical model. From this figure it can be seen that the model results are quite similar with minor differences occurring during the morning after the pump has switched on and in the afternoon before the pump is switched off.

The mathematical model developed is classified as a non-linear constrained model. In order to solve this model, the fmincon function in MATLAB was used. The interior point, trustregion-reflective, active-set and sequential-quadratic-programming (SQP) algorithms were all tested. It was fount that the interior point algorithm produced the best results.

In order to further validate the results of the mathematical model, a second function was formulated. This function is designed to determine the overall system gain as a function of the mass flow rates. The resulting flow rates produced by the fmincon function were inserted as inputs to the second function in order to evaluate what the resulting gain of the system would be. It was found that the second function produces the same gain as that of the 
fmincon function.

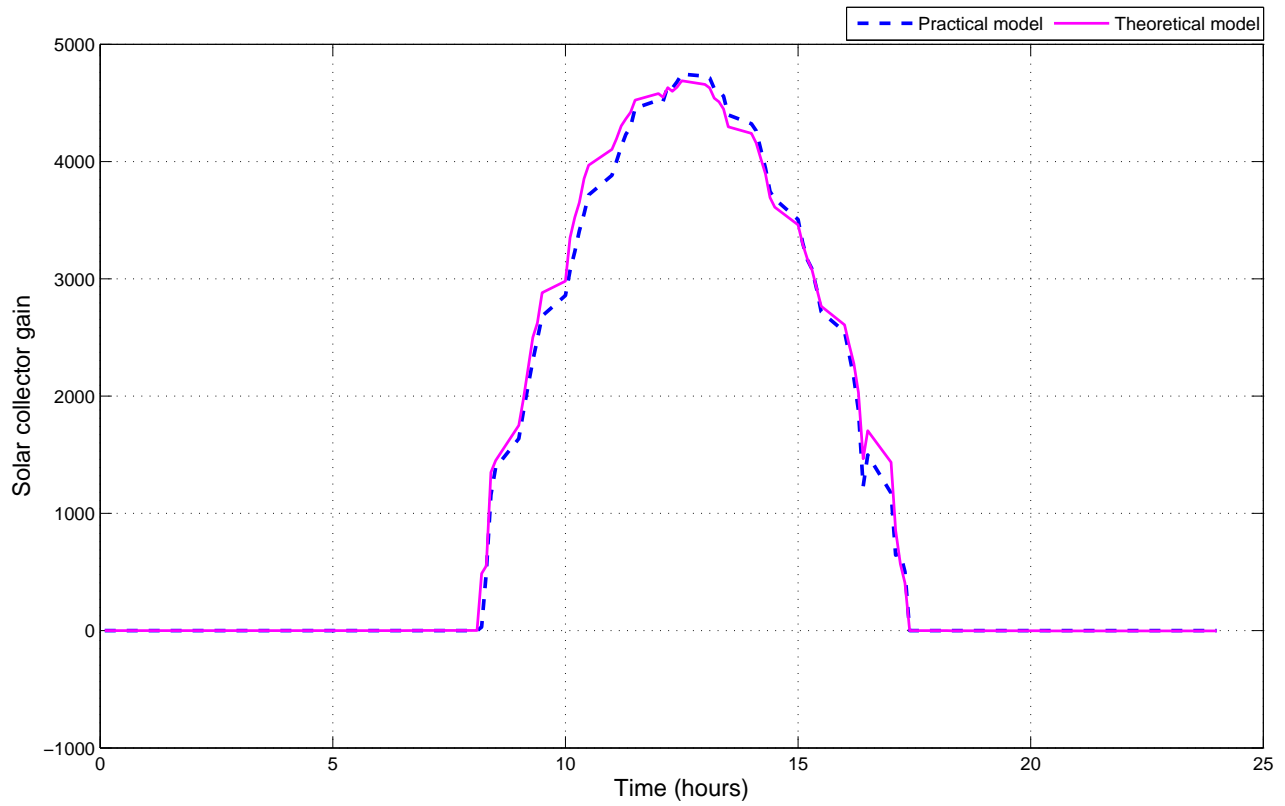

Figure 3.11: SWHS considered in the model validation. 
Table 3.1: Summary of results

\begin{tabular}{lll}
\hline Solar collector parameters & Value & Unit \\
\hline Collector aperture area & 12.54 & $\mathrm{~m}^{2}$ \\
Zero loss efficiency & 0.839 & - \\
First order thermal loss coefficient & 3.2 & $\frac{\mathrm{W}}{\mathrm{m}^{2} \mathrm{~K}}$ \\
Second order thermal loss coefficient & 0.0137 & $\frac{\mathrm{W}}{\mathrm{m}^{2} K}$ \\
Flow rate (when solar radiation is available) & 0.35 & $\frac{\mathrm{kg}}{\mathrm{s}}$ \\
Flow rate (no solar radiation available) & 0.00001 & $\frac{\mathrm{kg}}{\mathrm{s}}$ \\
Mean plate temperature & 50 & ${ }^{\circ} \mathrm{C}$ \\
\hline
\end{tabular}




\section{CHAPTER 4}

\section{CASE STUDY}

The objective of this case study is to illustrate the effects of mass flow rate optimization on the total energy gain, pipe thermal losses and overall system efficiency of a SWHS. The system to be optimized is a residential forced circulation SWHS that consists of an array of six flat plate solar collectors connected to a circulation fluid storage tank, which in turn is connected to a water tank as shown in figure 3.1.

\subsection{DATA PRESENTATION}

Table 4.1 (values adapted from $[5,7,41]$ ) shows the parameters of tank 1 and tank 2 as well as the parameters of the fluids in the tanks.

The system's solar collector parameters are shown in table 4.2 (values adapted from [5, 7, 27]). The heat exchanger, connecting pipe and primary and secondary loop pump parameters are shown in table 4.3 (values adapted from $[5,7,26]$ ).

Meteorological obtained from [12] was used in this study. The measured radiation and ambient temperature (at a constant wind velocity of $3.4 \mathrm{~m} / \mathrm{s}$ ) for 10 minute intervals over a 24 hour optimization interval are shown in fig. 4.1 and fig.4.2. 


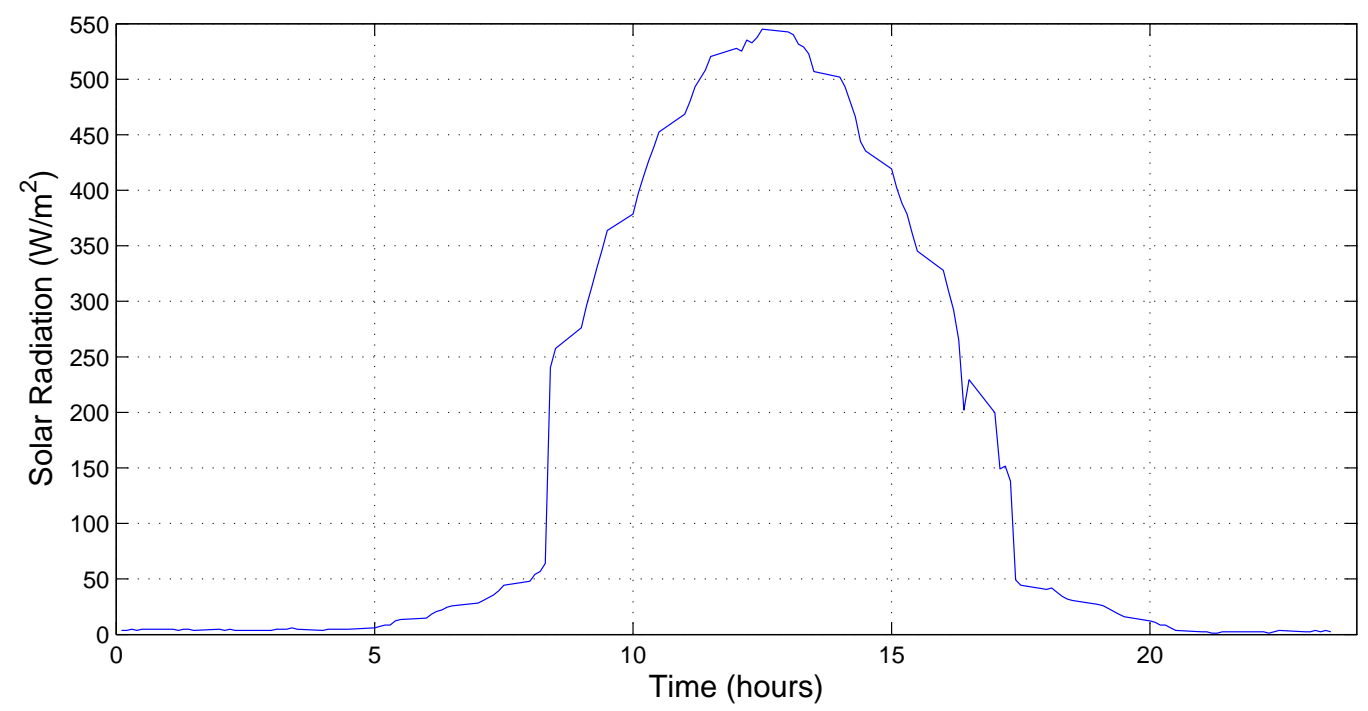

Figure 4.1: Solar radiation over the 24 hour optimization interval.

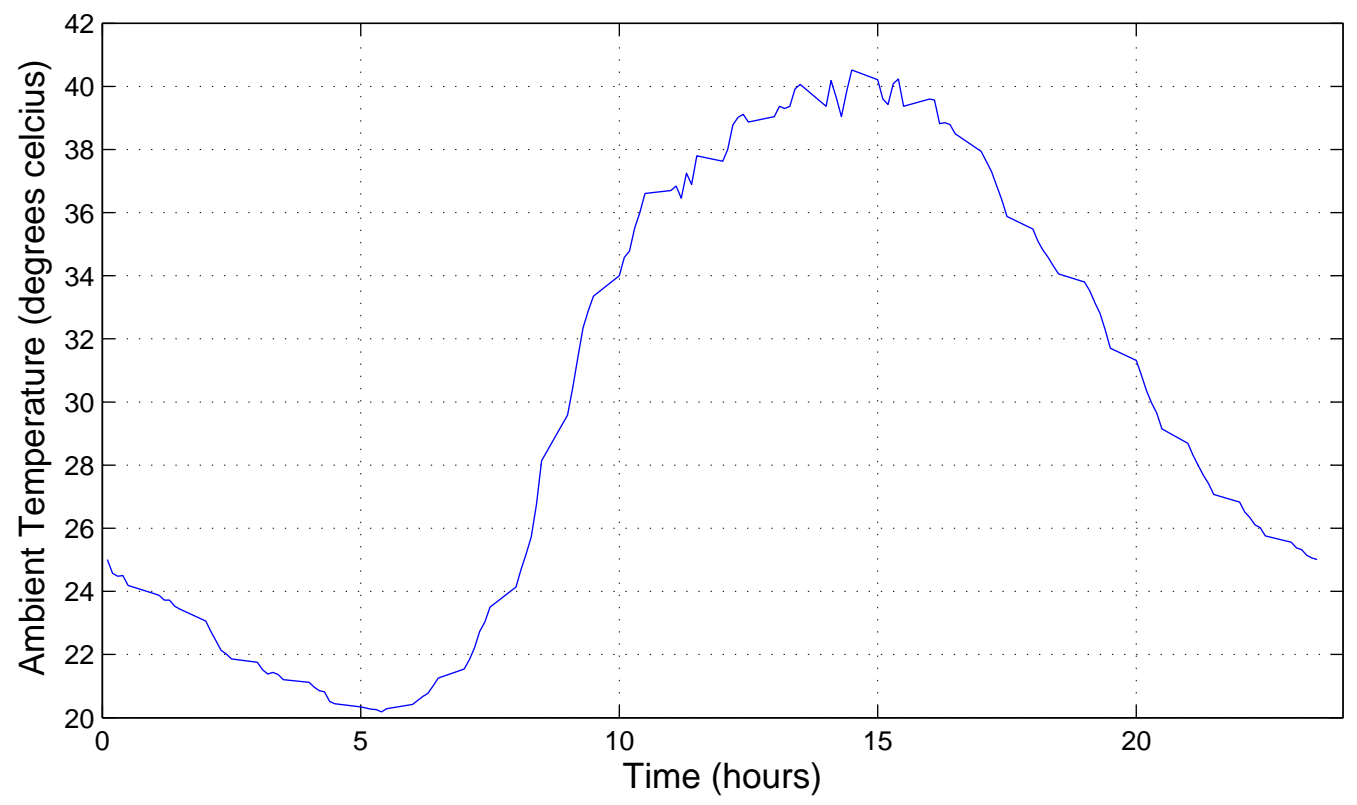

Figure 4.2: Ambient temperature. 
Table 4.1: Fluid and tank parameters

\begin{tabular}{llll}
\hline Parameter & Symbol & Value & Unit \\
\hline Tank 1 (circulation fluid (Duratherm 600)) & & & \\
Tank diameter & $D_{\text {tank }_{1}}$ & 0.69 & $\mathrm{~m}$ \\
Tank height & $H_{\text {tank }_{1}}$ & 1.6 & $\mathrm{~m}$ \\
Tank Volume & $V_{\text {tank }_{1}}$ & 598 & $l$ \\
Fluid specific heat capacity & $C_{c f}$ & 1967 & $\mathrm{~J}(\mathrm{~kg} \mathrm{~K})^{-1}$ \\
Fluid mass density & $\rho_{c f}$ & 844.17 & $\mathrm{~kg} \cdot \mathrm{m}^{-3}$ \\
Tank 2 (water) & & & \\
Tank diameter & $D_{\operatorname{tank}_{2}}$ & 0.69 & $\mathrm{~m}$ \\
Tank height & $H_{\text {tank }_{1}}$ & 0.535 & $\mathrm{~m}$ \\
Tank volume & $V_{\text {tank }_{1}}$ & 200 & $\mathrm{l}$ \\
Tank specific heat capacity & $C_{w}$ & 4185 & $\mathrm{~J}\left(\mathrm{~kg} \mathrm{~K}^{-1}\right.$ \\
Tank mass density & $\rho_{w}$ & 1000 & $\mathrm{~kg} \cdot \mathrm{m}^{-3}$ \\
\hline
\end{tabular}


Table 4.2: Flat plate solar collector parameters

\begin{tabular}{|c|c|c|c|}
\hline Parameter & Symbol & Value & Unit \\
\hline \multicolumn{4}{|l|}{ Medium 1 (Air) } \\
\hline Relative reflective index & $n_{1}$ & 1 & - \\
\hline \multicolumn{4}{|l|}{ Medium 2 (Transparent layer) } \\
\hline Number of Transparent layers (cover) & $\mathrm{N}$ & 1 & - \\
\hline Thickness of each layer & lt & 0.004 & $m$ \\
\hline Relative reflective index & $n_{2}$ & 1.526 & - \\
\hline Emittance & $\varepsilon_{g}$ & 0.88 & - \\
\hline Absorbtion factor/coificient & $k_{a b s}$ & 4 & $m^{-1}$ \\
\hline \multicolumn{4}{|l|}{ Absorber plate (Aluminium) } \\
\hline Emittance & $\varepsilon_{p}$ & 0.1 & - \\
\hline Absorbance & $\alpha$ & 0.9 & - \\
\hline Thickness & $\delta_{p}$ & 0.0015 & $m$ \\
\hline Thermal conductivity & $k p$ & 211 & $W(m \cdot K)^{-1}$ \\
\hline Mass density & $\rho_{m}$ & 2700 & $\mathrm{~kg} \cdot \mathrm{m}^{-3}$ \\
\hline Specific heat capacity & $c_{m}$ & 896 & $J(k g . K)^{-1}$ \\
\hline Tube external diameter & $D_{\text {out }}$ & 0.013 & $m$ \\
\hline Tube internal diameter & $D_{i}$ & 0.01 & $m$ \\
\hline Tube length & $l_{\text {pipe }}$ & 1.5 & $m$ \\
\hline Drum Diameter & $d_{\text {coll }}$ & 0.035 & $m$ \\
\hline Bond conductance & $C_{b}$ & 15 & $m K . W^{-1}$ \\
\hline \multicolumn{4}{|l|}{ Bottom thermal insulation (Polyurethane) } \\
\hline Thickness of the bottom thermal insulation & $L_{b}$ & 0.05 & $m$ \\
\hline Thermal conductivity & $k_{b}$ & 0.034 & $W m^{-2} K^{-1}$ \\
\hline
\end{tabular}


Table 4.3: Heat exchanger, connecting pipe and pump parameters

\begin{tabular}{llll}
\hline Parameter & Symbol & Value & Unit \\
\hline Heat exchanger (serpentine): & & & \\
Length & $L_{\text {serp }}$ & 10 & $m$ \\
Inner diameter & $D_{\text {serp }}$ & 0.025 & $m$ \\
pipe wall thickness & $w_{\text {serp }}$ & 0.002 & $m$ \\
Heat transfer efficiency & $\eta_{0}$ & 0.1 & - \\
Surface area & $S_{0}$ & 1.57 & $\mathrm{~m}^{2}$ \\
Connecting pipes: & & & \\
Pipe inner diameter & $D_{1}$ & 0.0825 & $\mathrm{~m}$ \\
Pipe inner diameter & $D_{2}$ & 0.0825 & $\mathrm{~m}$ \\
Pipe outer diameter & $D_{3}$ & 0.189 & $\mathrm{~m}$ \\
Length of each of the pipes & $L_{c p}$ & 5 & $\mathrm{~m}$ \\
Thermal conductivity of pipe & $K_{\text {pipe }}$ & 67 & $\mathrm{~W} .(\mathrm{m} . K)^{-1}$ \\
Thermal conductivity of insulating material & $K_{\text {ins }}$ & 0.07 & $\mathrm{~W} .(\mathrm{m} . K)^{-1}$ \\
Pump 1 and pump 2: & & & \\
Rated power & $p_{\text {pump_r }}$ & 53 & $\mathrm{~W}$ \\
Maximum pump angular velocity & $w_{a}$ & 2430 & $\mathrm{rpm}$ \\
Maximum pump linear velocity & $w_{l}$ & 1.2732 & $\mathrm{~m} / \mathrm{s}$ \\
\hline
\end{tabular}


The initial temperature of fluid in storage tank 1 is set at $75^{\circ} \mathrm{C}$ to ensure that there is sufficient energy to meet the water heating requirement of tank 2 during during the initial optimization period without solar radiation. The required water mass flow rates and water temperature at the output of the SWHS over the 24 hour optimization interval is shown in table 4.4.

From table 4.4, it can be seen that the hot water demand occurs at different periods over the 24 hour optimization interval, which presents the opportunity to optimize the mass flow rates in both the primary and the secondary loops of the SWHS during periods where solar radiation is available (daytime), and in the systems secondary loop during periods where there is no available solar radiation (nighttime). 
Table 4.4: Required output water mass flow rate and output temperature

\begin{tabular}{lll}
\hline Time $(30 \mathrm{~min})$ & $M_{\text {out }}\left({\left.\mathrm{kg} \cdot \mathrm{s}^{-1}\right)}^{\text {Required } T_{s 2}\left({ }^{\circ} \mathrm{c}\right)}\right.$ \\
\hline 00:00 - 03:00 & 0.00001 & 41 \\
03:00 - 03:10 & 0.1 & 50 \\
03:10 - 03:20 & 0.1 & 60 \\
03:20- 13:00 & 0.00001 & 41 \\
13:00 - 13:10 & 0.1 & 50 \\
13:10 - 20:00 & 0.00001 & 41 \\
20:00 - 20:10 & 0.1 & 50 \\
20:10 - 22:00 & 0.00001 & 41 \\
22:00 - 22:10 & 0.1 & 50 \\
22:10 - 22:20 & 0.01 & 45 \\
22:20 - 24:00 & 0.00001 & 41 \\
\hline
\end{tabular}




\section{CHAPTER 5}

\section{RESULTS AND ANALYSIS}

\subsection{CHAPTER OVERVIEW}

This section presents the results of the case study that was presented in the previous section.

\subsubsection{Primary and secondary loop mass flow rates}

Operating the pump at one single speed is a common practice that is applied to such systems, however the system does not operate at its optimal state. In order to illustrate the difference in system performance based on different control strategies, the results of two different strategies are compared to the results obtained using the developed model and the fmincon solver in the MATLAB optimization toolbox [42]. The first control strategy is bang-bang control. This strategy is commonly used in practice with mass flow rate values switching from $0.00001 \mathrm{~kg} / \mathrm{s}$ (during periods without solar radiation) to $0.1 \mathrm{~kg} / \mathrm{s}$ (during periods with solar radiation) $[7,43]$. The second control strategy is adapted from [7]. This strategy is referred to as optimal switching and requires the flow rate to be kept at a minimum during periods where there is little to no available solar radiation. The flow rate then alternates between its minimum and maximum limits during periods where the energy to be collected exceeds the energy used by the pump. This is done to reduce the system's overall pump power utilized as well as the system thermal losses [7]. This strategy is only applied to the primary loop of the system as the secondary loop is not exposed to solar radiation. Fig.5.1 and fig.5.2 show the different mass flow rates corresponding to the control strategies discussed above for the primary and secondary loops of the SWHS. 


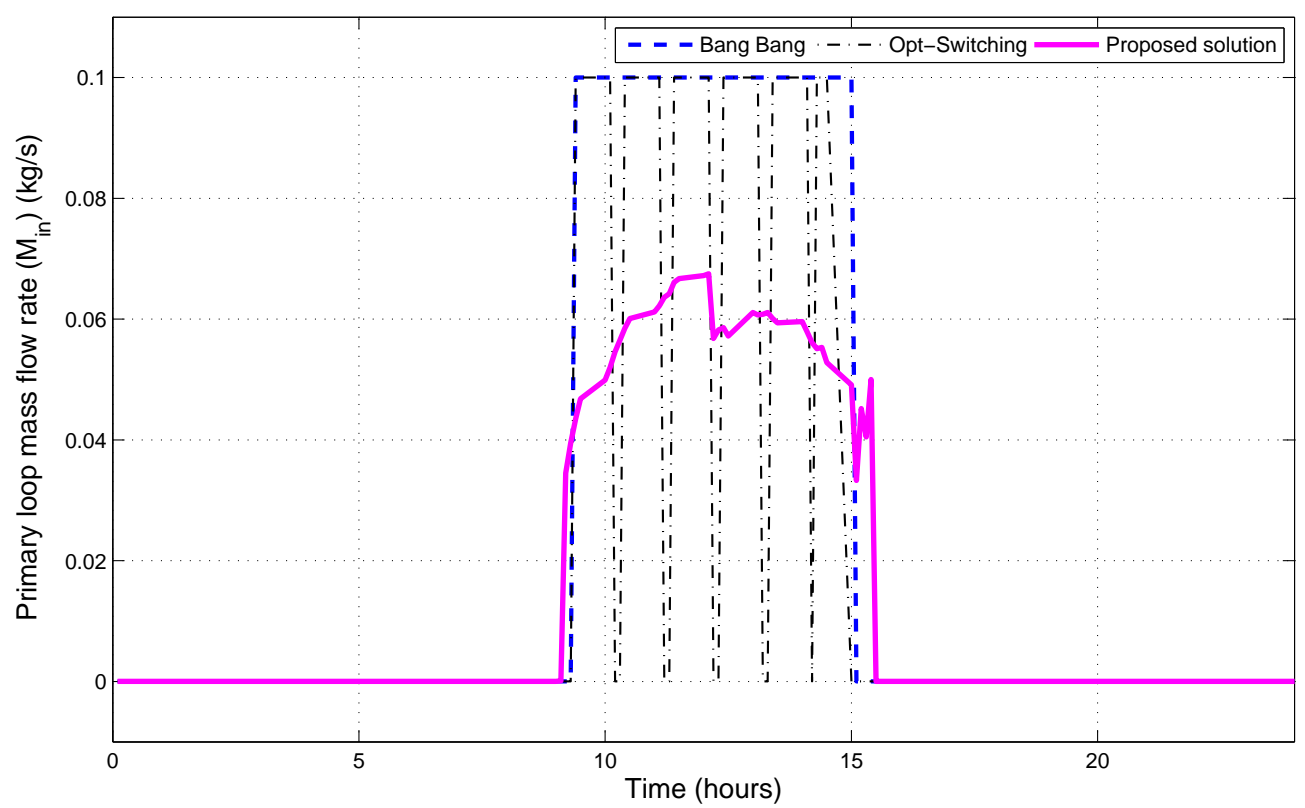

Figure 5.1: Primary loop Mass flow rates.

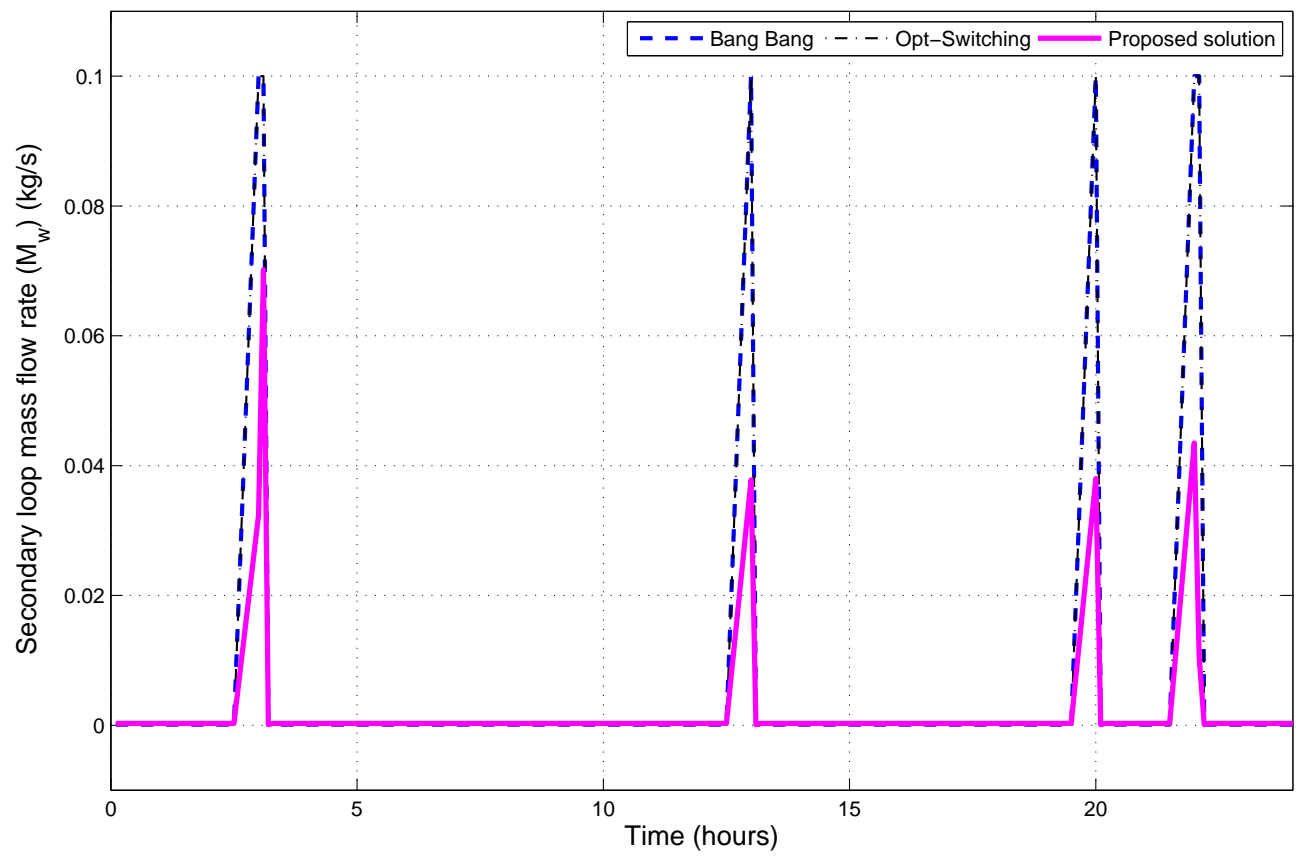

Figure 5.2: Secondary loop Mass flow rates.

When analysing fig.5.1, it can be seen that the primary loop average mass flow rates of the 
optimal solution is less than that of any of the other control strategies. It is expected that the resulting solar collector rate of energy extraction will be less than that of the other two strategies. The pump power used in the primary loop is also expected to be less than that of the other two strategies due to the lower mass flow rates of the optimal solution. In fig.5.2, it can be seen that the secondary loop mass flow rates of the proposed solution are less than those of any of the two strategies. It should be noted that in fig.5.2, the mass flow rates for strategy 1 and 2 are the same. The rate of energy extraction of the heat exchanger for the optimal solution and secondary loop pump power is expected to be less than that of the other two strategies due to the lower mass flow rates of the optimal solution.

\subsubsection{Primary and secondary loop pump power}

The power utilized by the pumps in the systems primary and secondary loop is shown in fig.5.3 and fig.5.4.

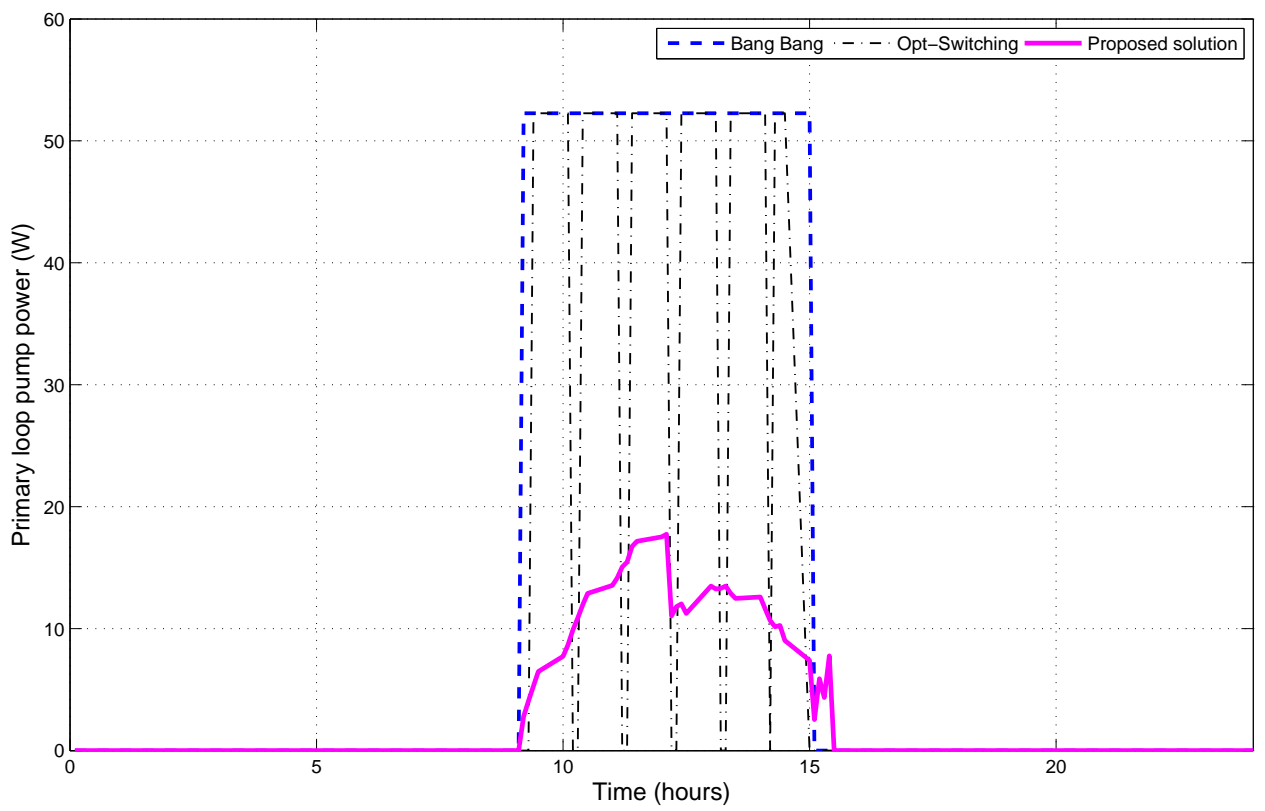

Figure 5.3: Primary loop pump power. 


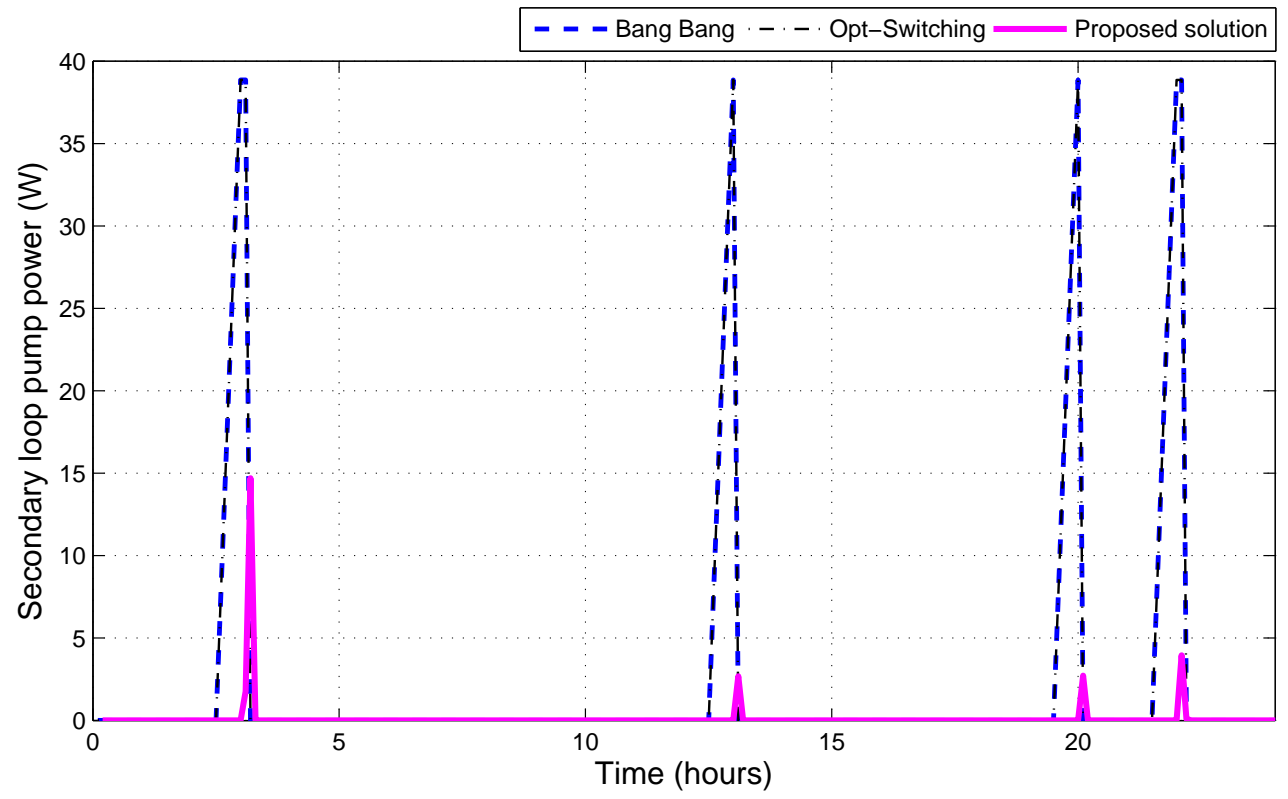

Figure 5.4: Secondary loop pump power.

\subsubsection{Rate of energy extraction, gain and thermal losses}

The gain of the solar collector is shown in fig.5.5. 


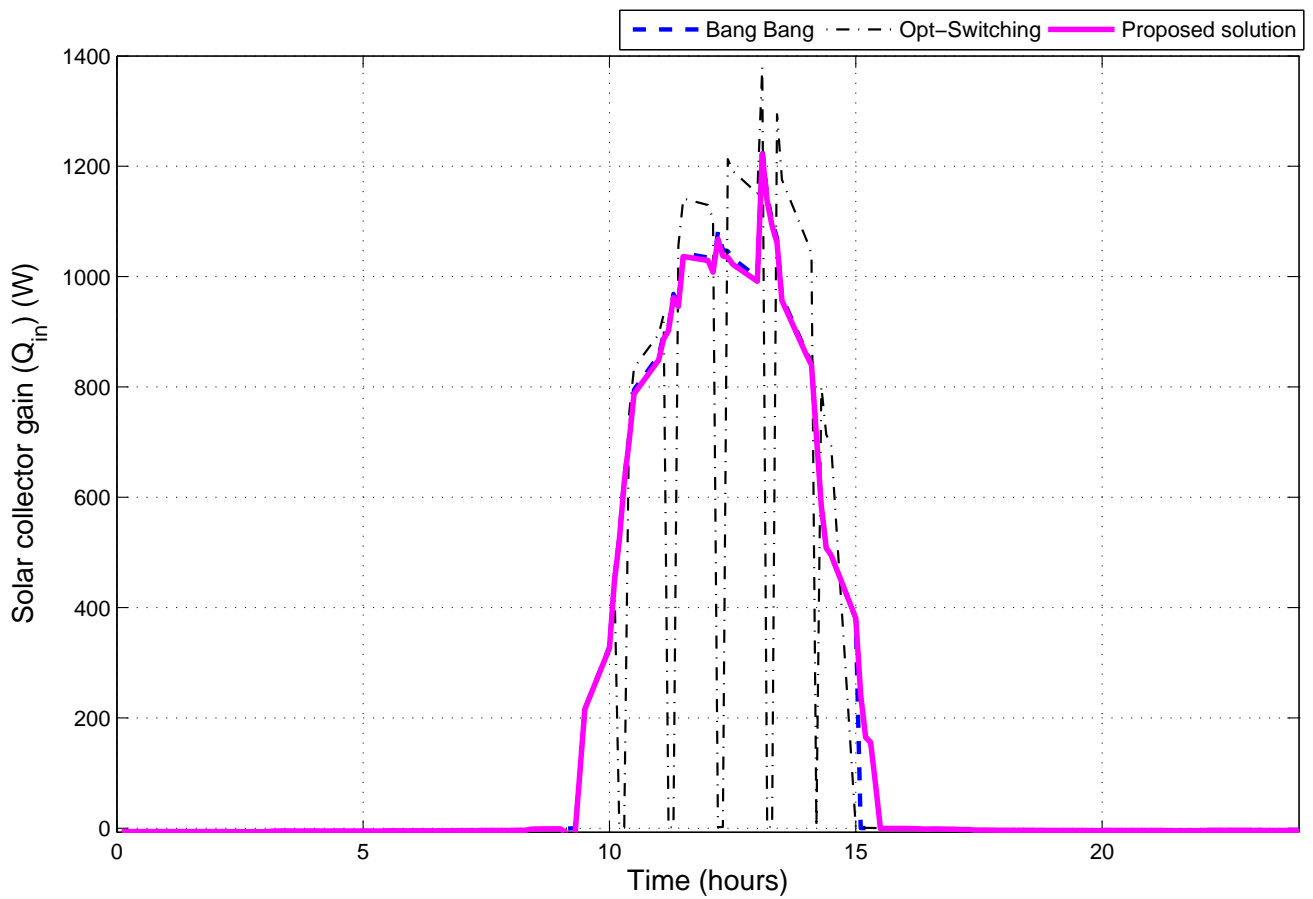

Figure 5.5: Solar collector gain.

When analysing fig.5.5, it can be seen that for the proposed solution, the gain over the solar collector is less than that of the two other strategies as was expected due to the lower mass flow rates of the optimal solution.

The overall gain of the system is shown in fig.5.6. 


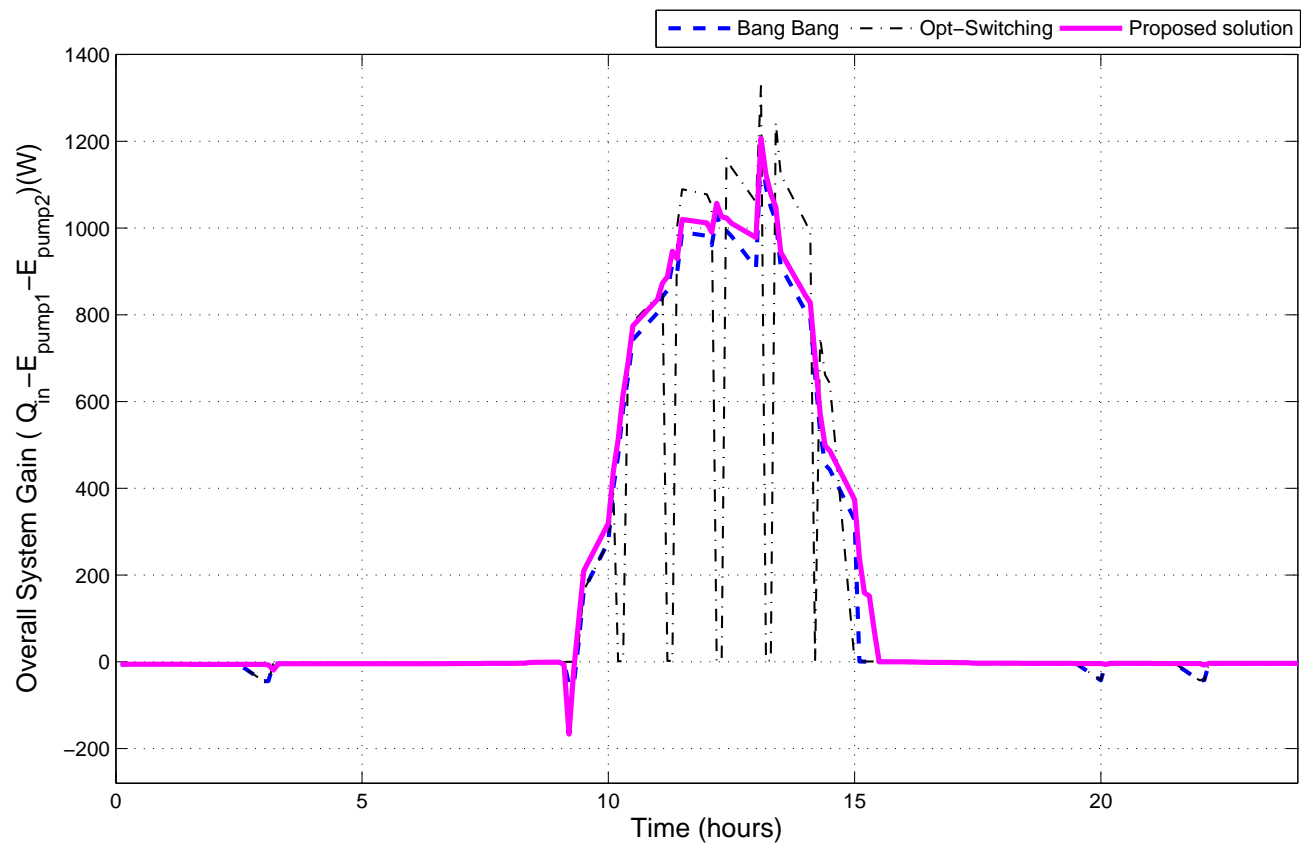

Figure 5.6: Overall system gain.

The overall gain of the system is characterised as the difference between the gain of the solar collector and power used by the pumps in the primary and secondary loops. From this figure, it can be seen that the different control strategies result in both positive as well as negative power gains over the 24 hour interval. The negative gains are attributed to the heating requirement of tank tank 2 in order to reach the required output temperature $T_{\text {out }}$. Negative gains are obtained when the heating requirement occurs during periods where there is no available solar radiation. From fig.5.6, it can be seen that the mass flow rates of the proposed solution result in the largest gain over the 24 hour interval and this is attributed to the following reasons:

a) The pump flow rates are kept to a minimum during periods without solar radiation and with no water heating requirement tank 2 .

b) During periods where there is a heating requirement for tank 2 but with no available solar radiation, the secondary loop flow rates are the minimum flow rates required to ensure that the required water heating is achieved.

c) The average pump power of the proposed solution is smaller than any of the other strate- 
gies, resulting in smaller pump power usage values and a smaller heat exchanger energy extraction rate when compared to the other strategies.

With smaller pump power usage and heat exchanger energy extraction rate values, the proposed solution results in an overall system gain that is maximized beyond that of the other two control strategies.

When analysing the rate of energy gain of the heat exchanger, it was found that the optimal solution results in the least amount of energy extracted by the heat exchanger in tank 1 to meet the temperature requirements of tank 2. This is shown in table 5.1. The combination of minimum values for heat exchanger energy extraction rate and secondary loop pump usage power ensure that energy in the secondary loop is minimized.

Fig.5.7 shows the systems overall accumulative gain.

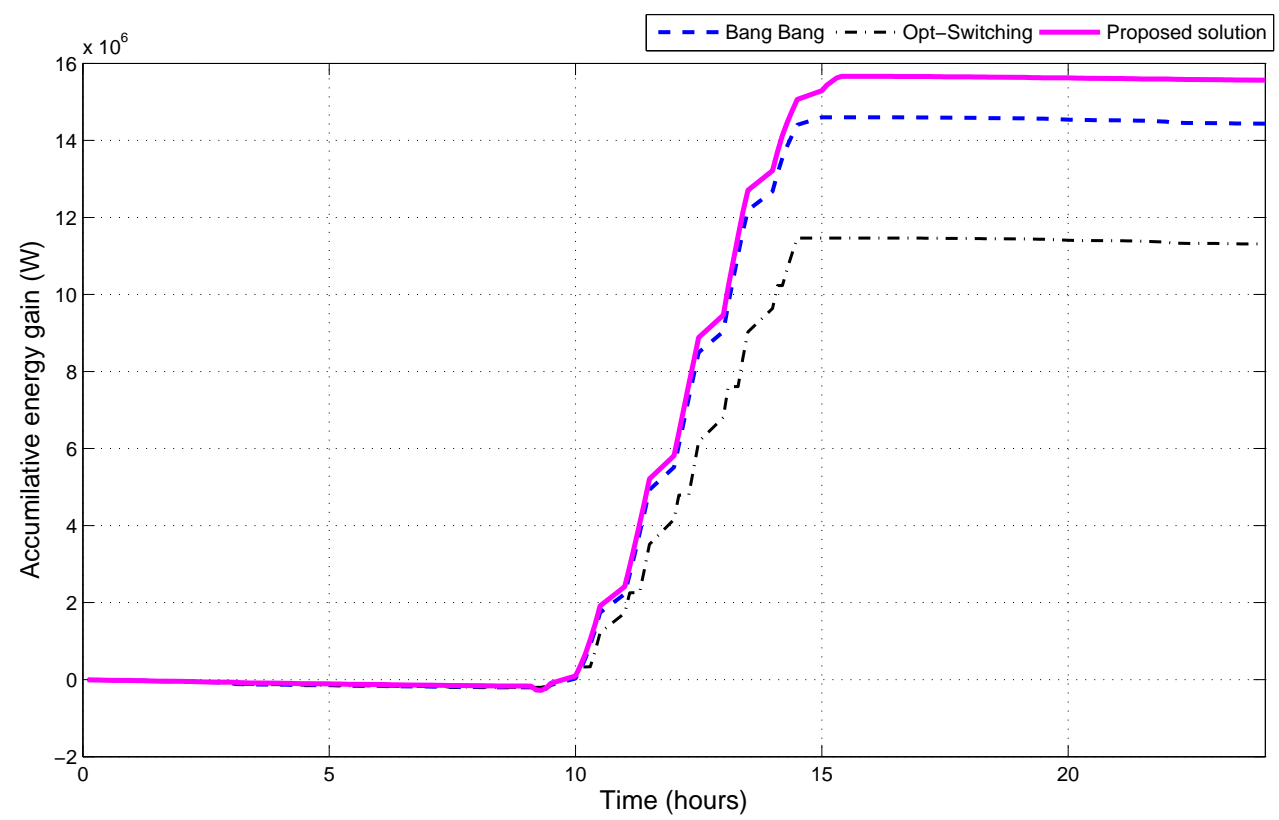

Figure 5.7: Accumilative energy gain.

Since the maximum gain is obtained using the optimal flow rates (Fig.5.6), it follows that these flow rates will also produce the highest accumulative energy as can be seen in fig.5.7.

The temperature profiles for tank 1 and tank 2 are shown in fig.5.8 and fig.5.9. 


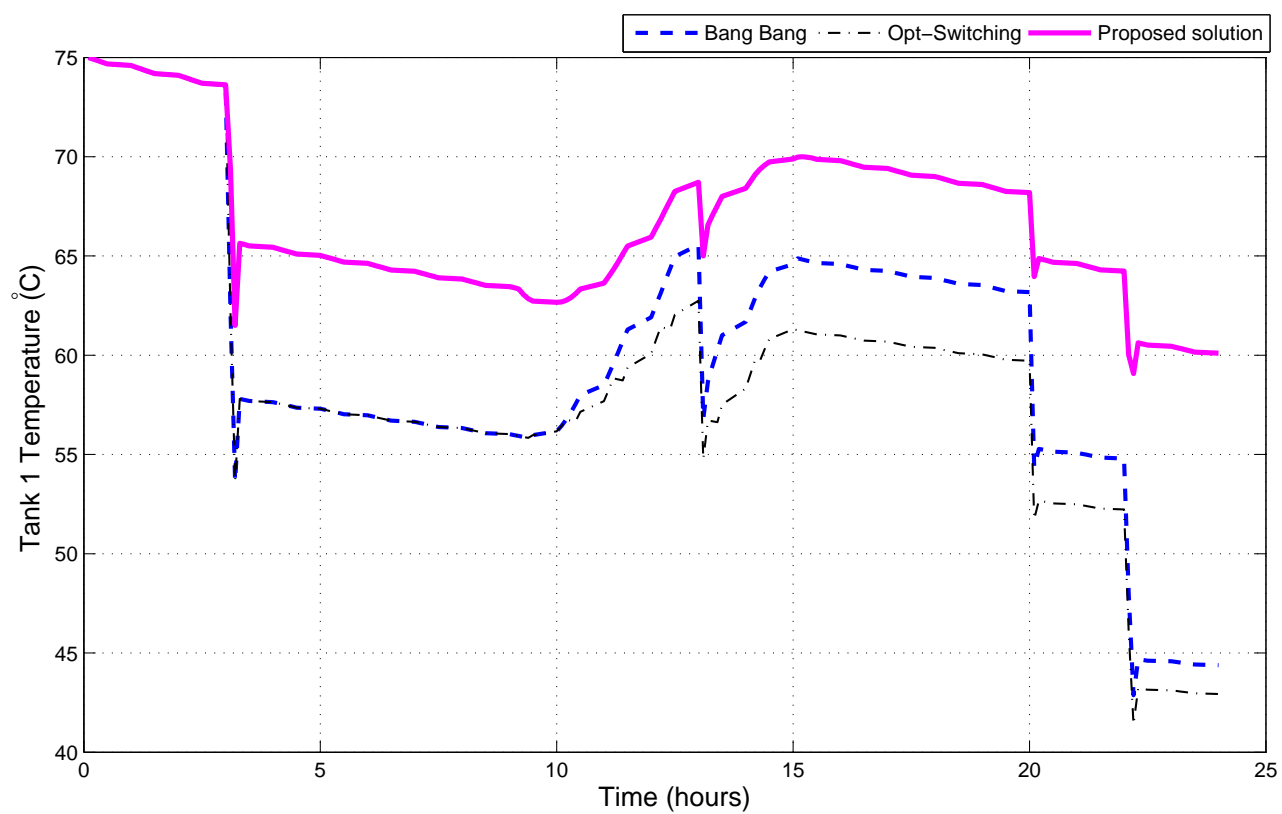

Figure 5.8: Tank 1 Temperature.

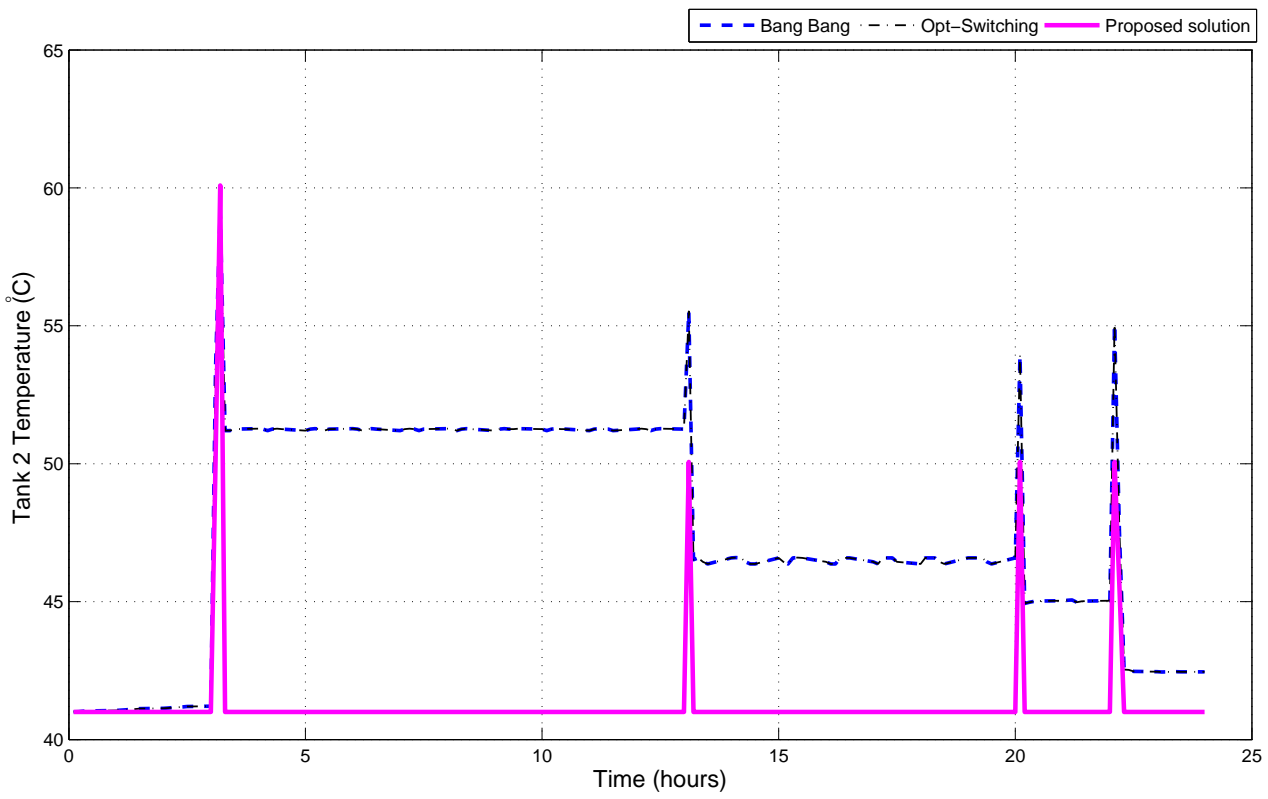

Figure 5.9: Tank 2 Temperature.

From fig.5.8, it can be seen that the initial temperature of tank 1 is $75^{\circ} \mathrm{C}$. This temperature starts to gradually decrease in order to maintain the temperature required in tank 2 . The gradual decrease in temperature is initially small as the required output flow rate $\left(M_{\text {out }}\right)$ is 
minimum, thereby reducing the rate at which cold water enters tank 2 . This reduces the amount of heat transfer required from tank 1 to tank 2 during these periods. There are five periods where there is high increase in the temperature requirement of tank 2 at a significantly high flow rate. The first period occurs between $03: 00$ and $03: 10$. At $03: 00$, the required tank temperature is $50^{\circ}$ and at $03: 10$ the required temperature is $60^{\circ}$. The output mass flow rate is $0.1 \mathrm{~kg} / \mathrm{s}$ for both periods. The output mass flow rate indicates that 60 liters of cold water enters the inlet of tank 2 whilst 60 liters of water exits the outlet of tank 2 . This results in a high transfer of energy from tank 1 to tank 2 during this period as can be seen in fig.5.8. When the temperature of tank 2 reduces when compared to its previous value, energy is transferred back to tank 1 (reverse circulation) in order to ensure that the temperature of tank 2 is always reached. The reverse circulation results in an increase in the temperature of tank 1. Once solar radiation is available, the primary loop pump switches on and energy is transferred from the SC to tank 1 . The temperature of tank 1 gradually starts to increase. The drops in the temperature of tank 1 during this period are attributed to the hot water demand at $13: 00$ and at $16: 00$. Once there is no solar radiation available for collection, pump 1 switches off and the temperature in tank 1 starts to gradually decrease in order to meet the temperature requirements of tank 2 It is evident in fig.5.8 that the proposed solution minimizes the rate of energy extraction of the serpentine and the rate of energy usage of the pump. This conserves energy stored in the tank.

In fig.5.9, it can be seen that for the proposed solution, the required tank temperatures are obtained, where as the bang-bang control strategy and optimal switching control strategy result in a temperature that is slightly higher than the required temperature. This is due to the high mass flow rates of the pump in the secondary loop during the periods when there is a heating requirement for tank 2 .

The thermal losses for the two storage tanks is shown in fig.5.10. 

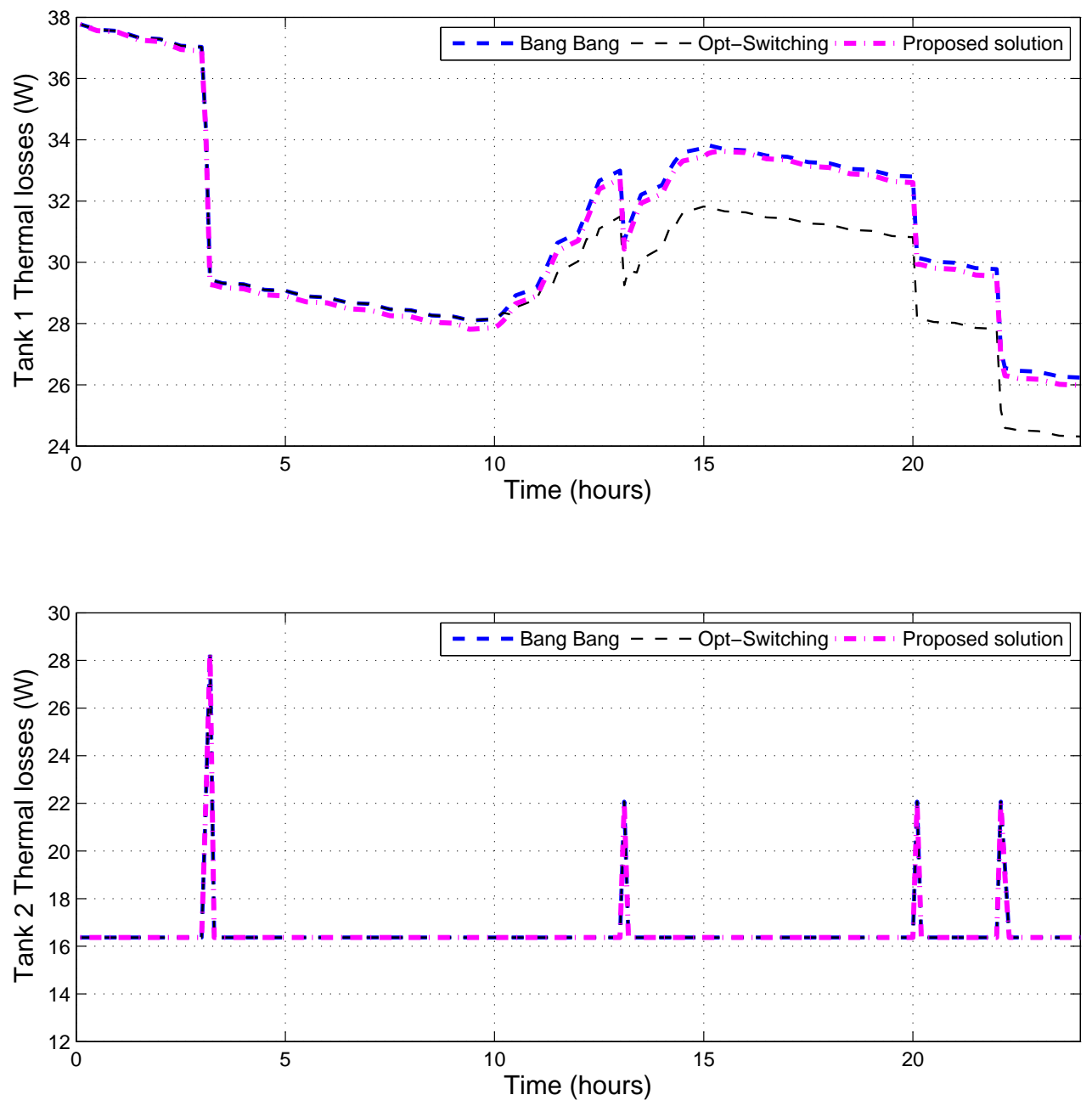

Figure 5.10: Thermal losses for tank 1 and tank 2 .

From table 5.1, it can be seen that the optimal switching control strategy results in the lowest tank thermal losses whilst the bang-bang control strategy results in the highest losses. This is expected as a higher mass flow rates would result in larger tank thermal losses. The alternating action of the optimal switching control strategy results in a reduction in the tank thermal losses during instances when the pump is off, thereby reducing the overall thermal losses of the tank. The connecting pipe thermal losses are shown in fig.5.11. 


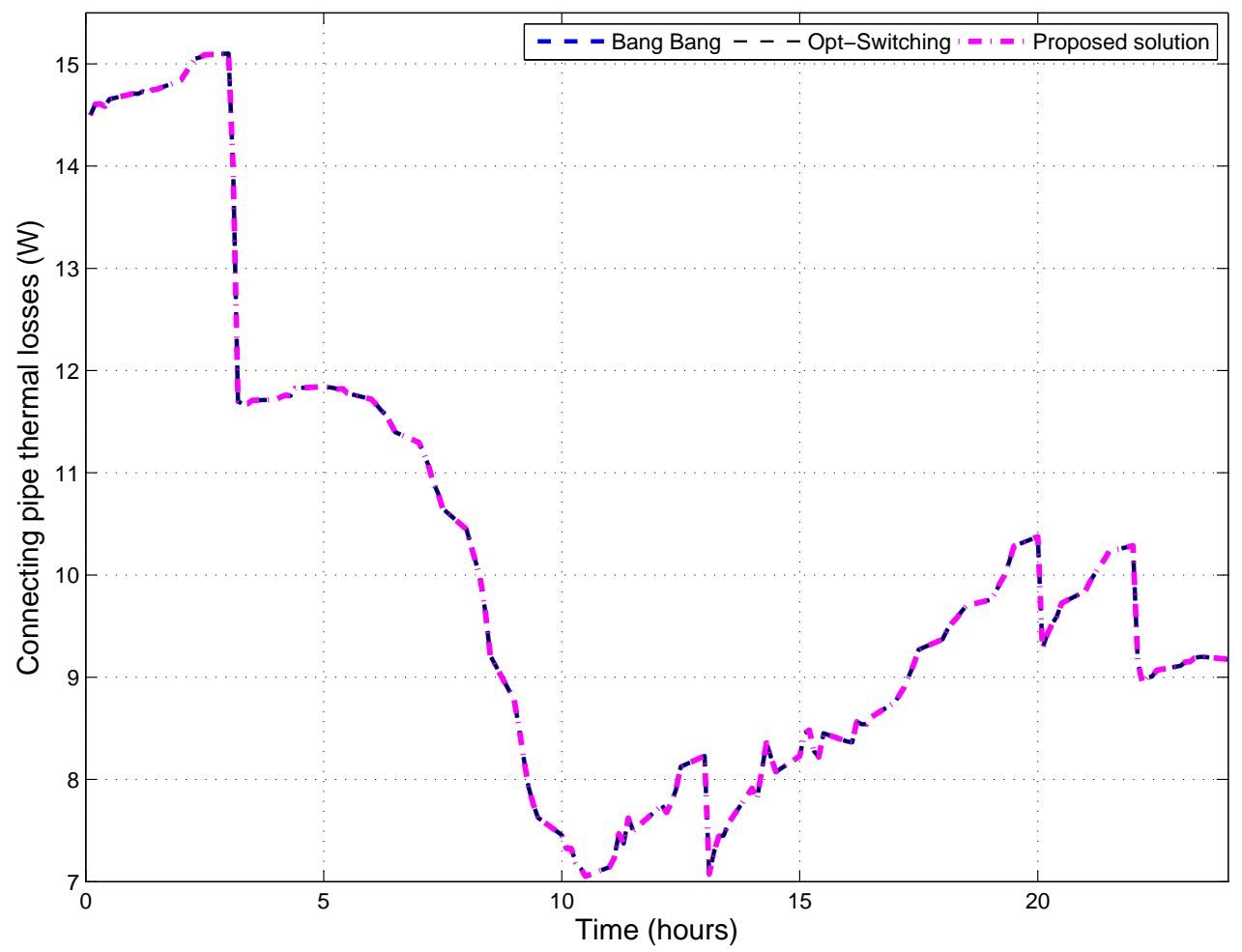

Figure 5.11: Connecting pipe thermal losses.

The results of this study are summarised in table 5.1. In this table, it can be seen that the proposed solution results in the lowest average pump power in the primary and secondary loops of the SWHS. This leads to an accumulative energy gain of $15.56 M J$ which is a $7.82 \%$ increase in energy gain when compared to the second highest accumulative energy gain obtained using the bang-bang control strategy. The results in this table also show that with the flow rates of the proposed solution, the gain of the heat exchanger over the optimization interval is $51.64 \mathrm{KW}$ which is less than those obtained with the other two strategies. Finally, it is noted that the optimal switching strategy produces the least tank and connecting pipe thermal losses.

Table 5.2 shows the overall impact of the pipe thermal losses on the energy collected. From this table it can be seen that pipe thermal losses range from $5.54 \%$ to $7.34 \%$ of the total energy from the collector system for each control strategy. It is important to note that insulation also plays an important role in the overall thermal losses of any system. 
Table 5.1: Summary of results

\begin{tabular}{llll}
\hline Control strategy & Bang-bang & Opt-switching & Proposed solution \\
\hline Primary loop pump average power (W) & 15.37 & 8.34 & 2.95 \\
Secondary loop pump average power (W) & 1.62 & 1.62 & 0.18 \\
Heat exchanger gain (KW) & 88.13 & 88.13 & 51.64 \\
Accumulative energy gain (MJ) & 14.43 & 11.31 & 15.56 \\
Tank thermal losses (KW) & 6.89 & 6.75 & 6.86 \\
Pipe thermal losses (KW) & 1.45 & 1.38 & 1.43 \\
\hline
\end{tabular}

Table 5.2: Pipe thermal loss impact

\begin{tabular}{llll}
\hline Control strategy & Bang-bang & Opt-switching & Proposed solution \\
Thermal loss impact (\%) & 6.03 & 7.34 & 5.54 \\
\hline
\end{tabular}




\subsubsection{Solar collector and system efficiency}

The equation used to determine the efficiency of the array of solar collectors are shown below: [5]:

$$
\eta_{s c}=\frac{Q_{\text {in }}}{N \cdot A_{\text {coll }} \cdot G},
$$

where $Q_{\text {in }}$ represents the gain of the solar collector, $N$ represents the number of solar collectors, $A_{\text {coll }}$ represents the aperture area of each solar collector and $\mathrm{G}$ represents the solar irradiation. The equation used to determine the efficiency of a the whole system is shown below: [5]:

$$
\eta_{s}=\frac{G_{s}}{N \cdot A_{\text {coll }} \cdot G},
$$

where $G_{s}$ represents the gain of the system. In this equation, $\eta_{s}$ is determined taking into account the rate of energy extraction of the solar collector, the power utilized by each of the pumps as well as the tank and connecting pipe thermal losses. The solar collector efficiency and system efficiency (during the periods with available solar radiation) is shown in fig.5.12 and fig.5.13.

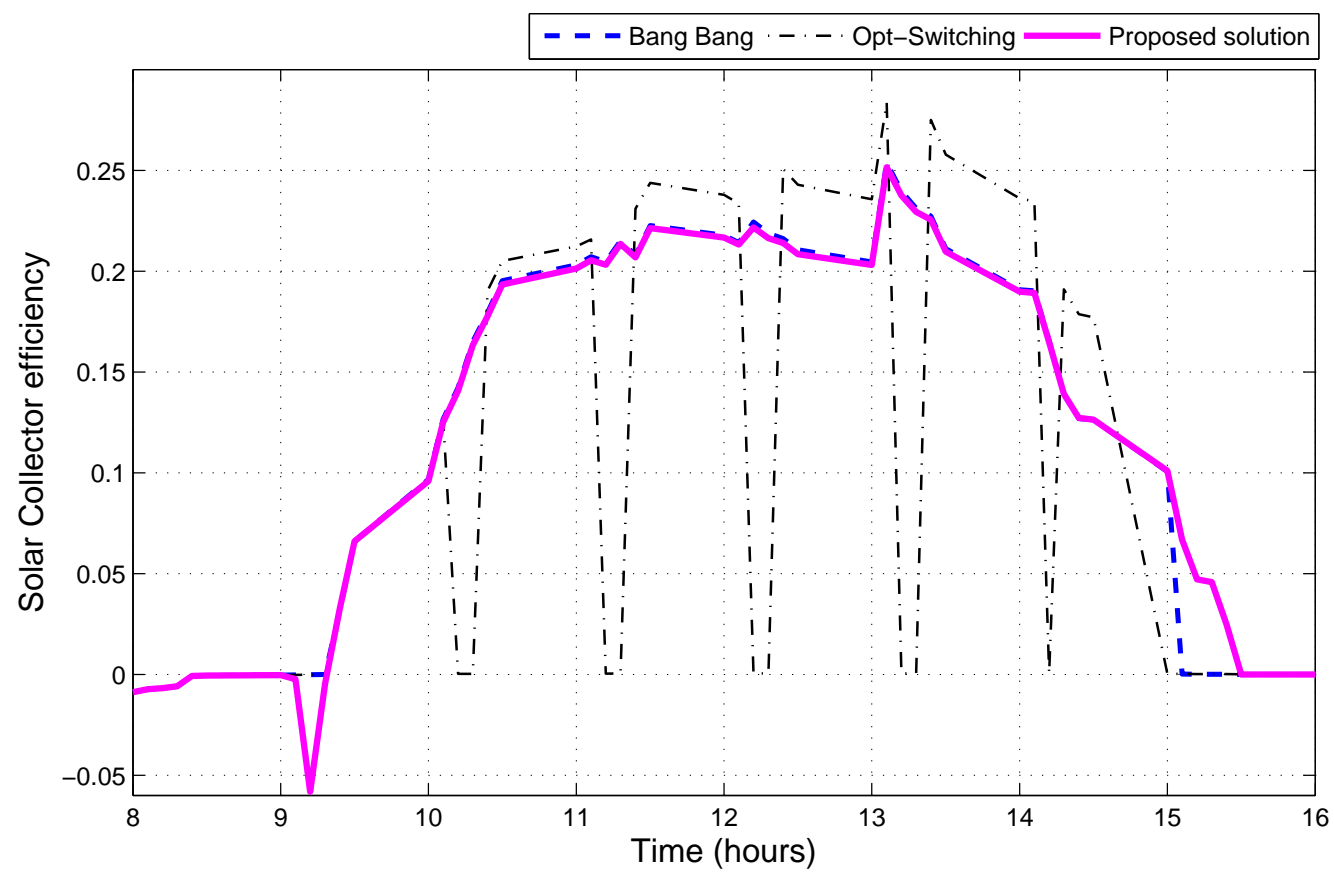

Figure 5.12: Solar collector efficiency. 


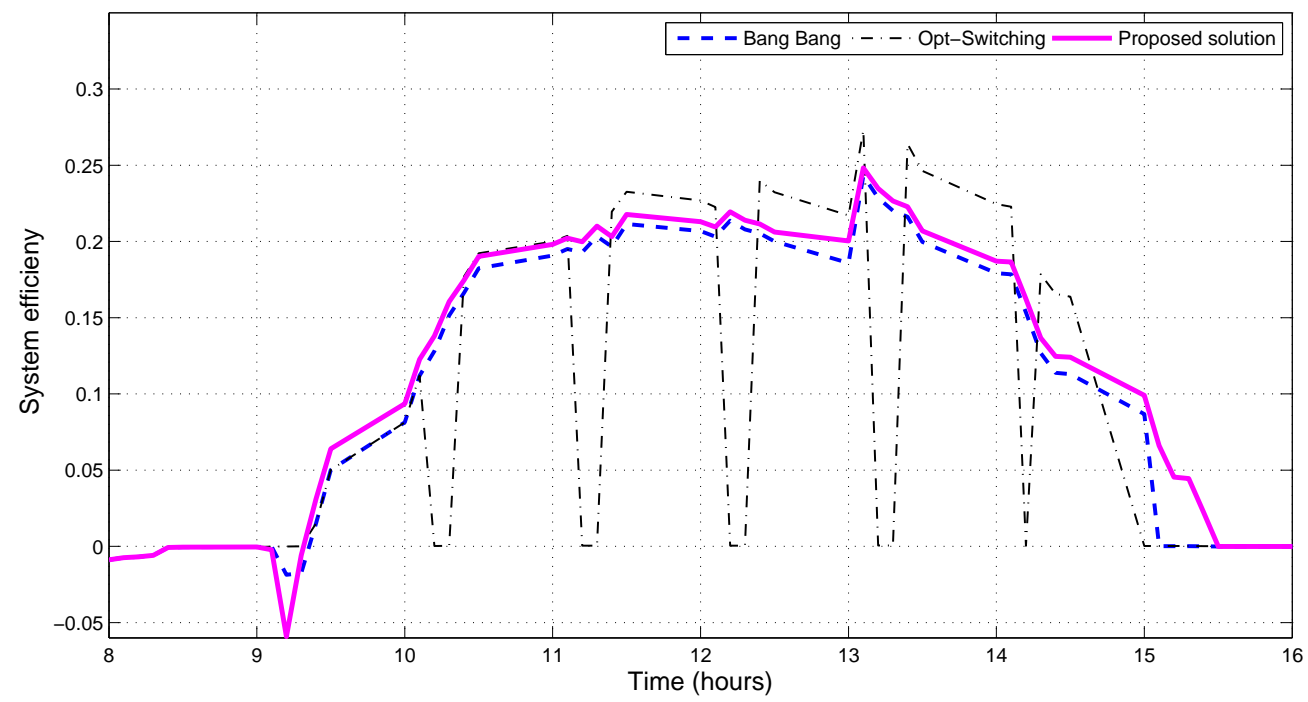

Figure 5.13: System efficiency. 


\section{CHAPTER 6}

\section{DISCUSSION}

\subsection{CHAPTER OVERVIEW}

In this section, a conclusive analysis of the results presented in the previous section is discussed in order to address the research questions presented in section 1.

\subsection{OPTIMAL MASS FLOW RATES}

One of the research questions to be addressed in this study is whether or not it it is possible to obtain mass flow rates that will increase the overall gain of the SWHS shown in fig 3.1. It was hypothesized that there should exist optimal flow rates ranging between the pumps min and max flow rates that would result in an increase in the system gain when compared to other considered control strategies. A common control strategy that was not included in the results analysis involves keeping the pump on at a constant flow rate. With this strategy, no flow control device such a variable speed drive (VSD) would be needed to control the speed of the pump, and by extension the mass flow rates of the different loops in the system. The cost of a variable speed flow control device is therefore avoided. When analysing the performance of keeping the pump on constantly, it becomes evident that a large portion of the energy gathered from the solar collector during the period in which solar radiation is available (daytime) is lost to the surrounding during the period where no solar radiation is available (night-time) due to reverse circulation. This makes the option of keeping a pump on consistently over a 24 hour period undesirable.

The next control strategy involves maximizing the mass flow rates of the system at times 
where there is an opportunity to gain energy (bang-bang control). More specifically, the pumps are not just switched on during periods where solar radiation is available. The pump in the primary loop of the system is switched on when the output from the solar collector at the maximum mass flow rates is greater than the power utilized by the pump to reach the maximum flow rates, whilst in the secondary loop the pump flow rates are maximized during during periods when water heating is required at the output. The benefit of this strategy when compared to previous strategy is that reverse circulation is avoided, thereby increasing the overall SC gain, whilst reducing system energy leakage to a minimum during periods with no solar radiation. This strategy produces a significantly high overall system gain as shown in fig. 5.6. Maximizing the primary loop mass flow rates during periods with available solar radiation results in the highest SC energy extraction rate as shown in fig.5.5. However, there is a cubic relation that exists between the mass flow rate of a pump and the resulting pump power usage as shown in (3.50) and (3.52). Therefore, the high mass flow rates result in high pump power values while the pump is on. Though maximizing the primary loop mass flow rates has a positive impact on the SC rate of energy extraction, the high pump power values result in a decrease in the overall system gain. Another disadvantage to maximizing the flow rates is that this increases the difference in temperature between the fluid in the tank and primary loop of the system, which results in an increase in the storage tank and connecting pipe thermal losses. This also reduces the overall system gain.

The next control strategy discussed in the results analysis section is referred to as the optimal switching control strategy. What differentiates this strategy form the bang-bang control strategy is the alternate switching from minimum to maximum flow rate during the period where solar radiation is available. The benefit to this control strategy is that the tank and connecting pipe thermal losses are reduced when the pump flow rates are minimized. This control strategy results in the least overall system thermal losses when compared to all other strategies discussed in this study. However, the SC rate of energy collection is reduced to its minimum when the mass flow rates are minimized. Therefore the system is not able to collect as much energy as it would have if the flow rate was maximized during the period where solar radiation is available. This reduces the overall system gain as shown in fig.5.6.

The proposed flow rates obtained from the fmincon solver of the MATLAB optimization toolbox are shown in fig.5.1 and fig.5.2. 
At first glance, one can see that these flow rates vary with time and are substantially lower than those of the other control strategies. Lower mass flow rates result in a lower SC rate of energy extraction, as shown in fig.5.5. What makes this method ideal is that by adjusting the control variables (the primary and secondary loop mass flow rates), the various parameters that contribute to the overall system gain are calculated for each sample period and an optimal value is found for the primary and secondary loop mass flow rates for each sample interval. Therefore, every sample interval has a corresponding set of optimal mass flow rates that will result a maximization of the overall system gain. Lower mass flow rates also result in lower pump power usage values when compared to the bang-bang and optimal switching control strategy. The tank and connecting pipe thermal losses are smaller than those resulting from the bang-bang control strategy, but larger than those resulting from the optimal switching control strategy. The combination of reduced pump flow rates and reduced system thermal losses result in a lower difference between the rate of energy gain and rate of energy usage for the system. Hence the overall gain of the system is increased. It should also be noted that in the secondary loop of the system, the mass flow rates are optimized to minimize the rate of energy extraction from the primary loops. These optimized mass flow rates result in the extraction of the exact amount of energy required to overcome the thermal losses of tank 2 and the connecting pipes, as well as to heat water in tank 2 to the desired temperature level. When comparing this flow rate to the maximum flow rate used in the other two control strategies during periods with a water heating requirement, it can be seen that by reducing the mass flow rates to the optimal values (the exact minimum values that is required to raise the water temperature to the desired value), the system energy loss in the secondary loop is minimized, thereby maximizing the overall system gain.

In light of the first research question, the formulated objective function was solved and optimal flow rates values were obtained for the primary and secondary loops of the SWHS. It was found that the resulting average mass flow rate of the proposed solution for the systems primary loop is $0.057 \mathrm{~kg} / \mathrm{s}$ during the period where solar radiation is available. This is lower than that of the bang bang control strategy $(0.069 \mathrm{~kg} / \mathrm{s})$ and that of the optimal switching control strategy $(0.1 \mathrm{~kg} / \mathrm{s})$. For the proposed solution, the average mass flow rate for the secondary loop (during periods where water heating is required) is $0.02 \mathrm{~kg} / \mathrm{s}$ which is significantly lower than that of the other two control strategies $(0.1 \mathrm{~kg} / \mathrm{s}$ for both control strategies). These results illustrate that for the considered system, there exists optimal mass flow rate values 
that are different from the maximum and minimum mass flow rate limits such that the overall system gain can be maximized. It should be noted that the mass flow rates of any SWHS are dependent on the SWHS configuration as well as a number of chosen system parameters defining the system. These parameters will have an influence on the system optimization. For instance, if the diameter of the connecting pipes connected to the pump is increased, the overall pressure drop over these pipes decreases, therefore, the power required to overcome these pressure drops will also decrease, and this will result in optimal pump mass flow rate values that will be closer to the maximum mass flow rates.

\subsection{BENEFITS AND DRAWBACKS OF THE DIFFERENT CONTROL STRATEGIES}

Each control strategy presented in this section has its benefits as well as drawbacks. In the case of bang-bang control, the control action is generally two switches during a 24 hour period. The benefit to this is that no other control device is required to control the on and off switching. The drawback to using this strategy is that during its on cycle, fluid is pumped at the maximum possible flow rate, and though this increases the collector gain, it also increases the SC, tank, and connecting pipe thermal losses, thereby reducing the overall gain of the system. The optimal switching strategy on the other hand results in a reduction of SC, tank, and connecting pipe thermal losses due to the continuous on and off switching of the pump during when solar radiation is available. However, this switching also reduces the collector gain during this period. Another drawback to this control strategy is that the continuous on and off switching has a damaging effect on pump in the long term. When considering the proposed mass flow rates, though the overall system gain is increased, it should be noted that in order to obtain the varying mass flow rates, a variable flow control device such as a variable speed drive (VSD) would be required in order to control the speed of the pump. This would increase overall system cost.

\subsection{SYSTEM GAIN AND PUMP OPERATING EFFICIENCY}

From fig.5.3 and fig.5.4, it is seen for the proposed solution, the corresponding pump power utilized over the optimization interval is less than that of the other two strategies as was expected. Upon closer inspection of these two figures, it is evident that in the primary loop, 
the maximum power of the pump is $17.73 \mathrm{~W}$ which is $33 \%$ of the pump's rated power, whilst in the secondary loop, the maximum power of the pump is $15 \mathrm{~W}$ which is $28.3 \%$ of the pump's rated power. Though the optimal mass flow rates result in lower pump power values and an increased system gain, it should be noted that the pumps operate at a reduced operational efficiency due to the lower pump power values resulting from the low mass flow rates of the proposed solution. In order to increase the operational efficiency of a pump, it must be operated as close as possible to it's rated power. Therefore, a solution for this would be to reduce the size of the selected pump.

\subsection{TANK THERMAL LOSSES}

In section 5.1.3, it was established that the bang-bang control strategy results in the highest thermal losses whilst the optimal switching control strategy results in the lowest thermal losses. When analysing (3.13) and (3.23), which characterise the thermal loss experienced by tank 1 and tank 2 respectively, one can see that the thermal loss experienced by each tank is directly proportional to the difference between the tank temperature and the ambient indoor temperature. An increase in the tank temperature would therefore increase the tank thermal losses of the system. In fig.5.10, it is evident that though the losses of the different control strategies are very similar during the early hours of the day, the loss profiles start to deviate from each other from the times where solar radiation is available. It is also noted that the all the profiles have four areas where there is a step decrease in the thermal losses. This occurs during the periods where water heating for tank 2 is required. As energy is transferred from tank 1 to tank 2, there is a steep drop in the temperature of tank 1 in order to meet the heating requirements of tank 2. This reduces the difference between the tank temperature and the indoor ambient temperature, resulting in a decrease in the system thermal losses.

When considering the thermal loss profile of the bang-bang control strategy, it can be seen from fig.5.10 that the thermal losses corresponding to this control strategy increase beyond those of the other two. This occurs notably during the period where solar radiation is available as this period coincides with the period that the pump is switched on, allowing the circulation fluid in tank 2 to flow at a maximum flow rate of $0.1 \mathrm{~kg} / \mathrm{s}$. This gradually increases the temperature of tank 1 and in doing so increases the difference between the temperature 
of tank 1 and the indoor ambient temperature, resulting in an increase in the thermal losses of tank 1 . When analysing the thermal loss profile of tank 2 , it can be seen that during the periods where there is no water heating required for tank 2 , the thermal losses are constant. The profile has four notable spikes that correspond to the periods where energy is being transferred to tank 2 in order to meet its heating requirements. During these periods, the temperature of tank 2 increases, resulting in an increase in thermal losses.

When considering the optimal switching control strategy, it can be seen that the on and off switching of the pump results in a decrease in the thermal losses of tank 1 during the periods where solar radiation is available. This occurs because during the periods where the pump is off during the day, the amount of gain from the SC is minimized, thereby reducing the temperature of tank 1 and its corresponding thermal losses during these periods. The thermal losses of tank 2 for the optimal switching control strategy are identical to those of tank 2 for the bang-bang control strategy.

When considering the proposed solution, it can be seen that the thermal losses of tank 1 gradually increase during the period where solar radiation is available, just as was with the other two control strategies. The thermal losses of the proposed control strategy remain lower that those of the bang-bang control strategy due to the difference in the primary loop mass flow rates during these periods. The mass flow rates of the proposed solution are less than those of the bang-bang control strategy, resulting in a lower rate of temperature increase in tank 1 , thereby reducing the difference between the tank 1 temperature and the indoor ambient temperature and the corresponding thermal losses to be less than those resulting from the bang-bang control strategy. When considering tank 2 , the thermal losses resulting from the proposed solution are less than those of the other two control strategies. This is due to the mass flow rates in the secondary loop that are minimized to conserve energy in the primary tank. The proposed mass flow rates are less than those of the other two control strategies, but still large enough to ensure that the temperature requirement of tank 2 is achieved. These mass flow rates result in a decrease in the difference between the temperature of tank 2 and the indoor ambient temperature, thereby reducing the thermal losses of tank 2 . 


\subsection{SOLAR COLLECTOR AND SYSTEM EFFICIENCY}

The solar collector efficiency and system efficiency (during the periods with available solar radiation) are shown in fig.5.12 and fig.5.13. When analysing fig.5.12, it can be seen the the bang-bang control strategy results in the highest overall solar collector efficiency. This occurs as a result of the gain of the collector which is larger than that of any of the other two control strategies. When considering the optimal switching control strategy, the efficiency of the SC reaches higher peaks than those of the other two control strategies. The reason behind this is that the gain of the $\mathrm{SC}$ is proportional to the temperature difference between the inlet and outlet of the SC as shown in (3.7). Therefore, the on and off switching of the pump results in a greater temperature gradient between the inlet and outlet of the SC and hence a greater gain when the pump is on, resulting in a higher efficiency during those periods. When considering the proposed solution, it can be seen that the efficiency of the SC is less than that of the bang-bang control strategy. This is attributed to the lower SC gain corresponding to the lower mass flow rates of the proposed solution.

When analysing the system efficiencies (fig.5.13) resulting from the different control strategies, it can be seen that the system efficiency of the proposed solution is larger than those of the other control strategies. This occurs as a result of the system gain of the proposed solution being larger than any of the other two control strategies. These results highlight the fact that it is possible to increase the efficiency of the overall system by increasing the gain of the system, even though it is not possible to increase the SC efficiency through using mass flow rates that are less than the maximum possible flow rates.

\subsection{CONNECTING PIPE THERMAL LOSSES}

There are a number of factors that contribute to connecting pipe losses. The results of fig.5.10 illustrated the influence that mass flow rates have on thermal losses. It is therefore known that higher losses will be experienced with higher mass flow rates and lower losses with low mass flow rates. In fig.5.11, it can be seen that the connecting pipe thermal losses of the different control strategies are very close, though they do slightly differ as shown in table 5.1. The profile has four steep declines that correspond to the periods where energy is being transferred from the primary loop to the secondary loop to meet the water heating requirements. There 
is a decrease in thermal losses during the early hours of the day. This occurs because the temperature of the primary tank decreases as energy is being transferred from it, resulting in a small difference between the fluid temperature in the connecting pipes from the tank and the ambient temperature, and hence a reduction in the overall tank thermal losses according to (3.1). It can also be seen that the connecting pipe thermal losses gradually increase during periods where solar radiation is available as during these periods the primary loop mass flow rates are significantly high, thereby increasing the thermal losses of connecting pipes.

The results shown in fig.5.11 and table 5.2 highlight the fact that system thermal losses can be significant based on a number of factors such as the length and diameter of the connecting pipes, the type of insulation, as well as the difference in temperature between the fluid travelling inside and outside of the pipe. It is therefore important to include all system thermal losses (which include: SC thermal losses $\left(U_{L}\right)$, Tank thermal losses and connecting pipe thermal losses) in the modelling of SWHS in order to obtain a model whose results will be an accurate representation of the system modelled. 


\section{CHAPTER 7}

\section{CONCLUSION}

The growing popularity of SWHS as an alternative to geysers connected to the grid has led to a search for methods to improve the performance of SWHS whilst meeting user power demands. Pump flow rate optimization is one such method. This study presented a nonlinear constrained optimization model for a forced circulation SWHS with connecting pipes. The objective was to obtain optimal mass flow rates that can result in an increase in the overall gain of the system. The system considered consists of an array of six solar collectors, two storage tanks and connecting pipes. An optimization model was developed in order to determine the optimal flow rates that will maximize energy gain in the primary loop whilst meeting user defined tank temperatures with minimum energy usage in the secondary loop of the system. This made it possible to investigate the impact that mass flow rate optimization has on the system gain, pump operating efficiency, system efficiency, tank thermal losses and pipe thermal losses. The model was solved using the fmincon solver in the MATLAB optimization toolbox, and the results were compared to other control strategies that are commonly used in practice. The results show a $7.82 \%$ increase in the amount of energy extracted for the proposed solution, when compared to the most suitable energy efficient control strategy. The results also show system thermal losses that range between $5.54 \%$ and $7.34 \%$ for the different control strategies due to pipe losses. These results illustrate the significance and impact of mass flow rates on the system performance, overall energy gain and usage as well as on the system thermal losses. The following conclusions are made from the results of this study:

- It is possible to obtain optimal mass flow rates that differ from the maximum or minimum mass flow rate limits of the pump. Though these flow rates result in a lower 
solar collector gain, the power utilized by the pumps and thermal losses are reduced, resulting in an increase in the system's overall gain. One drawback to operating the pumps at the optimal mass flow rates of the proposed solution is that the pumps operational efficiency is reduced. This occurs as a result of not operating the pump at flow rates that are not close to the flow rates corresponding to the maximum rated angular velocity of the pump. A possible solution to this would be to select a pump with a reduced rated power power and angular velocity. In this way, the flow rates of the optimal solution would be closer to the maximum mass flow rate of the pump, thereby increasing the operational efficiency of the pump.

- Optimal mass flow rates can result in a reduction in the SC efficiency if the gain of the solar collector decreases. If the overall gain of the system is increased, then the system efficiency will increase as well.

- An increase in the storage tank temperature results in an increase in the tank thermal losses. The tank storage temperature is increased through heat exchange from the solar collector, using the circulation fluid and the heat transfer medium in the primary loop. It can be concluded that increasing the mass flow rates of the system will result in an increase in the system's tank thermal losses. A similar conclusion is drawn when considering the connecting pipe thermal losses.

\subsection{FUTURE RECOMENDATIONS}

The results of this study serve a foundation for future research that could include: feasibility studies on the cost viability of the proposed system (with the pump costs and VSD costs included) when compared to systems with a constant mass flow rate or thermosyphon systems, with emphasis on the payback period in order to determine the most cost effective system.

An investigation on the application of a modified version of the proposed model for industrial pre-heating or heating could also be conducted, with emphasis on finding a minimal cost solution that will meet the desired industrial pre-heating or heating demands. 


\section{REFERENCES}

[1] Y. Guo, M. Pan, and Y. Fang, "Optimal power management of residential customers in the smart grid," Parallel and Distributed Systems, IEEE Transactions on, vol. 23, no. 9, pp. 1593-1606, Sept 2012.

[2] A. Barbato, A. Capone, G. Carello, M. Delfanti, M. Merlo, and A. Zaminga, "Cooperative and non-cooperative house energy optimization in a smart grid perspective," in World of Wireless, Mobile and Multimedia Networks (WoWMoM), 2011 IEEE International Symposium on a, June 2011, pp. 1-6.

[3] M. Pedrasa, T. Spooner, and I. MacGill, "Coordinated scheduling of residential distributed energy resources to optimize smart home energy services," Smart Grid, IEEE Transactions on, vol. 1, no. 2, pp. 134-143, Sept 2010.

[4] F. Aghbalou, F. Badia, and J. Illa, "Exergetic optimization of solar collector and thermal energy storage system," International Journal of Heat and Mass Transfer, vol. 49, no. 7 Ü8, pp. $1255-1263,2006$.

[5] J. Duffie and W. Beckman, Solar Engineering of Thermal Processes, 3rd ed. Wiley, 2006.

[6] Y. W. WONG and K. SUMATHY, "Thermodynamic analysis and optimization of a solar thermal water pump," Applied Thermal Engineering, vol. 21, no. 5, pp. 613-627, 2001.

[7] V. Badescu, "Optimal control of flow in solar collector systems with fully mixed water storage tanks," Energy Conversion and Management, vol. 49, no. 2, pp. 169 - 184, 2008. 
[8] J. Vargas, J. Ordonez, E. Dilay, and J. Parise, "Modeling, simulation and optimization of a solar collector driven water heating and absorption cooling plant," Solar Energy, vol. 83, no. 8, pp. 1232 - 1244, 2009.

[9] V. Badescu, "Optimal control of flow in solar collectors for maximum exergy extraction," International Journal of Heat and Mass Transfer, vol. 50, no. 21Ü22, pp. 4311 - 4322, 2007.

[10] M. Kovarik and P. Lesse, "Optimal control of flow in low temperature solar heat collector," Solar Energy, vol. 18, no. 5, pp. 431 - 435, 1976.

[11] A. Orbach, C. Rorres, and R. Fischl, "Optimal control of a solar collector loop using a distributed-lumped model," Automatica, vol. 17, no. 3, pp. 535 - 539, 1981.

[12] R. Kicsiny, "Performance modelling of combined solar heating systems with ordinaryand with an energetically-based control," Energy and Environment in the practice, Proc. Seminar of Doctorate Students from Justus Liebig University (Giessen) and Szent Istvan University, Godollo, August 19-21,, pp. 67-78, 2008.

[13] R. Kicsiny and I. Farkas, "Improved differential control for solar heating systems," Solar Energy, vol. 86, no. 11, pp. 3489 - 3498, 2012.

[14] Y. Jannot and Y. Coulibaly, "Radiative heat transfer in a solar air heater covered with a plastic film," Solar Energy, vol. 60, no. 1, pp. 35 - 40, 1997. [Online]. Available: http://www.sciencedirect.com/science/article/pii/S0038092X96001454

[15] M. Sikkens, "Radiation heat losses in solar collectors with plastic covers," Applied Energy, vol. 4, no. 2, pp. 145 - 151, 1978. [Online]. Available: http://www.sciencedirect.com/science/article/pii/0306261978900089

[16] N. Wijeysundera and M. Iqbal, "Effect of plastic cover thickness on top loss coefficient of flat-plate collectors," Solar Energy, vol. 46, no. 2, pp. 83 - 87, 1991. [Online]. Available: http://www.sciencedirect.com/science/article/pii/0038092X9190019S

[17] H. Dagdougui, A. Ouammi, M. Robba, and R. Sacile, "Thermal analysis and performance optimization of a solar water heater flat plate col- 
lector: Application to tétouan (morocco)," Renewable and Sustainable Energy Reviews, vol. 15, no. 1, pp. 630 - 638, 2011. [Online]. Available: http://www.sciencedirect.com/science/article/pii/S1364032110002972

[18] A. A. Badran, M. F. Mustafa, W. K. Dawood, and Z. K. Ghazzawi, "On the measurement of bond conductance in solar collector absorber plate," Energy Conversion and Management, vol. 49, no. 11, pp. 3305 - 3310, 2008, special Issue 3rd International Conference on Thermal Engineering: Theory and Applications.

[19] A. Shariah, M.-A. Al-Akhras, and I. Al-Omari, "Optimizing the tilt angle of solar collectors," Renewable Energy, vol. 26, no. 4, pp. 587 - 598, 2002. [Online]. Available: http://www.sciencedirect.com/science/article/pii/S0960148101001069

[20] H. Gunerhan and A. Hepbasli, "Determination of the optimum tilt angle of solar collectors for building applications," Building and Environment, vol. 42, no. 2, pp. 779 - 783, 2007. [Online]. Available: http://www.sciencedirect.com/science/article/pii/S0360132305003872

[21] M. Despotovic and V. Nedic, "Comparison of optimum tilt angles of solar collectors determined at yearly, seasonal and monthly levels," Energy Conversion and Management, vol. 97, no. 0, pp. 121 - 131, 2015. [Online]. Available: http://www.sciencedirect.com/science/article/pii/S0196890415002721

[22] R. Bornatico, M. Pfeiffer, A. Witzig, and L. Guzzella, "Optimal sizing of a solar thermal building installation using particle swarm optimization," Energy, vol. 41, no. 1, pp. 31 - 37, 2012, 23rd International Conference on Efficiency, Cost, Optimization, Simulation and Environmental Impact of Energy Systems, \{ECOS\} 2010. [Online]. Available: http://www.sciencedirect.com/science/article/pii/S0360544211003513

[23] W. Yeo. (2012, Nov.) New solar energy storage system - thermocline @ONLINE. [Online]. Available: http://renewablekinabalu.blogspot.com/2012/11/new-solar-energystorage-system.html.

[24] J. Harman. (2013, May) Pax water technologies @ONLINE. [Online]. Available: http://www.paxwater.com/why-mix/. 
[25] S. Farahat, F. Sarhaddi, and H. Ajam, "Exergetic optimization of flat plate solar collectors," Renewable Energy, vol. 34, no. 4, pp. 1169 - 1174, 2009.

[26] Z. Morvay and D. Gvozdenac, Applied Industrial Energy and Environmental Management, international ed. John Wiley \& Sons, March 2009.

[27] R. Kicsiny, J. Nagy, and C. Szalóki, "Extended ordinary differential equation models for solar heating systems with pipes," Applied Energy, vol. 129, no. 0, pp. 166 - 176, 2014.

[28] J. Smith, H. Van Ness, and M. Abbott, Introduction to Chemical Engineering Thermodynamics, international ed. McGraw Hill, 2005.

[29] M. A. Stubblefield, S.-S. Pang, and V. A. Cundy, "Heat loss in insulated pipe the influence of thermal contact resistance: A case study," Composites Part B: Engineering, vol. 27 , no. 1 , pp. $85-93,1996$.

[30] A. D. Rosa, H. Li, and S. Svendsen, "Method for optimal design of pipes for low-energy district heating, with focus on heat losses," Energy, vol. 36, no. 5, pp. 2407 - 2418, 2011.

[31] A. A. M. Sayigh, Solar Thermal Engineering, illustrated ed. Acedemic Press, 1977.

[32] J. R. Howel, Solar-Thermal Energy Systems. McGraw-Hill, 1982.

[33] C. C. Smith and T. A. Weiss, "Design application of the hottel-whillier-bliss equation," Solar Energy, vol. 19, no. 2, pp. 109 - 113, 1977.

[34] S. A. Kalogirou, "Chapter 5 - solar water-heating systems," in Solar Energy Engineering (Second Edition), second edition ed., S. A. Kalogirou, Ed. Boston: Academic Press, 2014, pp. $257-321$.

[35] P. A. Stark, Introduction to numerical methods. Celtis Publisher, 1970.

[36] A. Lauschagne, A. van der Merwe, N. van Rensburg, and L. Zietsman, An introduction to numerical analysis, 7th ed. Celtis Publisher, 2014.

[37] M. Dehghandokht, M. G. Khan, A. Fartaj, and S. Sanaye, "Flow and heat transfer characteristics of water and ethylene glycol-water in a multi-port serpentine meso-channel 
heat exchanger," International Journal of Thermal Sciences, vol. 50, no. 8, pp. 1615 $1627,2011$.

[38] — - "Numerical study of fluid flow and heat transfer in a multi-port serpentine mesochannel heat exchanger," Applied Thermal Engineering, vol. 31, no. 10, pp. 1588 - 1599, 2011.

[39] W. Durfee and Z. Sun. (2009) Fluid power syatem dynamics @ONLINE. [Online]. Available:

http:www.me.umn.edu/ wkdurfee/projects/ccefp/fp-chapter/fluid-pwr.pdf.

[40] H. Zhang, X. Xia, and J. Zhang, "Optimal sizing and operation of pumping systems to achieve energy efficiency and load shifting," Electric Power Systems Research, vol. 86, no. 0 , pp. $41-50,2012$.

[41] (2015, May) Duratherm extended life fluids. @ONLINE. [Online]. Available: https://durathermfluids.com/pdf/productdata/heattransfer/duratherm-600.pdf

[42] C. Lopez, Matlab Optimization Techniques. Springer, 2014.

[43] F. Hilmer, K. Vajen, A. Ratka, H. Ackermann, W. Fuhs, and O. Melsheimer, "Numerical solution and validation of a dynamic model of solar collectors working with varying fluid flow rate," Solar Energy, vol. 65, no. 5, pp. 305 - 321, 1999. 


\section{APPENDIX A}

\section{SOLAR COLLECTOR PARAMETERS}

This section presents the equations used to determine the solar collector parameters used in the developed model.

\section{TRANSMITTANCE ABSORBANCE FACTOR}

In order to determine the transmittance absorbance factor $(\tau \alpha)$, snell's law is first used to determine the reflected angle $\left(\theta_{2}\right)$ with the incidence angle $\left(\theta_{1}\right)$, and the indices of reflection $n_{1}$ and $n_{2}$ known. Snell's equation is shown below:

$$
\frac{\sin \left(\theta_{2}\right)}{\sin \left(\theta_{1}\right)}=\frac{n_{1}}{n_{2}},
$$

where the perpendicular and parallel components of the reflectance are then determined using the following equations:

$$
\begin{aligned}
& r_{(\perp)}=\frac{\sin ^{2},\left(\theta_{2}-\theta_{1}\right)}{\sin ^{2}\left(\theta_{2}+\theta_{1}\right)}, \\
& r_{(\|)}=\frac{\tan ^{2}\left(\theta_{2}-\theta_{1}\right)}{\tan ^{2}\left(\theta_{2}+\theta_{1}\right)} .
\end{aligned}
$$

The overall reflectance for a non zero incidence angle and a zero incidence angle are given by:

$$
\begin{gathered}
r=\frac{r_{(\|)}+r_{(\perp)}}{2} \quad 0<\theta_{1} \leq 90, \\
r=\left(\frac{n-1}{n+1}\right)^{2} \quad \theta_{1}=0 .
\end{gathered}
$$


The perpendicular component of the transmittance is given by:

$$
\tau_{(\perp)}=\frac{1-r_{(\perp)}}{\left.1+r_{(\perp)}\right)} .
$$

The transmittances due to reflectance and absorbtion are determined using the following equations:

$$
\begin{gathered}
\tau_{r n}(\theta)=0.5\left(\frac{1-r_{(\|)}}{1+(2 n-1) \cdot r_{(\perp)}}+\frac{1-r_{(\perp)}}{1+(2 n-1) \cdot r_{(\perp)}}\right), \\
\tau_{a}=\exp \left(\frac{-K \cdot L}{\cos \left(\theta_{2}\right)}\right) .
\end{gathered}
$$

The overall transmittance and absorbance factors are then given by:

$$
\tau=t_{a} \cdot t_{r n},
$$

$$
\alpha=1-\tau_{a} .
$$

\section{OVERALL THERMAL LOSS COEFFICIENT}

The overall Thermal loss coefficient over the collector is given by (3.9), where $U_{t}, U_{b}$ and $U_{e}$ are top, bottom and edge loss coefficients. The bottom loss coefficient is given by:

$$
U_{b}=\frac{k b}{l b}
$$

where $k b$ and $l b$ are the collector bottom thermal insulation thickness and thermal conductivity shown in table 4.2. The edge loss coefficient is given by:

$$
U_{e}=\frac{U A_{\text {edge }}}{A_{c}},
$$

where $U A_{\text {edge }}$ and $A_{c}$ are the edge loss coefficient area product and the area of the collector. The top loss coefficient is determined using the following equation:

$$
U_{t}=\left(\frac{N}{\frac{C}{T_{p m}} \cdot\left[\frac{T_{p m}-T_{a}}{N+f}\right]^{e}}+\frac{1}{h_{w}}\right)^{-1}+\frac{\sigma\left(T_{p m}+T_{a}\right)\left(T_{p m}^{2}+T_{a}^{2}\right)}{\frac{1}{\varepsilon_{p}+0.0059 N h_{w}}+\frac{2 N+f-1+0.133 \varepsilon_{p}}{\varepsilon_{g}}-N},
$$

where $N$ is the number of glass covers of the collector, $\varepsilon_{p}$ and $\varepsilon_{g}$ are the glass and plate emmitance, $T_{p m}$ and $T_{a}$ are the mean plate and ambient temperatures, and $h_{w}$ represents the wind heat transfer coefficient. $T_{p m}, f, e$ and $C$ are determined using the following equations: 


$$
\begin{gathered}
T_{p m}=T_{F i}+\frac{Q_{i} n / A_{\text {coll }}}{F_{r} U_{L}}\left(1-F_{r}\right), \\
f=\left(1-0.09 h_{w}-0.1166 h_{w} \varepsilon_{p}\right)(1+0.07866 N), \\
e=0.430 \cdot\left(1-\frac{100}{T_{p m}}\right), \\
C=520\left(1-0.00005 \cdot \beta^{2}\right),
\end{gathered}
$$

where $T_{f i}$ is the initial fluid temperature, $\beta$ represents the collector tilt in degrees. For equation $3.49,0^{\circ} \leq \beta \leq 70^{\circ}$ otherwise $\beta=90^{\circ}$ should be used.

\section{COLLECTOR HEAT REMOVAL FACTOR}

When considering a standard solar collector, the fin efficiency is determined using the following equations:

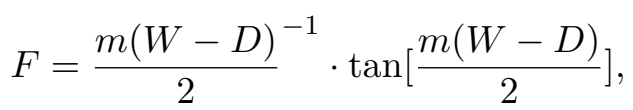

where

$$
m=\sqrt{\frac{U_{L}}{k_{p} \delta_{p}}} .
$$

In the above equations, $D$ and $W$ represent the collector tube external diameter and the distance between two neighbouring tubes, while $k_{p}$ and $\delta_{p}$ represent the collector plate thickness and thermal conductivity. The collector efficiency is determined using the following equations:

$$
\begin{gathered}
F_{\text {prime }}=\frac{1 / U_{L}}{w\left[\frac{1}{U_{L}[D+(W-D) F]}+\frac{1}{C_{b}}+\frac{1}{\pi D_{i} h_{f i}}\right]}, \\
D_{i}=D-2 \delta_{p}, \\
h_{f}=\left(1430+23.3 t-0.048 t^{2}\right) w_{\text {water }}^{0.8} D_{i}^{-0.2},
\end{gathered}
$$

where $C_{b}$ and $D_{i}$ are the bond conductance and collector tube inner diameter, and $h_{f}$ is the heat transfer coefficient between the circulation fluid and the tube walls. With $\rho_{1}$ representing the fluid mass density, the fluid speed is given by:

$$
w_{\text {water }}=\frac{\dot{m}_{1}}{A W}\left[\frac{4}{\rho_{1} \pi D_{i}^{2}}\right],
$$

while the average working fluid temperature $t$ inside the tube is given by:

$$
t=T_{f m}-273.15
$$


with

$$
T_{f m}=\frac{T_{f, \text { in }}+T_{F, \text { out }}}{2} .
$$

Finally, the collector heat removal factor can then be evaluated using (3.8). 


\section{APPENDIX B}

\section{HEAT EXCHANGER PARAMETERS}

This section presents the equations used to determine the heat exchanger parameters used in the developed model. The heat transfer coefficients $h_{0}$ and $h_{1}$ are used to determined the rate of energy from the heat exchanger. These parameters are determined using the following equations:

$$
\begin{gathered}
N u=0.021 R e^{0.8} \cdot P_{r f}^{0.45}, \\
N u=\frac{h_{f p} \cdot D_{\text {serp }}}{\lambda}, \\
\operatorname{Re}=\frac{w \cdot D_{\text {serp }}}{v}, \\
\operatorname{Pr}=\frac{c_{p} \cdot \rho \nu}{\lambda} .
\end{gathered}
$$

In these equations, $N u, R e$ and $\operatorname{Pr}$ are the Nusselt, Reynolds and Prandtl numbers. $\lambda, \nu, c_{p}$, and $\rho$ represent the fluids thermal conductivity, kinematic viscosity, specific heat and mass density. These parameters above are to determine the forced convection heat loss coefficient $h_{f p}$. The following equations are then used to determine the natural convection heat transfer coefficient $h_{p w}$ between the wall pipe and the circulation fluid or water that is in the storage tank:

$$
\begin{gathered}
N u=\frac{h_{p w}\left(D_{\text {serp }}+2 w_{\text {serp }}\right)}{\lambda}, \\
N u=0.5\left(G_{r f} \cdot P_{r f}\right)^{0.25}\left(\frac{P_{r f}}{P_{r p}}\right)^{(0.25)} \quad 10^{3} \leq\left(G_{r f} \cdot P_{r f}\right) \leq 10^{8},
\end{gathered}
$$




$$
G r=g \frac{h_{p w}\left(D_{\text {serp }}+w_{\text {serp }}\right)^{3} \beta\left(T-T_{s}\right)}{v^{2}},
$$

where $g, \beta$ represent the gravitational acceleration and the thermal expansion coefficient. $T$ and $T_{s}$ represent the average and tank temperature for the circulation fluid and water. $D_{\text {serp }}$ and $w_{\text {serp }}$ represent the serpentine diameter and circulation fluid/water speed through the serpentine. The average linear heat transfer coefficient is then determined using the following relation:

$$
\frac{1}{h_{\text {lin }}}=\frac{1}{\pi D_{\text {serp }} \cdot h_{f p}}+\frac{1}{2 \pi \cdot \lambda_{\text {serp }}} \times \ln \frac{D_{\text {serp }}+2 w_{\text {serp }}}{2 \pi \cdot D_{\text {serp }}}+\ln \frac{D_{\text {serp }}+2 w_{\text {serp }}}{\pi \cdot h_{\text {pw }}\left(D_{\text {serp }}+2 w_{\text {serp }}\right)},
$$

where $\lambda_{\text {serp }}$ is the thermal conductivity of the serpentine's material. The heat transfer coefficients $h_{0}$ and $h_{1}$ are determined using (3.27). 


\section{APPENDIX C}

\section{PUMP PARAMETERS}

This section presents the equations used to determine the parameters of the pumps used in the developed model.

\section{Computation of pump power}

The computation of the pump mechanical power required to circulate the fluid in the primary and secondary loops of the system is obtained using (3.29)-(3.45).

\section{Computation of the pressure loss coefficients}

The pressure loss coefficient $\delta_{\text {coll }}$ is calculated using:

$$
\delta_{\text {coll }}=\frac{1}{0.788 B_{3}+0.029 K+\frac{0.115 a_{\text {coll }}}{\dot{a}_{\text {coll }}}-\frac{0.115 a_{\text {coll }}}{\dot{a}_{\text {coll }}}-0.090},
$$

where $a_{\text {coll }}$ and $\dot{a}_{\text {coll }}$ are the inlet and outlet cross sectional areas of the drums at the inlet and outlet of the solar collector. Factors $K$ and $B$ are determined using the following equations:

$$
\begin{gathered}
K=1-\frac{a_{f}}{a_{\text {coll }}}, \\
B_{3}=\frac{\bar{a}}{\sqrt{0.6+\left(\frac{a_{p}}{a_{p}^{*}}\right)^{2}+\delta_{\text {dev }}+\delta_{p}}},
\end{gathered}
$$

where $a_{p}$ and $\dot{a}_{p}$ are the inlet and outlet cross sectional areas of the pipes at the inlet and outlet of the solar collector. These parameters are taken to be identical for solar collector used. The parameter $\delta_{\text {dev }}$ refers to the pressure losses in devices placed along the length of 
the pipe. Parameter $\bar{a}$ is obtained using:

$$
\bar{a} \equiv \frac{n a_{p}}{a_{\text {coll }}},
$$

where $n$ is the number of pipes in the solar collector. The linear pressure loss coefficient is given by:

$$
\delta_{p} \equiv \lambda_{p} \frac{l_{\text {pipe }}}{d_{\text {pipe }}},
$$

where $\lambda_{p}$ is the friction factor of the pipe. The friction factor is calculated using the following equation:

$$
\lambda= \begin{cases}0.3164 R e^{-0.25} & \text { if } 3^{3} \leq R e \leq 10^{5}, \\ 0.0054+0.3964 R e^{-0.3} & \text { if } 10^{5} \leq R e \leq 2 \times 10^{6}, \\ 0.0032+0.221 R e^{-0.3} & \text { if } R e \geq 2 \times 10^{6} .\end{cases}
$$

Reynolds number $R e$ is determined using:

$$
R e=\frac{w d}{v},
$$

where $w$ is the fluid speed at the duct, $d$ is the diameter of the duct and $v$ is the kinematic viscosity of the fluid. 